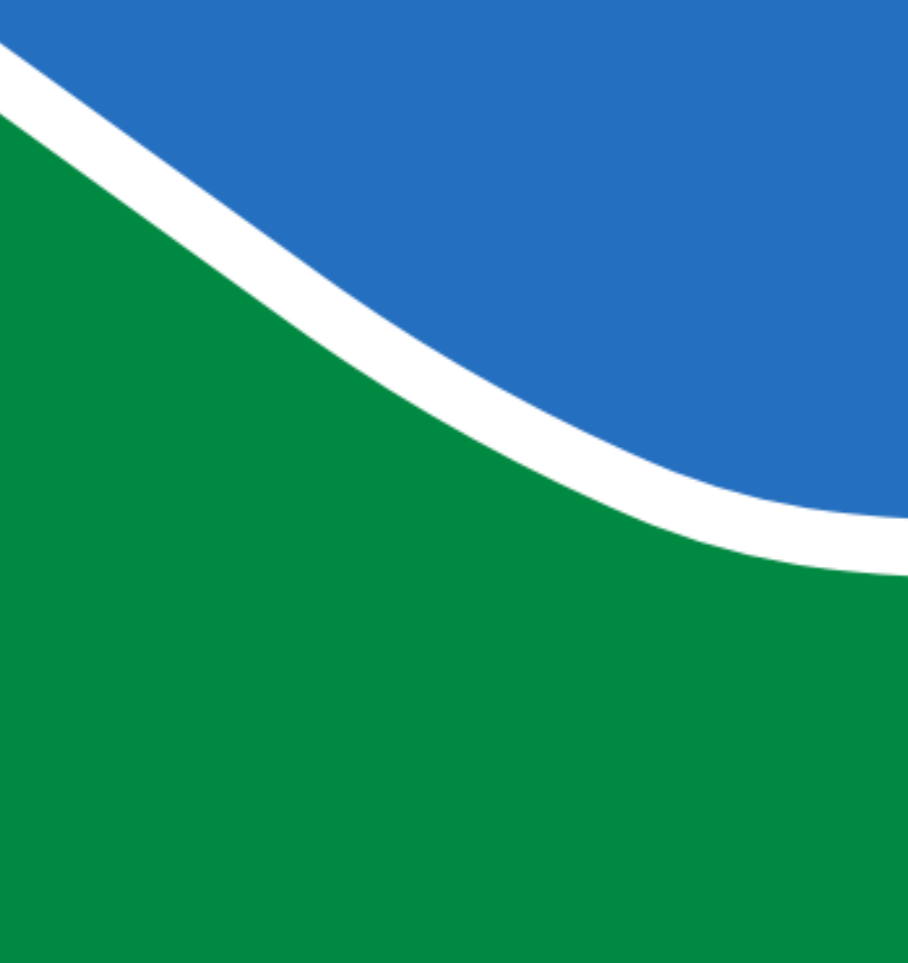

DISSERTAÇÃO DE MESTRADO

\title{
SISTEMA DE POSICIONAMENTO DINÂMICO PARA INSTALAÇÕES SUBMARINAS
}

\author{
Rafael Domenici Pereira Simões
}

Brasília, Julho de 2016

\section{UNIVERSIDADE DE BRASÍLIA}

\section{FACULDADE DE TECNOLOGIA}


UNIVERSIDADE DE BRASÍLIA

Faculdade de Tecnologia

DISSERTAÇÃO DE MESTRADO

\section{SISTEMA DE POSICIONAMENTO DINÂMICO PARA INSTALAÇÕES SUBMARINAS}

\section{Rafael Domenici Pereira Simões}

Dissertação submetida ao Departamento de Engenharia Mecânica da Faculdade de Tecnologia da Universidade de Brasília como requisito parcial para obtenção do grau de Mestre Engenheiro em Sistemas Mecatrônicos.

Banca Examinadora

Prof. Dr. Eugênio L. F. Fortaleza, ENM/UnB

Orientador

Prof. Dr. André Murilo de Almeida Pinto, FGA/UnB

Examinador interno

Prof. Dr. Éder Lima de Albuquerque, ENM/UnB

Examinador externo 


\section{FICHA CATALOGRÁFICA}

SIMÕES, RAFAEL DOMENICI PEREIRA

SISTEMA DE POSICIONAMENTO DINÂMICO PARA INSTALAÇÕES SUBMARINAS

[Distrito Federal] 2016.

xii, 78p., 210 x 297 mm (ENM/FT/UnB, Mestre, Sistemas Mecatrônicos, 2016).

Dissertação de Mestrado - Universidade de Brasília. Faculdade de Tecnologia.

Departamento de Engenharia Mecânica.

1. Sistema de Posicionamento Dinâmico

2. Planejamento de Trajetória

3. Solução Analítica de Cabo Amortecido

4. Acompanhamento de Trajetória

5. Planicidade Diferencial

I. ENM/FT/UnB

II. Título (série)

\section{REFERÊNCIA BIBLIOGRÁFICA}

SIMÕES, R. D. P. (2016). SISTEMA DE POSICIONAMENTO DINÂMICO PARA INSTALAÇÕES SUBMARINAS, Dissertação de Mestrado em Sistemas Mecatrônicos, Publicação ENM.DM-104A/16, Departamento de Engenharia Mecânica, Faculdade de Tecnologia, Universidade de Brasília, Brasília, DF, 78p.

\section{CESSÃO DE DIREITOS}

AUTOR: Rafael Domenici Pereira Simões TÍTULO: SISTEMA DE POSICIONAMENTO DINÂMICO PARA INSTALAÇÕES SUBMARINAS.

GRAU: Mestre ANO: 2016

É concedida à Universidade de Brasília permissão para reproduzir cópias desta dissertação e para emprestar ou vender tais cópias somente para propósitos acadêmicos e científicos. O autor reserva outros direitos de publicação e nenhuma parte desse trabalho de conclusão de curso pode ser reproduzida sem autorização por escrito do autor.

Rafael Domenici Pereira Simões

SQN 304 Bloco B Apt. 205

Asa Norte

CEP 70736-020 - Brasília - DF - Brasil 
Dedicatória

À minha família

Rafael Domenici Pereira Simões 


\section{Agradecimentos}

Agradeço à minha família, principalmente aos meus pais, Monica e Luiz Simões, e ao meu irmão, Felipe Simões, pelo amor, amizade, educação, princípios, incentivo e apoio incondicional.

À minha querida namorada, Paula Soares, por todo apoio e compreensão, e que de forma especial e carinhosa me deu força e coragem nos momentos de dificuldade.

Ao meu orientador e amigo, Prof. Eugênio Fortaleza, pela orientação, paciência, disposição e por sempre acreditar em meu potencial.

A todos que direta ou indiretamente contribuíram para a elaboração deste trabalho.

Rafael Domenici Pereira Simões 


\section{RESUMO}

Atualmente, a instalação submarina se tornou um tópico principal na indústria de petróleo offshore. Um dos desafios da instalação de equipamentos submarinos é o preciso posicionamento do equipamento no local desejado no leito marinho. No entanto, esse procedimento ainda é comumente realizado de forma manual por um operador. O operador desloca a embarcação de superfície considerando as imagens do equipamento submarino produzidas por um veículo operado remotamente. Sendo assim, esta operação torna-se totalmente dependente da experiência e habilidade do operador. Outra limitação é que esta operação só pode ser realizada na presença de boas condições climáticas e de visibilidade submarina. O presente manuscrito apresenta o desenvolvimento de um sistema de controle de trajetória para o posicionamento do equipamento submarino. O desenvolvimento deste trabalho se dará em duas etapas. Na primeira etapa, será apresentado um planejamento de trajetória para o sistema de posicionamento dinâmico (DP) da plataforma. Esse planejamento de trajetória consiste na obtenção antecipada da trajetória necessária para o sistema DP, de modo que o equipamento submarino seja deslocado de sua posição inicial até o local desejado de instalação, sem apresentar oscilação na posição final. Esse planejamento de trajetória será realizado por meio da solução analítica da equação simplificada do movimento do riser e será feito considerando a situação ideal, na qual não há perturbações externas não modeladas. Na segunda etapa deste trabalho, será apresentado o desenvolvimento de um sistema de controle para permitir a tarefa de acompanhamento de trajetória, ou seja, será desenvolvido um controlador para garantir que o equipamento submarino, de fato, siga corretamente a trajetória desejada mesmo na presença de perturbações externas não modeladas na equação governante. Assim, a instalação do equipamento submarino poderá ser realizada sem a interferência direta do operador. Este processo automatizado tende, também, a aumentar a confiabilidade e a eficiência da operação, reduzindo o seu tempo total e os riscos de dano ao equipamento submarino.

Palavras Chaves: Sistema de Posicionamento Dinâmico, Planejamento de Trajetória, Solução Analítica de Cabo Amortecido, Acompanhamento de Trajetória, Planicidade Diferencial. 


\begin{abstract}
Nowadays, the subsea installation became a main topic in the offshore oil industry. One of the challenges of subsea equipment installation is the precise positioning of the equipment in the desired location on the seabed. However, this procedure is still commonly performed manually by an operator. The operator displaces the surface vessel considering the images of the subsea equipment produced by a remotely operated vehicle. Therefore, this operation becomes totally dependent on the experience and skill of the operator. Another limitation is that this operation can only be done in the presence of good weather and underwater visibility. This manuscript presents the development of a trajectory control system to the positioning of the subsea equipment. The development of this work will be done in two stages. In the first stage, will be presented a motion planning for the dynamic positioning (DP) system of the platform. This motion planning consists in the early obtaining of the trajectory needed for the DP system, so that the subsea equipment is displaced from its initial position to the desired installation point, without presenting oscillation in the final position. This motion planning will be done through the analytical solution of the simplified equation of motion of the riser and will be done considering the ideal situation, in which there is no external disturbances not modeled. In the second stage of this work, will be presented the development of a control system to allow the tracking trajectory task, that is, a controller will be developed to ensure that the subsea equipment, in fact, properly follow the desired trajectory even in the presence of external disturbances not modeled in the governing equation. Thus, the installation of the subsea equipment may be carried out without the direct interference of the operator. This automated process also tends to increase the reliability and the efficiency of the operation, reducing the total time and the risk of damage to the subsea equipment.
\end{abstract}

Keywords: Dynamic Positioning System, Motion Planning, Damped Cable Analytical Solution, Trajectory Tracking, Differential Flatness. 


\section{SUMÁRIO}

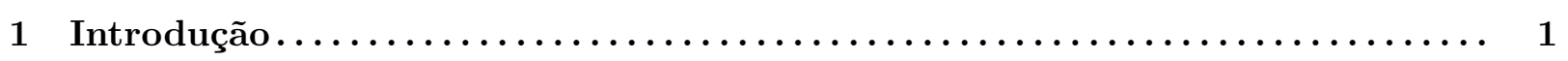

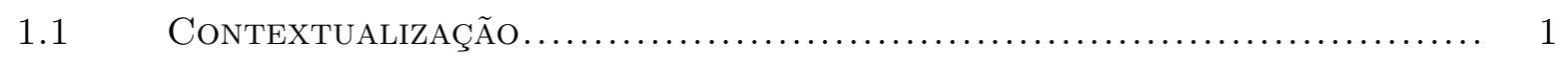

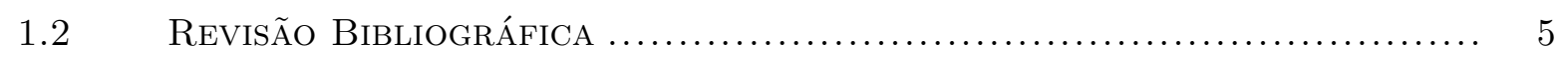

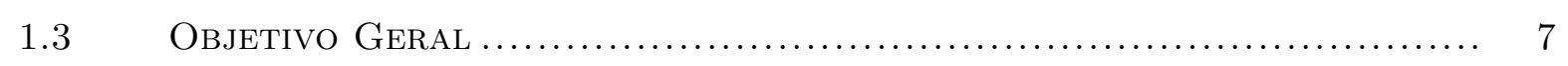

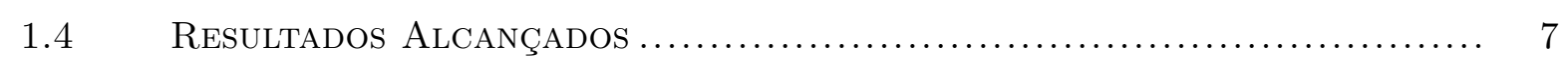

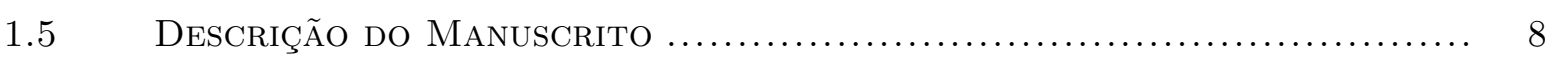

2 Modelagem Matemática $\ldots \ldots \ldots \ldots \ldots \ldots \ldots \ldots \ldots \ldots \ldots \ldots \ldots \ldots \ldots \ldots \ldots \ldots \ldots$

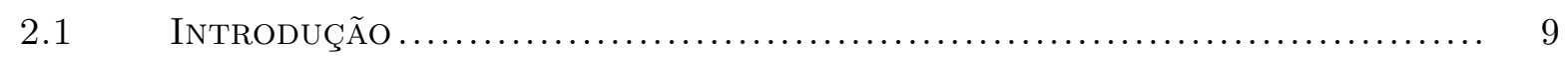

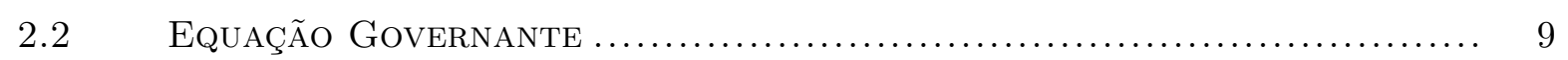

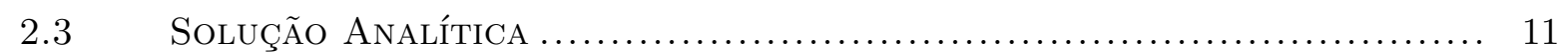

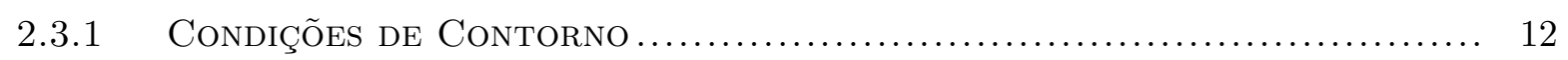

2.3.2 DeterminaÇÃo DAS FunÇÕES ....................................... 14

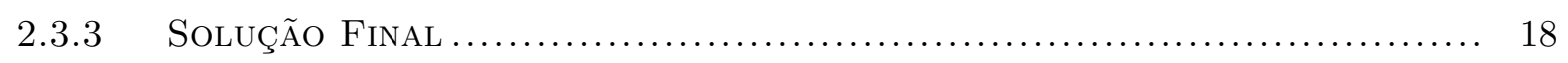

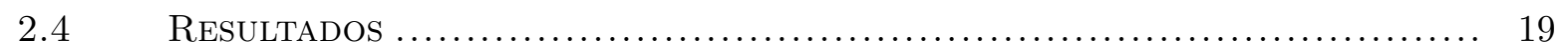

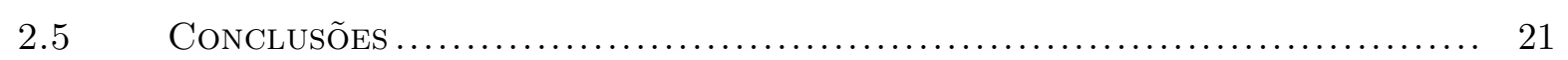

3 Simulação Numérica da Estrutura........................ 22

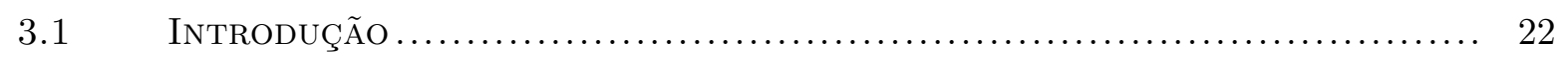

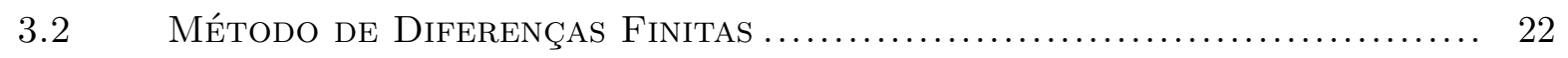

3.2.1 DiscretizaÇÃo do Sistema ............................................ 23

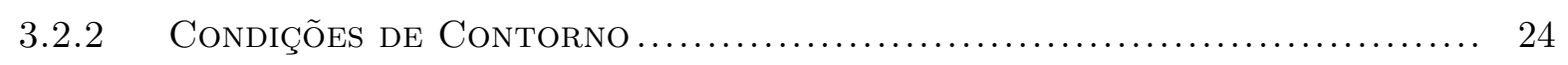

3.2.3 Modelo Discreto com o Arrasto linear .............................. 26

3.2.4 Modelo Discreto com o Arrasto Não-linear .......................... 28

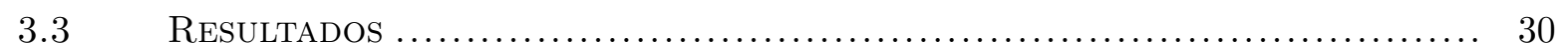

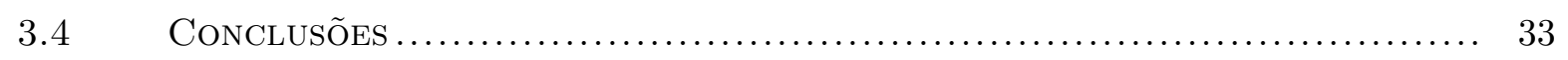

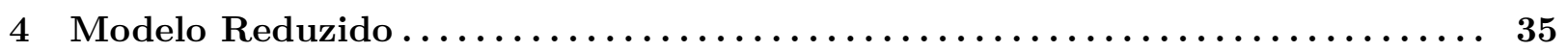

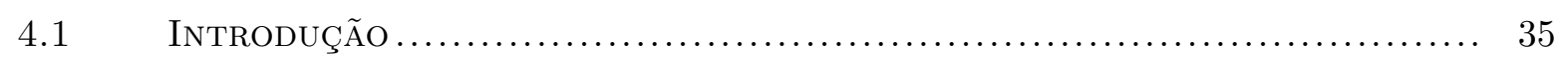

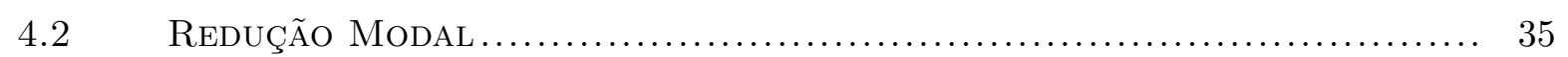

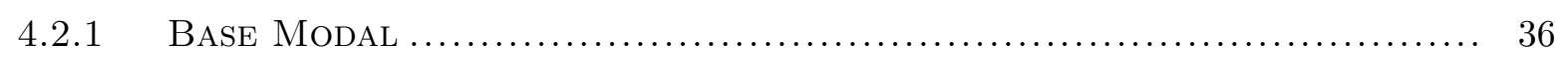

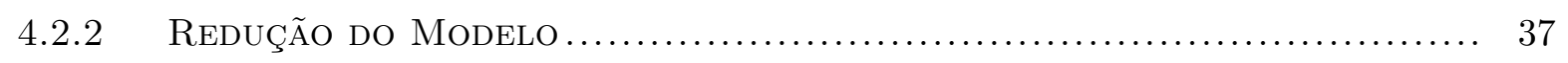

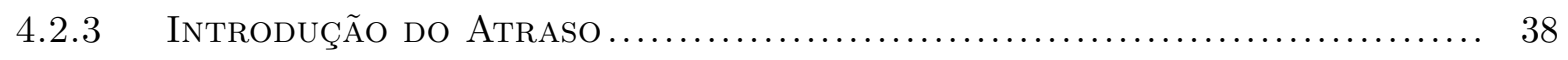




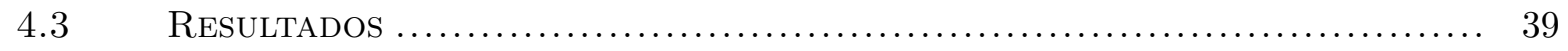

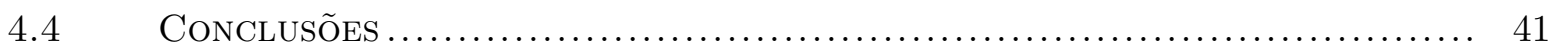

5 Controle de Trajetória via Planicidade Diferencial.................. 42

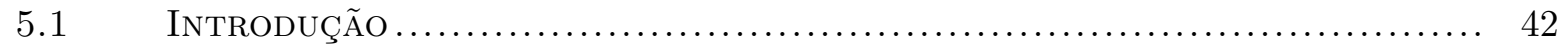

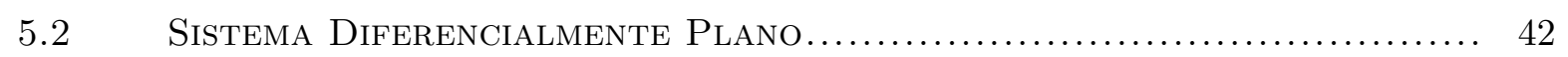

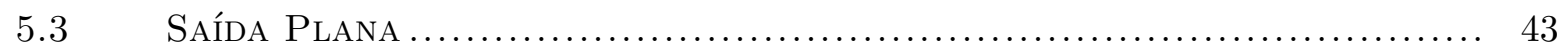

5.3 .1 Forma Canônica de Controle .................................... 44

5.3.2 Saída Plana para o Sistema na Forma Canônica de Controle......... 46

5.4 OBSERVAdor de Estado ............................................ 48

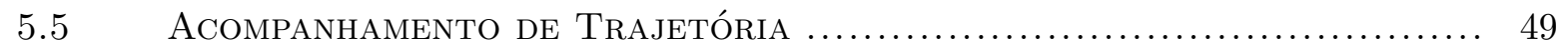

$5.6 \quad$ Preditor de SMith ........................................................ 50

$5.7 \quad$ Projeto do Controlador ........................................... 51

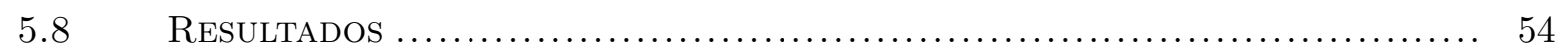

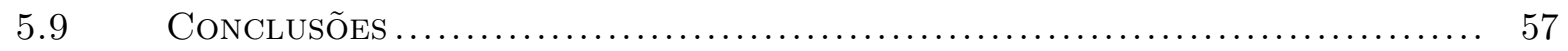

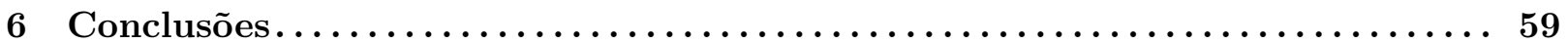

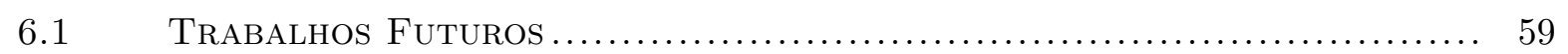

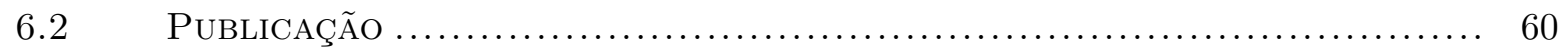

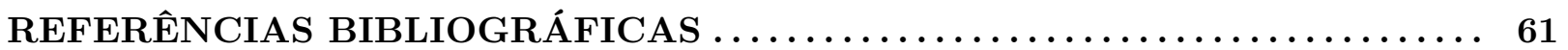




\section{LISTA DE FIGURAS}

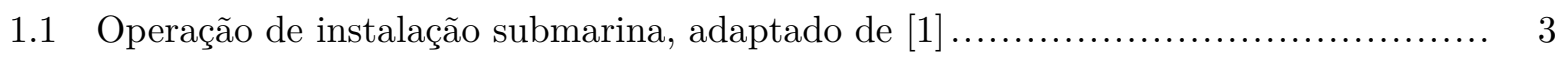

1.2 Diagrama de blocos do sistema (arquitetura mestre/escravo) $\ldots \ldots \ldots \ldots \ldots \ldots \ldots \ldots \ldots \ldots \ldots$

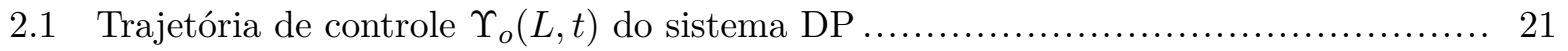

3.1 Simulação numérica do modelo discreto do sistema com o arrasto linear .............. 31

3.2 Simulação numérica do modelo discreto do sistema com o arrasto não-linear .......... 32

3.3 Imagem ampliada da simulação numérica do modelo discreto do sistema com o

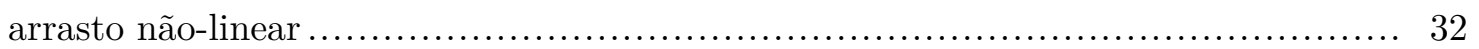

3.4 Respostas dos modelos discretos para uma entrada em forma de rampa.............. 33

4.1 Respostas dos modelos a uma entrada em degrau unitário .......................... 39

4.2 Imagem ampliada das respostas dos modelos a uma entrada em degrau unitário .... 40

4.3 Comparação da respostas do modelo original e do modelo reduzido de ordem 4 com atraso a uma entrada em degrau unitário ...................................... 41

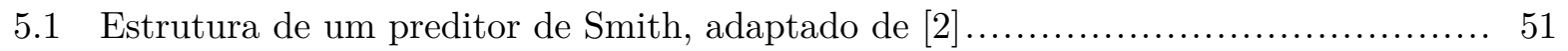

5.2 Diagrama de blocos da estrutura do sistema de controle, adaptado de [3] ........... 53

5.3 Comparação das respostas em malha aberta e em malha fechada para o caso do sistema deslocado de $0,2 m$ da referência ......................................... 55

5.4 Comparação das respostas em malha aberta e em malha fechada para o caso da

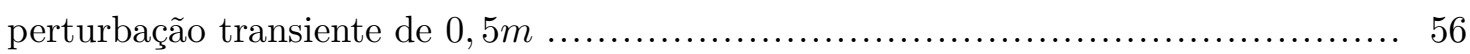

5.5 Comparação das respostas em malha aberta e em malha fechada para o caso da

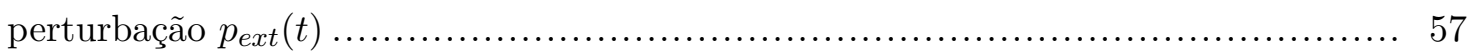




\section{LISTA DE TABELAS}

2.1 Parâmetros do sistema de instalação submarina.................................... 20 


\section{LISTA DE SÍMBOLOS}

\section{Letras maiúsculas}

A Matriz de estados

A $\quad$ Matriz de estados do sistema não-linear sem os termos de amortecimento

$\mathbf{A}_{2} \quad$ Matriz de estados do sistema não-linear com apenas os termos de amortecimento

$\mathbf{A}^{\prime} \quad$ Matriz de rigidez

$\mathbf{A}_{\mathbf{1}}^{\prime} \quad$ Matriz com os termos das duas primeiras linhas da matriz $\mathbf{A}^{\prime}$

$\mathbf{A}_{\mathbf{2}}^{\prime} \quad$ Matriz com os demais termos da matriz $\mathbf{A}^{\prime}$

B Matriz de entrada

C Matriz de saída

$C_{d} \quad$ Coeficiente de arrasto

$\mathbf{C}_{\mathbf{K}} \quad$ Matriz de controlabilidade de Kalman

$C_{m} \quad$ Coeficiente de massa adicional

D Diâmetro externo do riser

D Matriz de transferência direta

E $\quad$ Módulo de elasticidade

F Vetor de saídas planas

$F_{e} \quad$ Força exercida pelo riser sobre o equipamento submarino

$F_{h} \quad$ Força hidrodinâmica

$\mathbf{G}_{\mathbf{e}} \quad$ Matriz de ganho estático

I Matriz identidade

$I_{\nu} \quad$ Função modificada de Bessel de primeira espécie e ordem $\nu$

$J \quad$ Momento de inércia de área

$J_{\nu} \quad$ Função de Bessel de primeira espécie e ordem $\nu$

K Matriz que contém as acelerações associadas ao amortecimento hidrodinâmico linear

K' Matriz que contém as acelerações associadas ao amortecimento hidrodinâmico não-linear

$\mathbf{K}_{\mathbf{f}} \quad$ Matriz de ganho do filtro de Kalman

$K_{\nu} \quad$ Função modificada de Bessel de segunda espécie e ordem $\nu$

$L \quad$ Comprimento do riser

$N \quad$ Número de pontos da discretização 


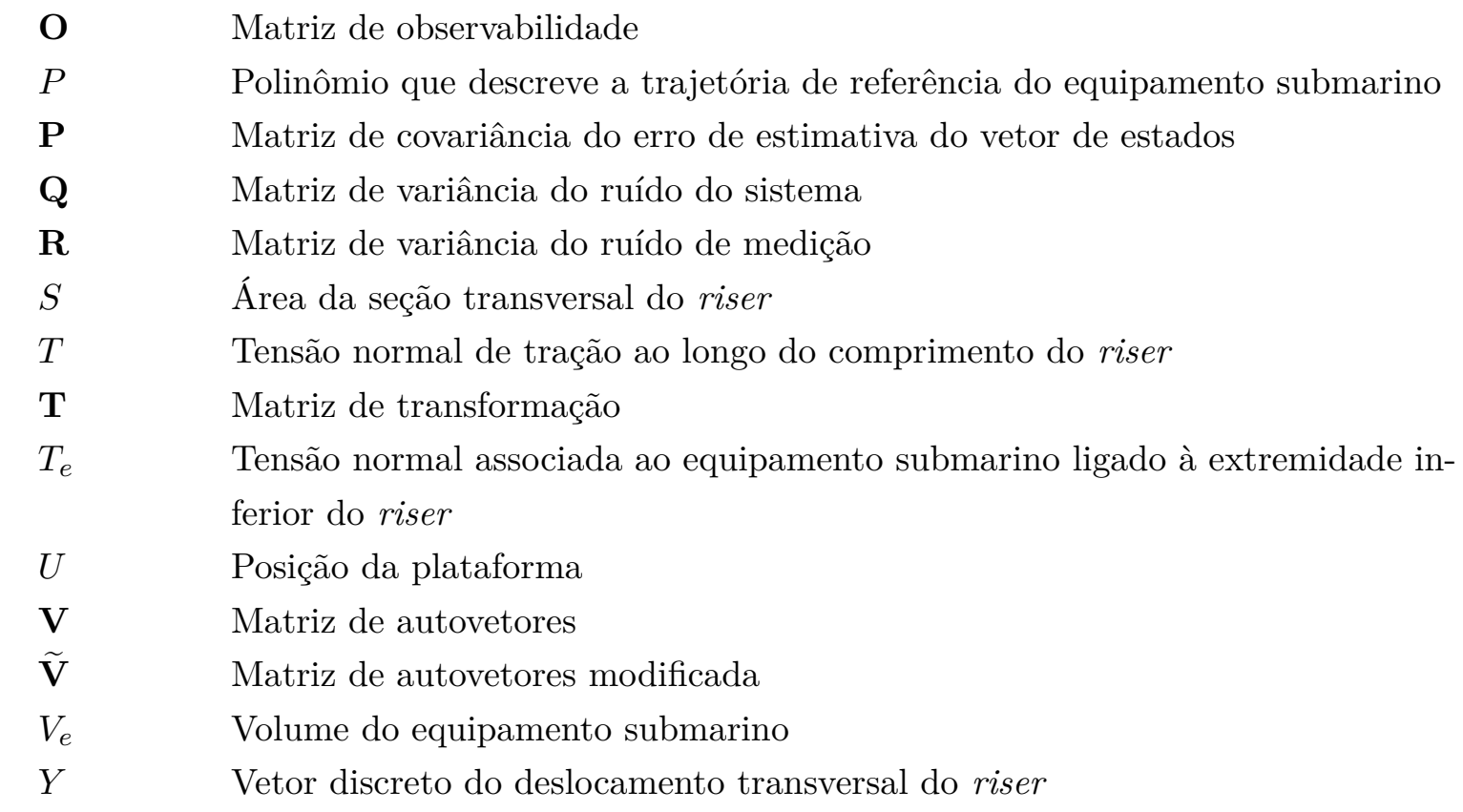

\section{Letras minúsculas}

$\begin{array}{ll}e_{x} & \text { Erro de estimativa do vetor de estado } \\ g & \text { Aceleração devido à gravidade } \\ g^{\prime} & \text { Gravidade efetiva } \\ k_{i} & \text { Ganhos do controlador em malha fechada } \\ l & \text { Distância entre dois pontos da discretização } \\ m & \text { Soma da massa linear do riser com a massa adicional de fluido por unidade } \\ & \text { de comprimento } \\ m_{e} & \text { Massa do equipamento submarino } \\ m_{F} & \text { Massa adicional de fluido por unidade de comprimento } \\ m_{s} & \text { Massa linear do riser } \\ m_{t e} & \text { Massa do equipamento submarino adicionada de sua massa adicional de fluido } \\ n & \text { Posição do elemento da discretização } \\ p & \text { Polinômio característico do controlador } \\ p_{e x t} & \text { Perturbação externa } \\ t & \text { Tempo } \\ t_{e} & \text { Tempo de estabilização } \\ t_{p} & \text { Tempo de propagação de uma perturbação ao longo do comprimento total do } \\ t_{s} & \text { riser } \\ u & \text { Tempo de simulação } \\ u_{x} & \text { Entrada do sistema } \\ v & \text { Função degrau unitário } \\ \mathrm{v} & \text { Velocidade de propagação de onda mecânica } \\ w & \text { Autovetor } \\ & \text { Ruído branco do sistema }\end{array}$




$\begin{array}{ll}\mathbf{x} & \text { Vetor de estados } \\ y & \text { Saída do sistema } \\ z & \text { Eixo vertical }\end{array}$

\section{Letras gregas}

$\alpha$

$\alpha_{e}$

$\gamma$

$\delta$

$\Delta t$

$\epsilon$

$\lambda$

$\mu$

$\mu_{e}$

$\nu$

$\rho$

$\sigma$

$v$

$\Upsilon$

$\Upsilon_{i}$

$\Upsilon_{f}$

$\varphi$

$\omega$

\section{Subscritos}
$R$
Referente ao sistema reduzido
$D$
Referente ao sistema reduzido com atraso

Arrasto dissipativo linearizado associado ao riser

Arrasto dissipativo linearizado associado ao equipamento submarino

Parte real do autovetor

Função Delta de Dirac

Passo de tempo

Atraso

Autovalor

Arrasto dissipativo não-linear por unidade de comprimento do riser

Arrasto dissipativo não-linear do equipamento submarino

Termo de correção de acompanhamento de trajetória

Densidade do fluido

Parte real do autovalor

Ruído branco de medição

Deslocamento transversal de um elemento infinitesimal do riser

Posição inicial do equipamento submarino

Posição final do equipamento submarino

Parte imaginária do autovetor

Parte imaginária do autovalor

\section{Sobrescritos}

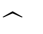

$\cdot$

$\cdot \cdot$

$*$

Referente à variável na base modal

- $\quad$ Referente à variável na base canônica de controle

Referente à transformada de Laplace da variável

Primeira derivada temporal

Segunda derivada temporal

Terceira derivada temporal

Quarta derivada temporal

Referente ao valor nominal da variável 


\section{Siglas}

$\begin{array}{ll}\text { BOP } & \text { Blow-out Preventer } \\ \text { DP } & \text { Dynamic Positioning (Posicionamento Dinâmico) } \\ \text { LDA } & \text { Lâmina d'água } \\ \text { ROV } & \text { Remotely Operated Vehicle (Veículo Operado Remotamente) } \\ \text { SISO } & \text { Single-Input Single-Output (Uma-Entrada e Uma-Saída) }\end{array}$




\section{Capítulo 1}

\section{Introdução}

\subsection{Contextualização}

Atualmente, com a exploração e a produção offshore de petróleo e gás avançando para águas cada vez mais profundas (2000 metros e mais), a instalação submarina se tornou um tópico principal na indústria de petróleo offshore. Diversos equipamentos submarinos são construídos onshore e transportados offshore para o local de instalação, como por exemplo a árvore de natal (Christmas tree, do inglês), o BOP (Blow-out Preventer, do inglês) e o manifold.

Um dos desafios da instalação de equipamentos submarinos em águas profundas é o preciso posicionamento do equipamento no local desejado no leito marinho. A operação de posicionamento inclui tanto o posicionamento da embarcação de superfície (plataforma ou navio) como o posicionamento do equipamento submarino na posição desejada no fundo do mar.

O posicionamento da embarcação de superfície se refere ao posicionamento que a mantém na posição desejada durante todo o período da instalação [4]. Esse posicionamento pode ser feito por um sistema convencional de ancoragem ou por um sistema de posicionamento dinâmico (DP - Dynamic Positioning, do inglês) [5]. De forma simplificada, o sistema DP consiste em controladores, sensores e propulsores.

O sistema DP utiliza os sistemas acústico, mecânico, por radar e/ou via satélite para orientar e posicionar a embarcação. As embarcações equipadas com o sistema DP podem ajustar sua posição em curtos intervalos de tempo e, também, mudar sua orientação rapidamente para reduzir perturbações ambientes [5].

Uma vez posicionada a embarcação, o equipamento submarino pode ser descido até o seu local de destino no solo marinho. Dependendo do tipo de embarcação, da geometria e das características do equipamento submarino, este procedimento de descida pode ser realizado tanto por um sistema de guindaste como pelo próprio sistema de perfuração da embarcação.

Uma vez descido, o equipamento pode ser posicionado no local desejado de instalação. Segundo Bai e Bai [4], há dois métodos que são amplamente utilizados para o posicionamento: o método guiado e o método não guiado. O método guiado utiliza cabos guias (normalmente quatro 
cabos tensionados) para posicionar o equipamento submarino no local desejado no fundo do mar. O posicionamento por esse método é bastante conveniente, porém é limitado devido à própria utilização dos cabos guias. Conforme destacam Bai e Bai [4], para instalações em águas profundas, esse método pode ser bastante dispendioso, tanto em tempo como em valor.

Por sua vez, o método não guiado posiciona o equipamento submarino sem a necessidade dos cabos guias. O equipamento submarino tem sua posição alterada indiretamente, por meio da alteração da posição da embarcação ou por um sistema de guindaste. Entretanto, devido ao comportamento dinâmico do sistema e às limitações espaciais exigidas, este método é relativamente complexo.

Em alguns casos, no método não guiado, ainda acopla-se um sistema de propulsores ao equipamento submarino, de forma a possibilitar que se ajuste sua posição diretamente, conforme pode ser visto em [6-8]. No entanto, o alcance desse ajuste é limitado a uma certa área, determinada pela capacidade dos propulsores. Além disso, o desenvolvimento e a utilização desse sistema eleva o custo da operação, sem contar que, para sistemas muito pesados, a força necessária dos propulsores para movimentar o sistema pode ser demasiadamente grande, inviabilizando a operação.

As atividades de exploração e produção de petróleo podem ser classificadas de acordo com a profundidade da lâmina d'água (LDA) em que operam, isto é, a distância vertical entre a superfície do mar e o solo marinho. São consideradas LDAs rasas as de profundidade de até 300 metros, entre 300 e 1500 metros são consideradas profundas e acima de 1500 metros, ultraprofundas [9].

O preciso posicionamento do equipamento submarino é ainda mais difícil em águas ultraprofundas, devido à grande distância entre a embarcação de superfície e o equipamento a ser posicionado no fundo do mar. Perturbações ambientes, como correntes oceânicas, ondas e ventos, relativamente pequenas, podem causar grandes diferenças entre a posição real do equipamento submarino e a sua posição esperada. Além disso, condições climáticas severas podem fazer com que uma operação de posicionamento tenha que aguardar vários dias até que se torne possível realizá-la.

Neste manuscrito será abordado o caso do posicionamento do equipamento submarino em águas ultraprofundas, por meio do método não guiado e sem adicionar ao equipamento o sistema de propulsores. O posicionamento da embarcação de superfície será determinado por um sistema DP e o equipamento submarino será posicionado indiretamente, pela transmissão de movimento através do sistema de perfuração da embarcação, mais especificamente, através do riser de perfuração. Assim, a posição desejada para o equipamento submarino será obtida apenas pelo correto deslocamento da embarcação de superfície.

Atualmente, esse procedimento de posicionamento ainda é comumente realizado de forma manual. Isto é, um operador desloca a embarcação de superfície considerando as imagens do equipamento submarino produzidas por um veículo operado remotamente (ROV - Remotely Operated Vehicle, do inglês). Assim, o operador pode ajustar a posição da embarcação de forma a posicionar e instalar o equipamento submarino no local desejado. Sendo assim, esta operação torna-se totalmente dependente da experiência e habilidade do operador. Outra limitação é que esta operação só pode ser realizada na presença de boas condições climáticas e de visibilidade submarina. 
Neste contexto, faz-se necessário o contínuo desenvolvimento de pesquisas e tecnologias, de forma a aumentar a eficiência e a confiabilidade da operação de instalação submarina, tornando-a mais rápida e segura, e, também, expandir a gama de condições climáticas em que ela pode ser realizada.

Um típico procedimento de instalação de equipamento submarino é apresentado na Fig. 1.1, que basicamente consiste em uma plataforma, um riser marinho e um equipamento submarino a ser posicionado. A plataforma é equipada com um sistema DP, que permite modificar sua posição por meio de propulsores e hélices. A extremidade superior do riser é conectada à plataforma e a sua extremidade inferior é conectada ao equipamento submarino. Um ROV monitora a posição do equipamento submarino durante toda a operação.

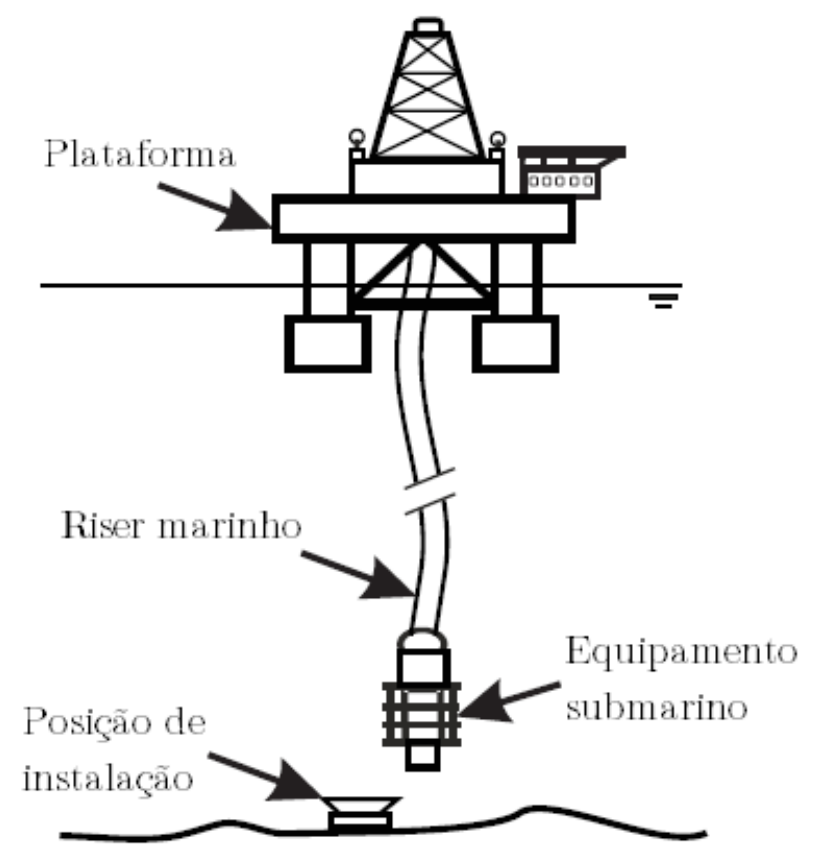

Figura 1.1: Operação de instalação submarina, adaptado de [1]

O sistema pode ser representado por uma arquitetura mestre/escravo (Fig. 1.2). O loop escravo se refere ao sistema DP e à plataforma, e a sua dinâmica é muito mais rápida se comparada à dinâmica do loop mestre. Por sua vez, o loop mestre se refere ao conjunto do riser, do equipamento submarino e do operador. A dinâmica do loop mestre é influenciada principalmente pela propagação de onda mecânica ao longo do riser. Destaca-se que, neste trabalho, a análise será focada apenas no loop mestre e será considerado que o sistema DP posiciona a plataforma na posição desejada instantaneamente. 


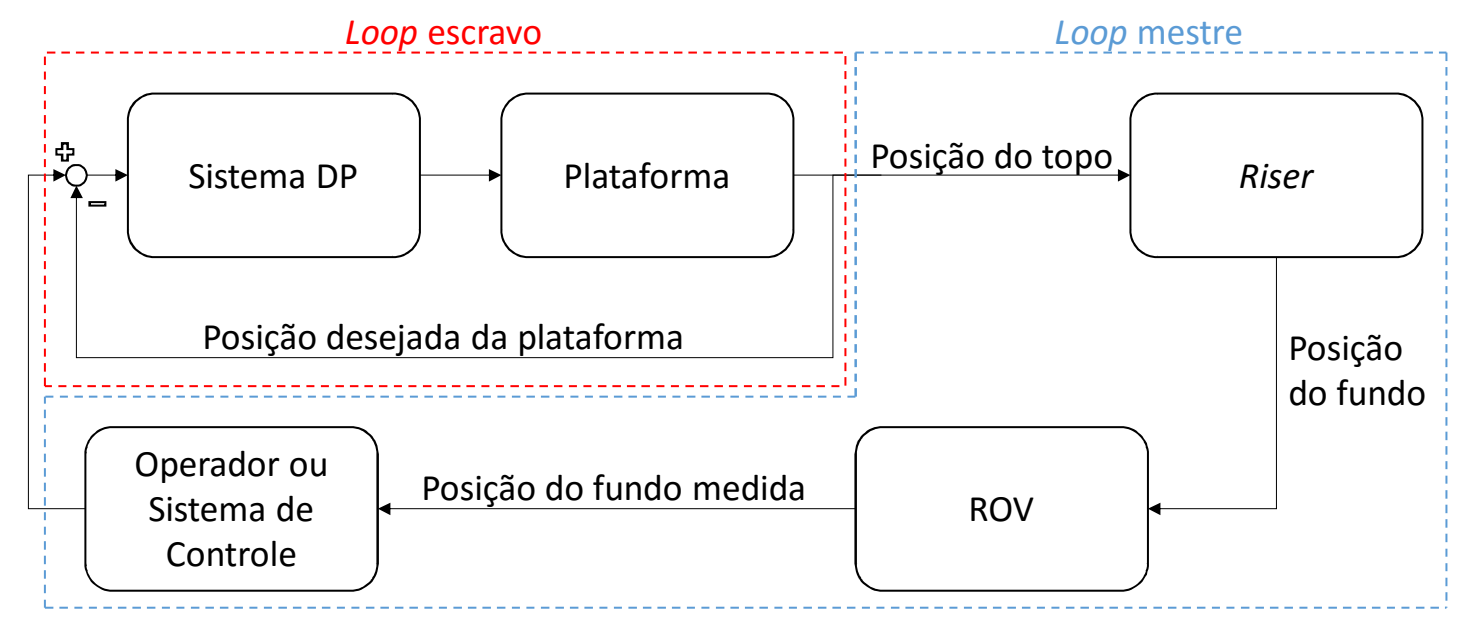

Figura 1.2: Diagrama de blocos do sistema (arquitetura mestre/escravo)

O presente manuscrito apresenta o desenvolvimento de um sistema de controle para substituir o operador humano no loop mestre. O sistema de controle deve ser capaz de determinar a correta posição da plataforma que irá permitir a instalação submarina. Trata-se, portanto, de uma estratégia de controle de trajetória para o posicionamento do equipamento submarino.

A estratégia consiste em posicionar o equipamento submarino, na posição desejada no leito marinho, modificando dinamicamente a extremidade superior do riser, cujo deslocamento é determinado pelo sistema DP da plataforma. Isto permite determinar o preciso movimento da plataforma que é necessário para se obter a posição desejada do equipamento submarino (deslocamento e estabilização do equipamento submarino). A posição do equipamento submarino é monitorada pelas imagens produzidas em tempo real por um ROV.

O desenvolvimento deste trabalho se dará em duas etapas. Na primeira etapa, será apresentado um planejamento de trajetória para o sistema DP. Esse planejamento de trajetória consiste na obtenção antecipada da trajetória necessária para o sistema DP, de modo que o equipamento submarino seja deslocado de sua posição inicial até o local desejado de instalação, sem apresentar oscilação na posição final. Esse planejamento de trajetória será realizado por meio de uma abordagem analítica da equação simplificada do movimento do riser e será feito considerando a situação ideal, na qual não há perturbações externas não modeladas.

Entretanto, em uma operação real, há a presença de perturbações externas não conhecidas, como correntes oceânicas, ondas e ventos. A presença dessas perturbações não modeladas demanda o projeto de um sistema de controle para garantir que o equipamento submarino, de fato, siga corretamente a trajetória desejada. Por isso, na segunda etapa deste trabalho, será apresentado um sistema de controle para permitir a tarefa de acompanhamento de trajetória.

Assim, a instalação do equipamento submarino poderá ser realizada sem a interferência direta do operador, mesmo na presença de perturbações externas. Este processo automatizado tende, também, a aumentar a confiabilidade e a eficiência da operação, reduzindo o seu tempo total e os riscos de dano ao equipamento submarino. 


\subsection{Revisão Bibliográfica}

O comportamento dinâmico e o controle de sistemas mecânicos marinhos sobre influência de perturbações oceânicas não conhecidas foram amplamente estudados nos últimos anos. Esse crescente aumento do interesse se deve ao aumento da demanda por energia e a busca por novos campos de petróleo em águas cada vez mais profundas.

Como o enfoque deste manuscrito é o comportamento e controle do riser utilizado no procedimento de instalação de um equipamento submarino, a dinâmica e o controle da embarcação de superfície não foi estudada, sendo apenas uma entrada do sistema.

A revisão bibliográfica realizada durante o desenvolvimento do trabalho abrangeu os seguintes temas: modelagem matemática de um riser marinho e técnicas de planejamento de trajetória e de controle para o procedimento de posicionamento do riser livre e/ou acoplado a um equipamento submarino.

Os comportamentos estático e dinâmico de risers marinhos têm sido extensivamente pesquisados e encontra-se diversos artigos na literatura. Assim, cumpre destacar apenas os considerados mais importantes para o desenvolvimento deste trabalho. A maioria dos artigos encontrados analisam o comportamento do riser com a sua extremidade inferior fixa à cabeça do poço, em uma típica operação de perfuração ou de produção.

Burke [10] analisou estática e dinamicamente o comportamento de um riser de perfuração para águas profundas. A análise foi baseada na equação geral diferencial linear de uma viga com carregamentos laterais em um plano vertical. A solução da equação diferencial parcial foi obtida por um método de integração numérica para uma determinada distribuição de força ao longo do comprimento do riser e com condições de contorno em cada extremidade.

Já Brouwers [11] focou a análise apenas na dinâmica do riser. O riser foi modelado pela equação de uma viga tracionada e submetida a forças hidrodinâmicas descritas pela equação de Morison. Entretanto, neste artigo a solução da equação diferencial parcial foi obtida por métodos analíticos. Para permitir a abordagem analítica, o riser foi divido em três regiões distintas e para cada uma adotou-se as simplificações consideradas cabíveis.

Um interessante artigo é o desenvolvido por Chakrabarti e Frampton [12]. Apresenta-se uma revisão do estado da arte da análise de risers desde 1950 até 1982. No artigo, ilustra-se como a análise dos risers progrediram desde as primeiras análises estáticas até as análises dinâmicas mais sofisticadas e complexas.

O comportamento dinâmico de um riser marinho livre foi estudado por Patel e Jesudasen [13]. Neste artigo, investigou-se a dinâmica lateral de um riser ligado à embarcação de superfície pela extremidade superior e com a outra extremidade desconectada da cabeça do poço. Os autores procederam uma análise teórica utilizando o método de elementos finitos e, também, uma análise experimental utilizando um modelo em escala reduzida. Hover [14] também investigou experimentalmente o posicionamento dinâmico de uma estrutura rebocada pela sua extremidade superior. Neste caso, diferentes técnicas de controle foram utilizadas para comparar a performance do po- 
sicionamento.

Petit e Rouchon [15] analisaram três diferentes casos de posicionamento de correntes pesadas (heavy chains, do inglês). Esse tipo de posicionamento se assemelha ao caso do posicionamento de um riser marinho, entretanto, apresenta a simplificação de não considerar o termo de amortecimento na equação governante do sistema. Os autores solucionaram analiticamente a equação governante no domínio de Laplace e posteriormente apresentaram uma estratégia para retornar ao domínio do tempo. Assim, obtiveram a expressão do deslocamento da estrutura no domínio do tempo.

Tal abordagem analítica de solução da equação governante no domínio de Laplace também foi utilizada por Fortaleza et al. [16] para estudar o caso do posicionamento de um riser livre amortecido. Entretanto, devido ao termo de amortecimento agora considerado, foi necessário utilizar uma expansão em série de Taylor para retornar a expressão do deslocamento do riser ao domínio do tempo.

Em um trabalho mais recente de Fortaleza et al. [1] a mesma abordagem analítica foi empregada. Entretanto, agora, analisou-se o caso do posicionamento de um equipamento submarino preso à extremidade inferior do riser. De forma a simplificar a equação governante do sistema, considerou-se como constante a tensão de tração ao longo da estrutura do riser, sendo causada exclusivamente pela massa do equipamento submarino. Novamente, utilizou-se a expansão em série de Taylor para permitir o retorno da expressão do deslocamento do riser ao domínio do tempo.

Albuquerque [17] apresentou uma estratégia de planejamento de trajetória para o posicionamento de risers. As duas situações apresentadas em [16] e [1] foram estudadas: o posicionamento de um riser com um equipamento preso a sua extremidade inferior e o posicionamento de um riser livre. Entretanto, neste trabalho, voltou-se a expressão do deslocamento do riser ao domínio do tempo utilizando o teorema da Convolução, dispensando a utilização da expansão em série de Taylor. Tal estratégia será a mesma utilizada neste manuscrito e será apresentada no Capítulo 2.

O problema do controle de trajetória para o caso do posicionamento do riser livre foi estudado por Fortaleza [18] e para o caso do riser com um BOP preso à sua extremidade inferior foi estudado por Yamamoto e Morooka [19]. Ambos os trabalhos apresentaram um sistema de controle para permitir o posicionamento mesmo na presença de perturbações externas não modeladas na equação governante do sistema. Em [18] utilizou-se o método de Lyapunov para a obtenção da lei de controle e em [19] utilizou-se o método do Regulador Quadrático Linear (Linear Quadratic Regulator, do inglês).

Monteiro et al. [3] também estudaram o controle de trajetória para o caso de instalação de equipamentos submarinos utilizando risers. Novamente, considerou-se que a tensão de tração ao longo da estrutura era constante e devida exclusivamente ao pesado equipamento a ser posicionado. Então, procedeu-se a discretização da equação governante do sistema utilizando o método das diferenças finitas e, posteriormente, reduziu-se a ordem do sistema discreto através de uma análise modal. Devido à propriedade plana do sistema, pôde-se desenvolver um controlador via planicidade diferencial. Neste manuscrito, essa abordagem também será utilizada para o projeto 
do controlador, conforme será apresentada no Capítulo 5 .

\subsection{Objetivo Geral}

O objetivo geral desta dissertação é desenvolver um sistema de controle para o sistema DP de uma plataforma de forma a permitir que o procedimento de instalação de equipamento submarino possa ser feita de maneira confiável e eficiente. Para atingir esse objetivo geral, propõem-se os seguintes objetivos específicos:

1. Apresentar a modelagem matemática do sistema e obter a equação governante com as devidas suposições e simplificações cabíveis para o caso em estudo;

2. Realizar a etapa de planejamento de trajetória por meio da solução analítica da equação governante, utilizando a estratégia de solução no domínio de Laplace e a posterior aplicação da transformada inversa de Laplace para trazer a solução ao domínio do tempo;

3. Apresentar a discretização da equação governante do sistema utilizando o método de diferenças finitas e obter o seu modelo discreto;

4. Validar a solução analítica a partir de simulações numéricas do modelo discreto e analisar a influência das suposições e simplificações consideradas;

5. Apresentar uma estratégia de redução de ordem do sistema utilizando a abordagem modal e a posterior substituição da transferência direta gerada por essa redução por um atraso de forma a melhorar a precisão do modelo;

6. Realizar a etapa de acompanhamento de trajetória por meio do projeto de um controlador a partir da teoria de planicidade diferencial;

7. Verificar a performance do controlador a partir de simulações numéricas considerando o posicionamento do equipamento submarino na presença de perturbações externas.

\subsection{Resultados Alcançados}

Neste trabalho, desenvolveu-se tanto o planejamento como o acompanhamento de trajetória para um típico caso de instalação submarina em águas ultraprofundas. A grande contribuição deste trabalho foi a etapa de planejamento de trajetória, na qual obteve-se analiticamente uma expressão para o sistema DP, capaz de fazer o equipamento submarino seguir uma trajetória desejada. A solução analítica foi validada por meio da discretização e simulação do sistema original no ambiente Simulink do MATLAB ${ }^{\circledR}$.

Na etapa de acompanhamento de trajetória, obteve-se um sistema de controle, a partir da teoria de planicidade diferencial, para garantir que o planejamento de trajetória fosse obedecido mesmo na presença de perturbações externas. A performance do sistema de controle foi verificada a partir de simulações numéricas, também implementadas no ambiente Simulink do MATLAB ${ }^{\circledR}$. 


\subsection{Descrição do Manuscrito}

Esta dissertação é organizada em seis capítulos.

No Capítulo 2, apresenta-se a modelagem matemática do sistema e obtém-se a equação que governa o sistema, com as suas devidas suposições e simplificações. Apresenta-se também uma abordagem analítica para solucionar a equação governante e obter a expressão da trajetória do sistema DP a fim de posicionar o equipamento no local desejado.

No Capítulo 3, apresenta-se simulações numéricas da estrutura a fim de validar a solução analítica obtida. As simulações numéricas são feitas a partir do modelo discreto da estrutura, obtido por meia do método de diferenças finitas. Os resultados são apresentados ao final do capítulo, juntamente com as análises que atestam a validade da solução analítica.

No Capítulo 4, apresenta-se uma estratégia de redução de ordem do sistema, baseando-se na teoria de análise modal. Apresenta-se também a introdução de um atraso no sistema reduzido para melhor aproximá-lo ao comportamento do sistema discreto original.

No Capítulo 5, apresenta-se o desenvolvimento do controle de acompanhamento de trajetória, utilizando-se a teoria de planicidade diferencial. Apresenta-se também simulações numéricas implementadas no ambiente Simulink do $M A T L A B^{\circledR}$ para verificar a performance do controlador ao se considerar a presença de perturbações externas. Os resultados são apresentados ao final do capítulo, juntamente com as análises de desempenho do controlador.

No Capítulo 6, apresenta-se as conclusões deste trabalho e as propostas de trabalhos futuros. 


\section{Capítulo 2}

\section{Modelagem Matemática}

\subsection{Introdução}

Este capítulo tem como objetivo apresentar a modelagem matemática do riser utilizado para o posicionamento do equipamento submarino, seguindo o desenvolvimento descrito em [18] e [1]. A partir dessa modelagem, obtém-se a equação governante do sistema e procede-se a sua solução analítica. Pela solução analítica, obtém-se a expressão da trajetória requerida do sistema DP a fim de posicionar o equipamento submarino no local desejado.

\subsection{Equação Governante}

Tipicamente, estruturas utilizadas na instalação de equipamentos submarinos, como os risers marinhos, podem ser consideradas estruturas delgadas, cujos deslocamentos transversais são pequenos se comparados ao seu comprimento.

No caso de um riser com seção transversal constante e sob tração axial, o comportamento dinâmico de um de seus elementos infinitesimais, na direção do seu deslocamento horizontal, pode ser modelado pela equação de viga de Euler-Bernoulli sob influência de forças transversais externas provenientes do fluido em que está submerso [20]:

$$
m_{s} \frac{\partial^{2} \Upsilon}{\partial t^{2}}(z, t)=-E J \frac{\partial^{4} \Upsilon}{\partial z^{4}}(z, t)+\frac{\partial}{\partial z}\left(T(z) \frac{\partial \Upsilon}{\partial z}(z, t)\right)+F_{h}(z, t)
$$

onde $\Upsilon$ representa a posição do elemento infinitesimal do riser na direção horizontal e é função de dois parâmetros: do tempo $t$ e da altura $z$ a partir do fundo do mar. As outras variáveis são: $m_{s}$ a massa linear do riser, $T$ a função que descreve a tensão normal de tração ao longo do comprimento da estrutura, $E$ o módulo de elasticidade do riser, $J$ o momento de inércia de área de sua seção transversal e $F_{h}$ as forças externas na direção horizontal por unidade de comprimento.

As forças externas atuando em toda a estrutura podem ser aproximadas pela equação modificada de Morison [20] (Eq. (2.2)). Destaca-se que a Eq. (2.2) representa as forças hidrodinâmicas 
associadas ao deslocamento de um corpo submerso e não inclui forças laterais resultantes do desprendimento de vórtices ao redor da estrutura.

$$
F_{h}(z, t)=-m_{F} \frac{\partial^{2} \Upsilon}{\partial t^{2}}(z, t)-\mu \frac{\partial \Upsilon}{\partial t}(z, t)\left|\frac{\partial \Upsilon}{\partial t}(z, t)\right|
$$

onde $m_{F}$ é a massa adicional de fluido por unidade de comprimento e $\mu$ é o arrasto por unidade de comprimento.

A massa adicional de fluido por unidade de comprimento é definida por:

$$
m_{F}=\rho C_{m} S
$$

onde $\rho$ é a densidade do fluido, $C_{m}$ é o coeficiente de massa adicional e $S$ é a área da seção transversal do riser.

O arrasto por unidade de comprimento é definido por:

$$
\mu=\frac{1}{2} \rho C_{d} D
$$

onde $C_{d}$ é o coeficiente de arrasto e $D$ é o diâmetro externo do riser.

Denotando $m=m_{s}+m_{F}$ e considerando as forças hidrodinâmicas, dadas pela equação modificada de Morison, como as únicas forças externas, pode-se reescrever a Eq. (2.1):

$$
\frac{\partial^{2} \Upsilon}{\partial t^{2}}(z, t)=-\frac{E J}{m} \frac{\partial^{4} \Upsilon}{\partial z^{4}}(z, t)+\frac{\partial}{\partial z}\left(\frac{T(z)}{m} \frac{\partial \Upsilon}{\partial z}(z, t)\right)-\frac{\mu}{m} \frac{\partial \Upsilon}{\partial t}(z, t)\left|\frac{\partial \Upsilon}{\partial t}(z, t)\right|
$$

Outra suposição que pode ser feita é que, devido à baixa velocidade de deslocamento do riser, o escoamento de fluido ao seu redor pode ser considerado laminar. Um escoamento ao redor de um cilindro é considerado laminar se tiver um número de Reynolds de até 2000 [21]. Sendo laminar, pode-se linearizar o termo de arrasto dissipativo que advém da Eq. (2.2).

A linearização é feita pela substituição do termo $\frac{\mu}{m}\left|\frac{\partial \Upsilon}{\partial t}\right|$ pelo termo constante $2 \alpha$, que é calculado em função de $\frac{\mu}{m}$ e do valor médio de $\frac{\partial \Upsilon}{\partial t}$ ao longo da estrutura. Assim, obtém-se a Eq. (2.6), que é a equação governante do sistema para o caso do amortecimento linearizado.

$$
\frac{\partial^{2} \Upsilon}{\partial t^{2}}(z, t)=-\frac{E J}{m} \frac{\partial^{4} \Upsilon}{\partial z^{4}}(z, t)+\frac{\partial}{\partial z}\left(\frac{T(z)}{m} \frac{\partial \Upsilon}{\partial z}(z, t)\right)-2 \alpha \frac{\partial \Upsilon}{\partial t}(z, t)
$$

Em uma típica instalação de equipamentos submarinos em águas ultraprofundas, o peso da própria estrutura do riser e o peso do equipamento submarino têm magnitudes de ordem similar. Sendo assim, ambos têm influência significativa na tensão normal de tração $T$ ao longo do comprimento do riser e não é razoável desprezar qualquer um dos dois. Assim, pode-se formular a expressão de $T$ pela diferença entre o peso total e o empuxo de Arquimedes:

$$
T(z)=\left(m_{s}-\rho S\right) g z+T_{e}
$$


onde $g$ é a aceleração devido à gravidade e $T_{e}$ é a tensão normal associada ao equipamento submarino ligado à extremidade inferior do riser.

A tensão normal $T_{e}$ é dada por:

$$
T_{e}=\left(m_{e}-\rho V_{e}\right) g
$$

onde $m_{e}$ é a massa do equipamento submarino e $V_{e}$ é o seu volume.

Como os risers utilizados nesse tipo de operação são estruturas muito longas (2000 metros ou mais), as relações entre seus diâmetros e seus comprimentos $\left(\frac{D}{L}\right)$ são da ordem de $10^{-4}$ ou menor. Assim, é razoável desprezar o termo de viga $E J \frac{\partial^{4} \Upsilon}{\partial z^{4}}$ associado à resistência a flexão, uma vez que $\frac{\partial}{\partial z}\left(T \frac{\partial \Upsilon}{\partial z}\right) \gg E J \frac{\partial^{4} \Upsilon}{\partial z^{4}}[18]$. Portanto, considerando essa simplificação, a equação governante do sistema se torna:

$$
\frac{\partial^{2} \Upsilon}{\partial t^{2}}(z, t)=\frac{\partial}{\partial z}\left[\left(\frac{\left(m_{s}-\rho S\right) g z}{m}+\frac{T_{e}}{m}\right) \frac{\partial \Upsilon}{\partial z}(z, t)\right]-2 \alpha \frac{\partial \Upsilon}{\partial t}(z, t)
$$

Para simplificar a notação, o termo constante $\frac{\left(m_{s}-\rho S\right) g}{m}$ pode ser substituído por $g^{\prime}$, que representa uma gravidade efetiva, e o termo constante $\frac{T_{e}}{m}$ pode ser substituído por $v^{2}$, onde $v$ é a velocidade de propagação de onda mecânica em uma corda submetida a uma tensão $T_{e}$. Assim, a Eq. (2.9) pode ser reescrita por:

$$
\frac{\partial^{2} \Upsilon}{\partial t^{2}}(z, t)=g^{\prime} \frac{\partial \Upsilon}{\partial z}(z, t)+\left(g^{\prime} z+v^{2}\right) \frac{\partial^{2} \Upsilon}{\partial z^{2}}(z, t)-2 \alpha \frac{\partial \Upsilon}{\partial t}(z, t)
$$

\subsection{Solução Analítica}

Nesta seção, a solução analítica da Eq. (2.10) no domínio do tempo é proposta, seguindo a ideia apresentada por Petit e Rouchon [15] de solução no domínio de Laplace e posterior inversão para o domínio do tempo. Petit e Rouchon [15] solucionaram o caso de posicionamento de um cabo livre sem amortecimento e, posteriormente, Fortaleza et al. [16] adaptaram para o caso com amortecimento.

Nos trabalhos de Fortaleza et al. [1] e de Albuquerque [17] a mesma estratégia foi utilizada para solucionar o caso de posicionamento de um equipamento submarino por um riser, entretanto, a tensão normal de tração ao longo da estrutura (Eq. (2.7)) foi considerada constante e causada exclusivamente pela massa do equipamento submarino $\left(T(z)=T_{e}\right)$, negligenciando-se a tensão normal associada à própria massa do riser.

No presente manuscrito é proposta uma solução analítica para o riser amortecido independentemente das condições de contorno de tensão e de deslocamento da extremidade inferior do riser.

Assim, o primeiro passo é aplicar a transformada de Laplace na Eq. (2.10), considerando o sistema em repouso no instante inicial $t=0$. Desta forma, a equação diferencial parcial torna-se 
uma equação diferencial ordinária em relação apenas a suas derivadas espaciais:

$$
\left(g^{\prime} z+v^{2}\right) \frac{\partial^{2} \widehat{\Upsilon}}{\partial z^{2}}(z, s)+g^{\prime} \frac{\partial \widehat{\Upsilon}}{\partial z}(z, s)-\left(s^{2}+2 \alpha s\right) \widehat{\Upsilon}(z, s)=0
$$

onde $\widehat{\Upsilon}$ é a transformada de Laplace de $\Upsilon$.

A solução da Eq. (2.11) em relação à variável $z$ é:

$$
\widehat{\Upsilon}(z, s)=\frac{\sqrt{2}}{\sqrt{g^{\prime}}} \widehat{C}_{1}(s) I_{0}\left(2 \sqrt{\frac{\left(s^{2}+2 \alpha s\right)\left(v^{2}+g^{\prime} z\right)}{g^{\prime 2}}}\right)+\frac{\sqrt{2}}{\sqrt{g^{\prime}}} \widehat{C}_{2}(s) K_{0}\left(2 \sqrt{\frac{\left(s^{2}+2 \alpha s\right)\left(v^{2}+g^{\prime} z\right)}{g^{\prime 2}}}\right)
$$

onde $\widehat{C}_{1}(s)$ e $\widehat{C}_{2}(s)$ são funções a ser determinadas pelas equações de contorno do sistema, $I_{0}$ e $K_{0}$ são as funções modificadas de Bessel de primeira e segunda espécie de ordem zero, respectivamente (ver [22]).

\subsubsection{Condições de Contorno}

Para determinar $\widehat{C}_{1}(s)$ e $\widehat{C}_{2}(s)$ são necessárias duas condições de contorno. As condições de contorno são: a trajetória da extremidade inferior do riser $\Upsilon(0, t)$ e a sua derivada espacial $\frac{\partial \Upsilon}{\partial z}(0, t)$, que representa a inclinação do riser nesse ponto.

A inclinação da extremidade inferior é determinada pela dinâmica do equipamento submarino. A Eq. (2.13) representa a equação do movimento do equipamento submarino, obtida pela aplicação da segunda lei de Newton e considerando como válida a suposição de pequenos ângulos $(\theta \rightarrow 0$, $\operatorname{sen} \theta \rightarrow 0$ e $\cos \theta \rightarrow 1)$.

$$
m_{e} \frac{\partial^{2} \Upsilon}{\partial t^{2}}(0, t)=F_{e}(t)+F_{h}(0, t)
$$

onde $F_{e}$ é a força exercida pelo riser sobre o equipamento submarino e $F_{h}$ é força hidrodinâmica associada ao equipamento e também definida pela equação modificada de Morison (Eq. (2.2)).

A força $F_{e}$ é proporcional à inclinação do riser em sua extremidade inferior e é definida por:

$$
F_{e}(t)=T_{e} \frac{\partial \Upsilon}{\partial z}(0, t)
$$

Assim, pode-se reescrever a Eq. (2.13):

$$
\frac{\partial^{2} \Upsilon}{\partial t^{2}}(0, t)=\frac{T_{e}}{m_{t e}} \frac{\partial \Upsilon}{\partial z}(0, t)-\frac{\mu_{e}}{m_{t e}} \frac{\partial \Upsilon}{\partial t}(0, t)\left|\frac{\partial \Upsilon}{\partial t}(0, t)\right|
$$

onde $m_{t e}$ é a massa do equipamento submarino adicionada de sua massa adicional de fluido e $\mu_{e}$ é o arrasto correspondente.

Reordenando a Eq. (2.15), define-se a expressão da inclinação do riser em sua extremidade inferior:

$$
\frac{\partial \Upsilon}{\partial z}(0, t)=\frac{1}{T_{e}}\left(m_{t e} \frac{\partial^{2} \Upsilon}{\partial t^{2}}(0, t)+\mu_{e} \frac{\partial \Upsilon}{\partial t}(0, t)\left|\frac{\partial \Upsilon}{\partial t}(0, t)\right|\right)
$$


Adotando a mesma suposição de escoamento laminar, lineariza-se o termo de arrasto dissipativo associado ao equipamento submarino, de forma análoga à apresentada anteriormente. Assim, obtém-se a Eq. (2.17), que representa a expressão da inclinação da extremidade inferior do riser considerando o arrasto dissipativo linearizado.

$$
\frac{\partial \Upsilon}{\partial z}(0, t)=\frac{1}{T_{e}}\left(m_{t e} \frac{\partial^{2} \Upsilon}{\partial t^{2}}(0, t)+2 \alpha_{e} \frac{\partial \Upsilon}{\partial t}(0, t)\right)
$$

onde $\alpha_{e}$ é o arrasto linearizado associado ao equipamento submarino.

Destaca-se que a solução analítica proposta neste capítulo também é válida para o caso em que o termo de arrasto dissipativo associado ao equipamento submarino é não-linear. Verificase essa situação quando, por exemplo, o equipamento submarino considerado possui um elevado comprimento característico, de tal forma que o número de Reynolds do escoamento ao seu redor seja bastante superior ao número de Reynolds do escoamento ao redor do riser.

A outra condição de contorno é a própria trajetória da extremidade inferior do $\operatorname{riser} \Upsilon(0, t)$. Ela é determinada de acordo com a trajetória pretendida para o equipamento submarino, uma vez que o equipamento encontra-se fixado à extremidade inferior do riser. Neste manuscrito optou-se por uma trajetória retilínea que leva o equipamento submarino de uma determinada posição em repouso até o local desejado de instalação.

Destaca-se que a escolha dessa trajetória deve ser tal que a função $\Upsilon(0, t)$ escolhida seja contínua e tenha, pelo menos, suas duas primeiras derivadas temporais também contínuas, uma vez que não é desejável haver pontos de descontinuidade na expressão da força exercida pelo riser sobre o equipamento submarino (Eq. (2.14)).

Assim, optou-se por uma trajetória polinomial que migra suavemente de uma posição inicial $\Upsilon_{i}$ em repouso até uma posição final $\Upsilon_{f}$, também em repouso, em um determinado tempo de estabilização $t_{e}$. Ao longo deste trabalho, essa trajetória polinomial será referenciada como a trajetória de referência para o equipamento submarino $\Upsilon_{R}(0, t)$. Define-se, então, uma função para a trajetória $\Upsilon_{R}(0, t)$ que respeite as seguintes condições:

$$
\Upsilon_{R}(0, t)= \begin{cases}\Upsilon_{i} & \text { se } t \leq t_{p} \\ P(t) & \text { se } t_{p}<t \leq t_{e}+t_{p} \\ \Upsilon_{f} & \text { se } t>t_{e}+t_{p}\end{cases}
$$

onde $t_{p}$ é o tempo de propagação de uma perturbação ao longo do comprimento total do riser e $P(t)$ é um polinômio tal que a função $\Upsilon_{R}(0, t)$ e as suas duas primeiras derivadas temporais sejam contínuas para todo o tempo $t$.

Assim, adota-se $P(t)$ como sendo um polinômio de $5^{a}$ ordem:

$$
P(t)=a t^{5}+b t^{4}+c t^{3}+d t^{2}+e t+f
$$

Mais precisamente, esse polinômio deve obedecer as seguintes restrições em relação as condições 
iniciais e finais das variáveis de saída do sistema:

$$
\begin{array}{lll}
P\left(t_{p}\right)=\Upsilon_{i} & \dot{P}\left(t_{p}\right)=0 & \ddot{P}\left(t_{p}\right)=0 \\
P\left(t_{p}+t_{e}\right)=\Upsilon_{f} & \dot{P}\left(t_{p}+t_{e}\right)=0 & \ddot{P}\left(t_{p}+t_{e}\right)=0
\end{array}
$$

\subsubsection{Determinação das Funções}

Especificadas as condições de contorno, pode-se proceder à determinação de $\widehat{C}_{1}(s)$ e $\widehat{C}_{2}(s)$. O primeiro passo é derivar a Eq. (2.12) em relação à coordenada $z$ :

$$
\begin{aligned}
\frac{\partial \widehat{\Upsilon}}{\partial z}(z, s) & =\frac{\sqrt{2}}{\sqrt{g^{\prime}}} \frac{\sqrt{s^{2}+2 \alpha s}}{\sqrt{v^{2}+g^{\prime} z}} \widehat{C}_{1}(s) I_{1}\left(2 \sqrt{\frac{\left(s^{2}+2 \alpha s\right)\left(v^{2}+g^{\prime} z\right)}{g^{\prime 2}}}\right) \\
& -\frac{\sqrt{2}}{\sqrt{g^{\prime}}} \frac{\sqrt{s^{2}+2 \alpha s}}{\sqrt{v^{2}+g^{\prime} z}} \widehat{C}_{2}(s) K_{1}\left(2 \sqrt{\frac{\left(s^{2}+2 \alpha s\right)\left(v^{2}+g^{\prime} z\right)}{g^{\prime 2}}}\right)
\end{aligned}
$$

onde $I_{1}$ e $K_{1}$ são as funções modificadas de Bessel de primeira e segunda espécie e ordem um, respectivamente (ver [22]).

Assumindo $z=0$, obtém-se o seguinte sistema pelas Eqs. (2.12) e (2.21):

$$
\left\{\begin{array}{l}
\widehat{\Upsilon}(0, s)=\frac{\sqrt{2}}{\sqrt{g^{\prime}}} \widehat{C}_{1}(s) I_{0}\left(\frac{2 v}{g^{\prime}} \sqrt{s^{2}+2 \alpha s}\right)+\frac{\sqrt{2}}{\sqrt{g^{\prime}}} \widehat{C}_{2}(s) K_{0}\left(\frac{2 v}{g^{\prime}} \sqrt{s^{2}+2 \alpha s}\right) \\
\frac{\partial \widehat{\Upsilon}}{\partial z}(0, s)=\frac{\sqrt{2}}{\sqrt{g^{\prime}}} \frac{\sqrt{s^{2}+2 \alpha s}}{v} \widehat{C}_{1}(s) I_{1}\left(\frac{2 v}{g^{\prime}} \sqrt{s^{2}+2 \alpha s}\right)-\frac{\sqrt{2}}{\sqrt{g^{\prime}}} \frac{\sqrt{s^{2}+2 \alpha s}}{v} \widehat{C}_{2}(s) K_{1}\left(\frac{2 v}{g^{\prime}} \sqrt{s^{2}+2 \alpha s}\right)^{(2.22}
\end{array}\right.
$$

Resolvendo esse sistema, determina-se as funções $\widehat{C}_{1}(s)$ e $\widehat{C}_{2}(s)$ :

$$
\begin{aligned}
\widehat{C}_{1}(s) & =\frac{\sqrt{g^{\prime}}}{\sqrt{2}}\left(\frac{K_{1}(x)}{I_{0}(x) K_{1}(x)+I_{1}(x) K_{0}(x)}\right) \widehat{\Upsilon}(0, s) \\
& +\frac{\sqrt{g^{\prime}}}{\sqrt{2}} \frac{v}{\sqrt{s^{2}+2 \alpha s}}\left(\frac{K_{0}(x)}{I_{0}(x) K_{1}(x)+I_{1}(x) K_{0}(x)}\right) \frac{\partial \widehat{\Upsilon}}{\partial z}(0, s) \\
\widehat{C}_{2}(s) & =\frac{\sqrt{g^{\prime}}}{\sqrt{2}}\left(\frac{I_{1}(x)}{I_{0}(x) K_{1}(x)+I_{1}(x) K_{0}(x)}\right) \widehat{\Upsilon}(0, s) \\
& -\frac{\sqrt{g^{\prime}}}{\sqrt{2}} \frac{v}{\sqrt{s^{2}+2 \alpha s}}\left(\frac{I_{0}(x)}{I_{0}(x) K_{1}(x)+I_{1}(x) K_{0}(x)}\right) \frac{\partial \widehat{\Upsilon}}{\partial z}(0, s)
\end{aligned}
$$

onde $x=\frac{2 v}{g^{\prime}} \sqrt{s^{2}+2 \alpha s}$ é definido para simplificar a notação.

O Wronskiano entre duas funções modificadas de Bessel é definido por (ver [22]):

$$
W\left\{K_{\nu}(x), I_{\nu}(x)\right\}=I_{\nu}(x) K_{\nu+1}(x)+I_{\nu+1}(x) K_{\nu}(x)=\frac{1}{x}
$$

onde $\nu$ é a ordem da função modificada de Bessel. 
Assim, são válidas as seguintes relações:

$$
\begin{gathered}
\frac{I_{0}(x)}{I_{0}(x) K_{1}(x)+I_{1}(x) K_{0}(x)}=x I_{0}(x) \\
\frac{I_{1}(x)}{I_{0}(x) K_{1}(x)+I_{1}(x) K_{0}(x)}=x I_{1}(x) \\
\frac{K_{0}(x)}{I_{0}(x) K_{1}(x)+I_{1}(x) K_{0}(x)}=x K_{0}(x) \\
\frac{K_{1}(x)}{I_{0}(x) K_{1}(x)+I_{1}(x) K_{0}(x)}=x K_{1}(x)
\end{gathered}
$$

Utilizando essas relações, reescreve-se as Eqs. (2.24) e (2.26) da seguinte maneira:

$$
\begin{aligned}
\widehat{C}_{1}(s) & =v \frac{\sqrt{2}}{\sqrt{g^{\prime}}} \sqrt{s^{2}+2 \alpha s} K_{1}\left(\frac{2 v}{g^{\prime}} \sqrt{s^{2}+2 \alpha s}\right) \widehat{\Upsilon}(0, s) \\
& +v^{2} \frac{\sqrt{2}}{\sqrt{g^{\prime}}} \sqrt{s^{2}+2 \alpha s} K_{0}\left(\frac{2 v}{g^{\prime}} \sqrt{s^{2}+2 \alpha s}\right) \frac{\partial \widehat{\Upsilon}}{\partial z}(0, s) \\
\widehat{C}_{2}(s) & =v \frac{\sqrt{2}}{\sqrt{g^{\prime}}} \sqrt{s^{2}+2 \alpha s} I_{1}\left(\frac{2 v}{g^{\prime}} \sqrt{s^{2}+2 \alpha s}\right) \widehat{\Upsilon}(0, s) \\
& -v^{2} \frac{\sqrt{2}}{\sqrt{g^{\prime}}} \sqrt{s^{2}+2 \alpha s} I_{0}\left(\frac{2 v}{g^{\prime}} \sqrt{s^{2}+2 \alpha s}\right) \frac{\partial \widehat{\Upsilon}}{\partial z}(0, s)
\end{aligned}
$$

Outra forma de representar uma função modificada de Bessel é por sua representação integral. As Eqs. (2.32), (2.33), (2.34) e (2.35) demonstram a representação integral da função modificada de Bessel de primeira e segunda espécie e ordens zero e um, para o argumento $x=\frac{2 v}{g^{\prime}} \sqrt{s^{2}+2 \alpha s}$ (ver $[22])$.

$$
\begin{gathered}
I_{0}\left(\frac{2 v}{g^{\prime}} \sqrt{s^{2}+2 \alpha s}\right)=\frac{1}{\pi} \int_{-1}^{1} \frac{\mathrm{e}^{-\frac{2 v}{g^{\prime}} \sqrt{s^{2}+2 \alpha s} k}}{\sqrt{1-k^{2}}} \mathrm{~d} k \\
I_{1}\left(\frac{2 v}{g^{\prime}} \sqrt{s^{2}+2 \alpha s}\right)=\frac{2 v}{\pi g^{\prime}} \sqrt{s^{2}+2 \alpha s} \int_{-1}^{1} \mathrm{e}^{-\frac{2 v}{g^{\prime}} \sqrt{s^{2}+2 \alpha s} k} \sqrt{1-k^{2}} \mathrm{~d} k \\
K_{0}\left(\frac{2 v}{g^{\prime}} \sqrt{s^{2}+2 \alpha s}\right)=\int_{1}^{\infty} \frac{\mathrm{e}^{-\frac{2 v}{g^{\prime}} \sqrt{s^{2}+2 \alpha s} k}}{\sqrt{k^{2}-1}} \mathrm{~d} k \\
K_{1}\left(\frac{2 v}{g^{\prime}} \sqrt{s^{2}+2 \alpha s}\right)=\frac{2 v}{g^{\prime}} \sqrt{s^{2}+2 \alpha s} \int_{1}^{\infty} \mathrm{e}^{-\frac{2 v}{g^{\prime}} \sqrt{s^{2}+2 \alpha s} k} \sqrt{k^{2}-1} \mathrm{~d} k
\end{gathered}
$$


Assim, as Eqs. (2.30) e (2.31) se tornam:

$$
\begin{aligned}
\widehat{C}_{1}(s) & =v^{2} \frac{2 \sqrt{2}}{g^{\prime} \sqrt{g^{\prime}}} \widehat{K}(s) \int_{1}^{\infty} \mathrm{e}^{-\frac{2 v}{g^{\prime}} \sqrt{s^{2}+2 \alpha s} k} \sqrt{k^{2}-1} \mathrm{~d} k \\
& +v^{2} \frac{\sqrt{2}}{\sqrt{g^{\prime}}} \frac{\partial \widehat{\Upsilon}}{\partial z}(0, s) \int_{1}^{\infty} \frac{\mathrm{e}^{-\frac{2 v}{g^{\prime}} \sqrt{s^{2}+2 \alpha s} k}}{\sqrt{k^{2}-1}} \mathrm{~d} k \\
\widehat{C}_{2}(s) & =v^{2} \frac{2 \sqrt{2}}{\pi g^{\prime} \sqrt{g^{\prime}}} \widehat{K}(s) \int_{-1}^{1} \mathrm{e}^{-\frac{2 v}{g^{\prime}} \sqrt{s^{2}+2 \alpha s} k} \sqrt{1-k^{2}} \mathrm{~d} k \\
& -v^{2} \frac{\sqrt{2}}{\pi \sqrt{g^{\prime}}} \frac{\partial \widehat{\Upsilon}}{\partial z}(0, s) \int_{-1}^{1} \frac{\mathrm{e}^{-\frac{2 v}{g^{\prime}} \sqrt{s^{2}+2 \alpha s} k}}{\sqrt{1-k^{2}}} \mathrm{~d} k
\end{aligned}
$$

onde $\widehat{K}(s)=\left(s^{2}+2 \alpha s\right) \widehat{\Upsilon}(0, s)$.

Para levar as funções $\widehat{C}_{1}(s)$ e $\widehat{C}_{2}(s)$ ao domínio do tempo, aplica-se a transformada inversa de Laplace: $C_{1}(t)=\mathcal{L}^{-1}\left[\widehat{C}_{1}(s)\right]$ e $C_{2}(t)=\mathcal{L}^{-1}\left[\widehat{C}_{2}(s)\right]$. Como $\widehat{K}(s)$ e $\frac{\partial \widehat{\Upsilon}}{\partial z}(0, s)$ são funções apenas da variável $s$, elas podem ser deslocadas para dentro do integrando das Eqs. (2.36) e (2.37). E, utilizando a identidade apresentada pela Eq. (2.38), pode-se inverter a transformada de Laplace (ver [23]):

$$
\mathrm{e}^{-x \sqrt{s^{2}+2 \alpha s}}=\mathrm{e}^{-\alpha x} \mathrm{e}^{-x s}-\{f(x, t)\} \mathrm{e}^{-x s}
$$

onde $J_{1}$ é a função de Bessel de primeira espécie e ordem um (ver [22]) e $f(x, t)$ é definida por:

$$
f(x, t)=\frac{x}{\sqrt{t^{2}+2 x t}} \mathrm{e}^{-\alpha(x+t)} i \alpha J_{1}\left(i \alpha \sqrt{t^{2}+2 x t}\right)
$$

Aplicando a identidade da Eq. (2.38) nas Eqs. (2.36) e (2.37) e adotando $x_{1}(k)=\frac{2 v}{g^{\prime}} k$ para simplificar a notação, obtém-se:

$$
\begin{aligned}
\widehat{C}_{1}(s) & =v^{2} \frac{2 \sqrt{2}}{g^{\prime} \sqrt{g^{\prime}}} \int_{1}^{\infty}\left[\widehat{K}(s) \mathrm{e}^{-\alpha x_{1}(k)}-\widehat{g}_{1}\left(x_{1}(k), s\right)\right] \mathrm{e}^{-x_{1}(k) s \sqrt{k^{2}-1} \mathrm{~d} k} \\
& +v^{2} \frac{\sqrt{2}}{\sqrt{g^{\prime}}} \int_{1}^{\infty}\left[\frac{\partial \widehat{\Upsilon}}{\partial z}(0, s) \mathrm{e}^{-\alpha x_{1}(k)}-\widehat{g}_{2}\left(x_{1}(k), s\right)\right] \frac{\mathrm{e}^{-x_{1}(k) s}}{\sqrt{k^{2}-1}} \mathrm{~d} k \\
\widehat{C}_{2}(s) & =v^{2} \frac{2 \sqrt{2}}{\pi g^{\prime} \sqrt{g^{\prime}}} \int_{-1}^{1}\left[\widehat{K}(s) \mathrm{e}^{-\alpha x_{1}(k)}-\widehat{g}_{1}\left(x_{1}(k), s\right)\right] \mathrm{e}^{-x_{1}(k) s} \sqrt{1-k^{2}} \mathrm{~d} k \\
& -v^{2} \frac{\sqrt{2}}{\pi \sqrt{g^{\prime}}} \int_{-1}^{1}\left[\frac{\partial \widehat{\Upsilon}}{\partial z}(0, s) \mathrm{e}^{-\alpha x_{1}(k)}-\widehat{g}_{2}\left(x_{1}(k), s\right)\right] \frac{\mathrm{e}^{-x_{1}(k) s}}{\sqrt{1-k^{2}}} \mathrm{~d} k
\end{aligned}
$$

onde $\widehat{g}_{1}\left(x_{1}(k), s\right)=\widehat{f}\left(x_{1}(k), s\right) \widehat{K}(s)$ e $\widehat{g}_{2}\left(x_{1}(k), s\right)=\widehat{f}\left(x_{1}(k), s\right) \frac{\partial \widehat{\Upsilon}}{\partial z}(0, s)$.

A transformada inversa de Laplace do produto de duas funções quaisquer $\left(\widehat{h}_{1}(s)\right.$ e $\left.\widehat{h}_{2}(s)\right)$ pode ser calculada pelo Teorema da Convolução (Eq. (2.42)) [22]. Entretanto, é necessário conhecer as 
transformadas inversas $h_{1}(t)$ e $h_{2}(t)$.

$$
\widehat{h}_{1}(s) \widehat{h}_{2}(s)=\int_{0}^{t} h_{1}(\tau) h_{2}(t-\tau) \mathrm{d} \tau
$$

Assim, utilizando o Teorema da Convolução, obtém-se $g_{1}\left(x_{1}(k), t\right)$ e $g_{2}\left(x_{1}(k), t\right)$ :

$$
\begin{gathered}
g_{1}\left(x_{1}(k), t\right)=\int_{0}^{t} f\left(x_{1}(k), \tau\right) K(t-\tau) \mathrm{d} \tau \\
g_{2}\left(x_{1}(k), t\right)=\int_{0}^{t} f\left(x_{1}(k), \tau\right) \frac{\partial \Upsilon}{\partial z}(0, t-\tau) \mathrm{d} \tau
\end{gathered}
$$

Destaca-se que a função $K(t)$ também é obtida ao aplicar o Teorema da Convolução entre $\left(s^{2}+2 \alpha s\right)$ e $\widehat{\Upsilon}(0, s)$. Logo, para se determinar $K(t)$ é necessário saber que:

$$
\mathcal{L}^{-1}\left[s^{2}+2 \alpha s\right]=2 \alpha \delta^{\prime}(t)+\delta^{\prime \prime}(t)
$$

onde $\delta^{\prime}(t)$ e $\delta^{\prime \prime}(t)$ são, respectivamente, a primeira e a segunda derivada temporal da função Delta de Dirac no domínio do tempo.

Assim, determina-se $K(t)$ :

$$
K(t)=\int_{0}^{t}\left[2 \alpha \delta^{\prime}(\tau)+\delta^{\prime \prime}(\tau)\right] \Upsilon(0, t-\tau) \mathrm{d} \tau
$$

Resolvendo a Eq. (2.46) para $\operatorname{Re}(t)>0$ e $\operatorname{Im}(t)=0$ :

$$
K(t)=u_{0}(t)\left[2 \alpha \frac{\partial \Upsilon}{\partial t}(0, t)+\frac{\partial^{2} \Upsilon}{\partial t^{2}}(0, t)\right]
$$

onde $u_{x}(t)$ é a função degrau unitário, definida pela Eq. (2.48).

$$
u_{x}(t)= \begin{cases}0 & \text { se } t<x \\ \frac{1}{2} & \text { se } t=x \\ 1 & \text { se } t>x\end{cases}
$$

Agora, o último passo para determinar $C_{1}(t)$ e $C_{2}(t)$ é aplicar o Teorema do Deslocamento (Eq. (2.49)) [22].

$$
f(t-x) u_{x}(t)=\mathrm{e}^{-x s} \widehat{f}(s)
$$

válido para $x>0$.

Assim, aplicando o Teorema do Deslocamento nas Eqs. (2.40) e (2.41), ambas podem ser 
reescritas no domínio do tempo:

$$
\begin{aligned}
C_{1}(t) & =v^{2} \frac{2 \sqrt{2}}{g^{\prime} \sqrt{g^{\prime}}} \int_{1}^{\infty} u_{x_{1}(k)}(t)\left[K\left(t-x_{1}(k)\right) \mathrm{e}^{-\alpha x_{1}(k)}-g_{1}\left(x_{1}(k), t-x_{1}(k)\right)\right] \sqrt{k^{2}-1} \mathrm{~d} k \\
+ & v^{2} \frac{\sqrt{2}}{\sqrt{g^{\prime}}} \int_{1}^{\infty} u_{x_{1}(k)}(t)\left[\frac{\partial \Upsilon}{\partial z}\left(0, t-x_{1}(k)\right) \mathrm{e}^{-\alpha x_{1}(k)}-g_{2}\left(x_{1}(k), t-x_{1}(k)\right)\right] \frac{1}{\sqrt{k^{2}-1}} \mathrm{~d} k \\
C_{2}(t) & =v^{2} \frac{2 \sqrt{2}}{\pi g^{\prime} \sqrt{g^{\prime}}} \int_{-1}^{1} u_{x_{1}(k)}(t)\left[K\left(t-x_{1}(k)\right) \mathrm{e}^{-\alpha x_{1}(k)}-g_{1}\left(x_{1}(k), t-x_{1}(k)\right)\right] \sqrt{1-k^{2}} \mathrm{~d} k \\
& -v^{2} \frac{\sqrt{2}}{\pi \sqrt{g^{\prime}}} \int_{-1}^{1} u_{x_{1}(k)}(t)\left[\frac{\partial \Upsilon}{\partial z}\left(0, t-x_{1}(k)\right) \mathrm{e}^{-\alpha x_{1}(k)}-g_{2}\left(x_{1}(k), t-x_{1}(k)\right)\right] \frac{1}{\sqrt{1-k^{2}}} \mathrm{~d} k
\end{aligned}
$$

\subsubsection{Solução Final}

Determinadas as funções $C_{1}(t)$ e $C_{2}(t)$, pode-se aplicar a transformada inversa de Laplace na Eq. (2.12) para se obter o deslocamento do riser no domínio do tempo: $\Upsilon(z, t)$.

Primeiro, representa-se as funções modificadas de Bessel por sua representação integral. As Eqs. (2.52) e (2.53) demonstram a representação integral da função modificada de Bessel de primeira e segunda espécie e ordem zero, para o argumento $x=2 \sqrt{\frac{\left(s^{2}+2 \alpha s\right)\left(v^{2}+g^{\prime} z\right)}{g^{\prime 2}}}$.

$$
\begin{aligned}
& I_{0}\left(2 \sqrt{\frac{\left(s^{2}+2 \alpha s\right)\left(v^{2}+g^{\prime} z\right)}{g^{\prime 2}}}\right)=\frac{1}{\pi} \int_{-1}^{1} \frac{\mathrm{e}^{-2 \sqrt{\frac{\left(s^{2}+2 \alpha s\right)\left(v^{2}+g^{\prime} z\right)}{g^{\prime 2}}}} k}{\sqrt{1-k^{2}}} \mathrm{~d} k \\
& K_{0}\left(2 \sqrt{\frac{\left(s^{2}+2 \alpha s\right)\left(v^{2}+g^{\prime} z\right)}{g^{\prime 2}}}\right)=\int_{1}^{\infty} \frac{\mathrm{e}^{-2 \sqrt{\frac{\left(s^{2}+2 \alpha s\right)\left(v^{2}+g^{\prime} z\right)}{g^{\prime 2}}}} k}{\sqrt{k^{2}-1}} \mathrm{~d} k
\end{aligned}
$$

Assim, a Eq. (2.12) se torna:

$$
\begin{aligned}
\widehat{\Upsilon}(z, s) & =\frac{\sqrt{2}}{\pi \sqrt{g^{\prime}}} \widehat{C}_{1}(s) \int_{-1}^{1} \frac{\mathrm{e}^{-2 \sqrt{\frac{\left.v^{2}+g^{\prime} z\right)}{g^{\prime 2}}} \sqrt{s^{2}+2 \alpha s} k}}{\sqrt{1-k^{2}}} \mathrm{~d} k \\
& +\frac{\sqrt{2}}{\sqrt{g^{\prime}}} \widehat{C}_{2}(s) \int_{1}^{\infty} \frac{\mathrm{e}^{-2 \sqrt{\frac{\left(v^{2}+g^{\prime} z\right)}{g^{\prime 2}}} \sqrt{s^{2}+2 \alpha s} k}}{\sqrt{k^{2}-1}} \mathrm{~d} k
\end{aligned}
$$

Como $\widehat{C}_{1}(s)$ e $\widehat{C}_{2}(s)$ são funções apenas da variável $s$, elas podem ser deslocadas para dentro do integrando da Eq. (2.54). Aplicando a identidade apresentada na Eq. (2.38) e adotando $x_{2}(z, k)=$ 
$2 \sqrt{\frac{\left(v^{2}+g^{\prime} z\right)}{g^{\prime 2}}} k$ para simplificar a notação, a Eq. (2.54) se torna:

$$
\begin{aligned}
\widehat{\Upsilon}(z, s) & =\frac{\sqrt{2}}{\pi \sqrt{g^{\prime}}} \int_{-1}^{1}\left[\widehat{C}_{1}(s) \mathrm{e}^{-\alpha x_{2}(z, k)}-\widehat{g}_{3}\left(x_{2}(z, k), s\right)\right] \frac{\mathrm{e}^{-x_{2}(z, k) s}}{\sqrt{1-k^{2}}} \mathrm{~d} k \\
& +\frac{\sqrt{2}}{\sqrt{g^{\prime}}} \int_{1}^{\infty}\left[\widehat{C}_{2}(s) \mathrm{e}^{-\alpha x_{2}(z, k)}-\widehat{g}_{4}\left(x_{2}(z, k), s\right)\right] \frac{\mathrm{e}^{-x_{2}(z, k) s}}{\sqrt{1-k^{2}}} \mathrm{~d} k
\end{aligned}
$$

onde $\widehat{g}_{3}\left(x_{2}(z, k), s\right)=\widehat{f}\left(x_{2}(z, k), s\right) \widehat{C}_{1}(s)$ e $\widehat{g}_{4}\left(x_{2}(z, k), s\right)=\widehat{f}\left(x_{2}(z, k), s\right) \widehat{C}_{2}(s)$.

As funções $g_{3}\left(x_{2}(z, k), t\right)$ e $g_{4}\left(x_{2}(z, k), t\right)$ também são obtidas pela aplicação do Teorema da Convolução:

$$
\begin{aligned}
& g_{3}\left(x_{2}(z, k), t\right)=\int_{0}^{t} f\left(x_{2}(z, k), \tau\right) C_{1}(t-\tau) \mathrm{d} \tau \\
& g_{4}\left(x_{2}(z, k), t\right)=\int_{0}^{t} f\left(x_{2}(z, k), \tau\right) C_{2}(t-\tau) \mathrm{d} \tau
\end{aligned}
$$

Por fim, ao aplicar o Teorema do Deslocamento na Eq. (2.55), obtém-se a expressão do deslocamento do riser no domínio do tempo:

$$
\begin{aligned}
\Upsilon(z, t) & =\frac{\sqrt{2}}{\pi \sqrt{g^{\prime}}} \int_{-1}^{1} u_{x_{2}(z, k)}(t)\left[C_{1}\left(t-x_{2}(z, k)\right) \mathrm{e}^{-\alpha x_{2}(z, k)}-g_{3}\left(x_{2}(z, k), t-x_{2}(z, k)\right)\right] \frac{1}{\sqrt{1-k^{2}}} \mathrm{~d} k \\
& +\frac{\sqrt{2}}{\sqrt{g^{\prime}}} \int_{1}^{\infty} u_{x_{2}(z, k)}(t)\left[C_{2}\left(t-x_{2}(z, k)\right) \mathrm{e}^{-\alpha x_{2}(z, k)}-g_{4}\left(x_{2}(z, k), t-x_{2}(z, k)\right)\right] \frac{1}{\sqrt{1-k^{2}}} \mathrm{~d} k
\end{aligned}
$$

Ao assumir $z=L$ na Eq. (2.58), onde $L$ representa o comprimento do riser, encontra-se a expressão da trajetória referente à extremidade superior do riser. Como a extremidade é presa à plataforma, essa trajetória é exatamente a mesma trajetória a ser realizada pelo sistema DP da plataforma.

Assim, este procedimento corresponde ao chamado planejamento de trajetória ou controle em malha aberta, no qual, a partir de uma determinada trajetória de referência para o equipamento submarino $\Upsilon_{R}(0, t)$, obtém-se a trajetória de controle, ou o controle nominal, $\Upsilon_{o}(L, t)$ do sistema DP que faz o equipamento seguir essa trajetória desejada. Destaca-se que nesta etapa não se considera a presença de perturbações externas não modeladas na equação governante do sistema.

\subsection{Resultados}

A fim de testar a solução analítica proposta, considera-se um caso de posicionamento de equipamento submarino em águas ultraprofundas por meio do sistema de perfuração da plataforma.

Os parâmetros do sistema são apresentados na Tab. 2.1. O equipamento submarino é assumido como sendo uma esfera de aço, mesmo material do riser de perfuração. O riser é assumido como sendo preenchido por água do mar. O sistema é considerado como estacionário na condição inicial 
$(t=0)$, com o riser e o equipamento submarino completamente alinhados ao eixo vertical.

Tabela 2.1: Parâmetros do sistema de instalação submarina

\begin{tabular}{ccc} 
Parâmetro & Valor & Unidade \\
\hline Comprimento do riser & 2000 & $\mathrm{~m}$ \\
Diâmetro externo do riser & 0,55 & $\mathrm{~m}$ \\
Diâmetro interno do riser & 0,50 & $\mathrm{~m}$ \\
Coeficiente de arrasto do riser & 1,2 & \\
Coeficiente de massa adicional do riser & 2 & \\
Massa do equipamento submarino & $4 \times 10^{5}$ & $\mathrm{~kg}$ \\
Diâmetro do equipamento submarino & 4,6 & $\mathrm{~m}$ \\
Coeficiente de arrasto do equipamento submarino & 0,4 & \\
Coeficiente de massa adicional do equipamento submarino & 0,5 & \\
Módulo de elasticidade do aço & $210 \times 10^{9}$ & $\mathrm{~Pa}$ \\
Densidade do aço & $7,860 \times 10^{3}$ & $\mathrm{~kg} / \mathrm{m}^{3}$ \\
Densidade da água do mar & $1,025 \times 10^{3}$ & $\mathrm{~kg} / \mathrm{m}^{3}$
\end{tabular}

Assim, o primeiro passo para se determinar o controle nominal do sistema DP é especificar uma trajetória de referência para o equipamento submarino. Conforme apresentado na Seção 2.3.1, adotou-se uma trajetória polinomial que migra suavemente de uma determinada posição inicial $\Upsilon_{i}$ em repouso até uma determinada posição final $\Upsilon_{f}$, também em repouso, em um tempo de estabilização $t_{e}$ predefinido. Assim, optou-se por um polinômio $P(t)$ de $5^{a}$ ordem, definido pela Eq. (2.19) e que deve respeitar as restrições evidenciadas na Eq. (2.20).

Conforme mencionado anteriormente, a velocidade de deslocamento do riser deve ser tal que o escoamento ao seu redor possa ser considerado laminar. Um escoamento ao redor de um cilindro é considerado laminar se tiver um número de Reynolds de até 2000 [21]. Assim, adotando esse valor limite de número de Reynolds e considerando as propriedades do fluido, encontrou-se a velocidade média de deslocamento do riser. A partir dessa velocidade média, determinou-se o tempo de estabilização correspondente.

A trajetória desejada é assumida como sendo a que desloca o equipamento submarino 1 metro de distância de sua posição inicial. Assim, ao definir $\Upsilon_{i}=0$ e $\Upsilon_{f}=1$ e encontra-se os coeficientes de $P(t)$ (Eq. (2.19)):

$$
\begin{array}{lll}
a=1,75 \times 10^{-13} & b=-2,50 \times 10^{-10} & c=1,05 \times 10^{-7} \\
d=-8,46 \times 10^{-6} & e=2,50 \times 10^{-4} & f=-0,0025
\end{array}
$$

Especificada a trajetória de referência, pode-se proceder à integração numérica da Eq. (2.58) considerando $z=L$ para encontrar a trajetória de controle $\Upsilon_{o}(L, t)$ do sistema DP. A Fig. 2.1 apresenta em vermelho a trajetória de referência do equipamento submarino e em preto a trajetória de controle do sistema DP. 


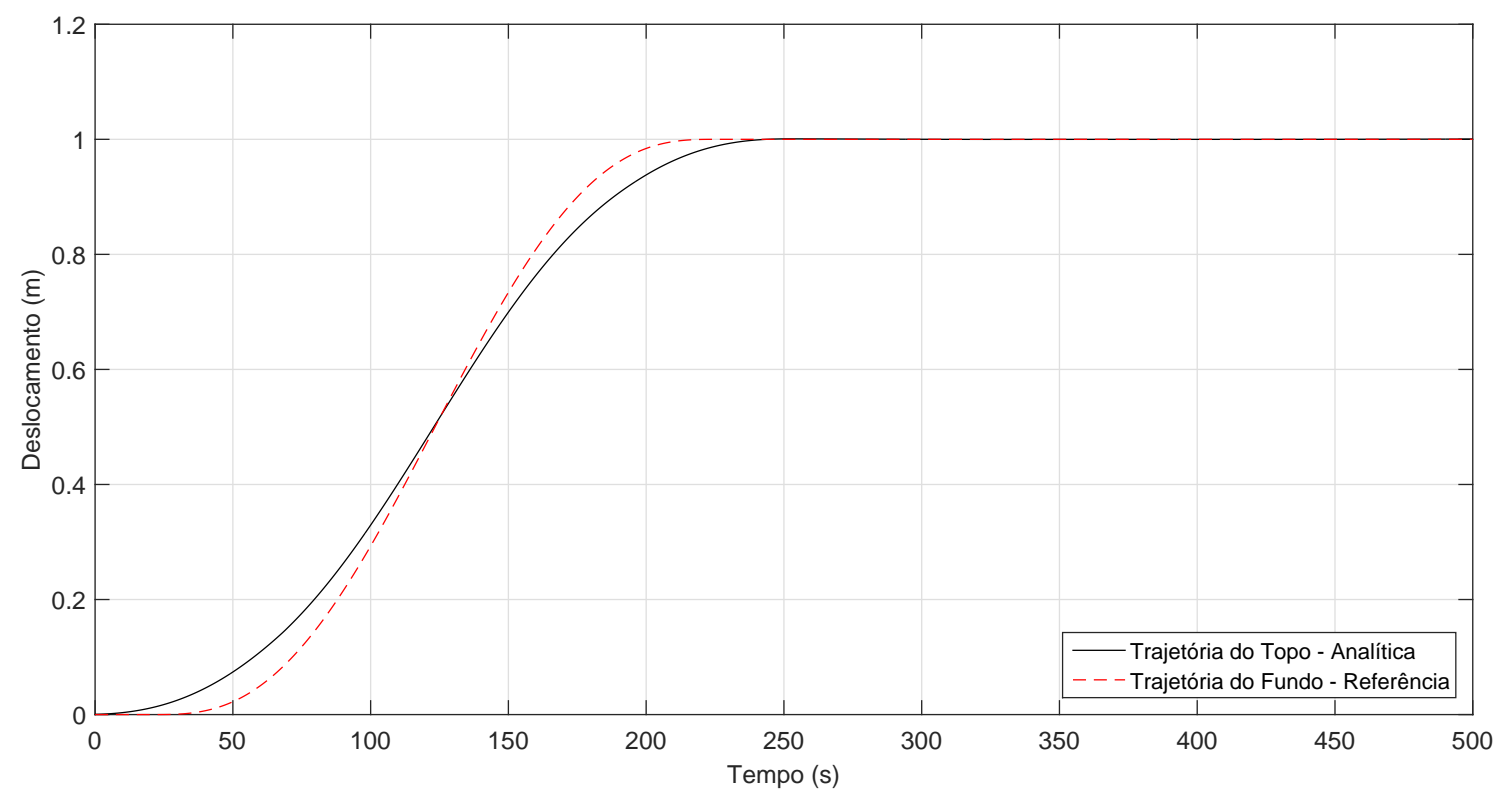

Figura 2.1: Trajetória de controle $\Upsilon_{o}(L, t)$ do sistema DP

\subsection{Conclusões}

Neste capítulo apresentou-se a modelagem matemática do problema de posicionamento de equipamento submarino e obteve-se a equação governante do sistema. Após as devidas considerações e simplificações aplicáveis ao caso em estudo, apresentou-se uma abordagem de solução da equação governante utilizando a transformada de Laplace.

Após obter-se a solução analítica no domínio de Laplace, retornou-se ao domínio do tempo e encontrou-se a expressão que descreve a posição do riser no domínio do tempo. Por fim, integrouse numericamente a expressão analítica da trajetória da extremidade superior do riser para se obter o controle nominal do sistema DP.

No Capítulo 3 será apresentado um método numérico utilizando diferenças finitas para simular o comportamento da estrutura. Assim, será possível verificar a influência das simplificações adotadas e validar a solução analítica obtida neste capítulo. 


\section{Capítulo 3}

\section{Simulação Numérica da Estrutura}

\subsection{Introdução}

Para avaliar a solução analítica encontrada, é proposto um método numérico utilizando diferenças finitas, seguindo a ideia apresentada em [18]. Esse método discretiza no espaço a função contínua do deslocamento transversal do riser $\Upsilon(z, t)$ e define $Y(t)$ como um vetor discreto da posição da estrutura para $N$ pontos equidistantes ao longo do riser.

A abordagem numérica permite que se considere tanto o termo de viga quanto o arrasto dissipativo não-linear na equação governante do sistema. Sendo assim, é possível avaliar a influência dessas simplificações e validar a solução analítica encontrada. Para isso, a trajetória de controle $\Upsilon_{o}(L, t)$ do sistema DP, calculada pela integração numérica da solução analítica, é utilizada como entrada do sistema para as simulações numéricas. Observa-se, então, a saída do sistema, escolhida como sendo a trajetória do equipamento submarino, e a compara com a trajetória de referência $\Upsilon_{R}(0, t)$.

\subsection{Método de Diferenças Finitas}

Pela aplicação do método de diferenças finitas é possível converter a equação diferencial parcial que modela o sistema em um sistema de equações diferenciais ordinárias acopladas. Esse método estima a derivada espacial da função em um determinado ponto utilizando os valores da função na vizinhança deste ponto.

Segundo Gilat e Subramaniam [24], a precisão da aproximação por diferenças finitas depende da precisão dos pontos do conjunto de dados, do espaçamento entre os pontos e da fórmula específica usada na aproximação. Existem diversas fórmulas de aproximação por diferenças finitas, sendo a mais simples a que aproxima a derivada primeira pela inclinação da reta que conecta dois pontos adjacentes. Dependendo da posição desses dois pontos adjacentes, tem-se as fórmulas de diferenças finitas progressiva, regressiva ou central.

A fórmula progressiva estima a derivada em um ponto pelo valor da inclinação da reta que 
liga esse ponto ao ponto posterior. A regressiva estima utilizando o ponto em análise e o ponto anterior. Já a fórmula central estima a derivada no ponto pela inclinação da reta formada pelos pontos anterior e posterior ao ponto em análise.

As fórmulas de diferenças finitas progressiva, regressiva e central podem ser deduzidas a partir de uma expansão em série de Taylor. Uma das vantagens de se utilizar a expansão em série de Taylor está no fato de ela também fornecer uma estimativa do erro de truncamento presente na aproximação [24].

Neste manuscrito, optou-se por utilizar, sempre que possível, a fórmula de diferenças finitas central, já que sua estimativa para a derivada é mais precisa do que a obtida pelas outras fórmulas, utilizando a mesma quantidade de pontos. Por exemplo, ao se estimar a derivada primeira utilizando dois pontos, obtém-se, pela fórmula central, um erro de truncamento da ordem de $h^{2}$ e, pelas fórmulas regressiva e progressiva, um da ordem de $h$. Entretanto, pelo próprio método de cálculo, a fórmula central só pode ser utilizada para avaliar as derivadas dos pontos internos da função. Para os pontos inicial e final deve-se utilizar as fórmulas progressiva e regressiva, respectivamente.

Destaca-se que, para se obter um erro de trucamento de ordem equivalente ao da fórmula central, é necessário utilizar mais pontos nas fórmulas regressiva e progressiva. Assim, para se estimar a derivada primeira dos pontos inicial e final da função, com o erro da ordem de $h^{2}$, utiliza-se as fórmulas progressiva e regressiva com três pontos. Essa fórmula progressiva estima a derivada utilizando o ponto em análise e os dois posteriores, e essa regressiva utiliza o ponto em análise e os dois anteriores.

A mesma ideia vale para as derivadas de ordem superior. A diferença está na quantidade de pontos vizinhos utilizados na fórmula para se estimar a derivada. A fórmula central, cujo erro de truncamento tem ordem $h^{2}$, utiliza três e cinco pontos para estimar as derivadas segunda e quarta, respectivamente. Já as fórmulas progressiva e regressiva utilizam quatro e seis pontos para essas derivadas e erro de mesma ordem.

\subsubsection{Discretização do Sistema}

Para discretizar o sistema, divide-se a estrutura em $N$ pontos, onde a distância $l$ entre dois pontos adjacentes é $l=L / N$. O primeiro elemento $(n=1)$ representa o equipamento submarino e o último elemento $(n=N)$ representa o ponto a $l$ de distância da extremidade superior do riser.

Considerando a equação governante completa do sistema (Eq. (2.5), para o caso do arrasto não-linear, e Eq. (2.6), para o caso do arrasto linear), verifica-se que há derivadas espaciais da função $\Upsilon(z, t)$ de primeira, segunda e quarta ordens.

Assim, para estimar essas derivadas nos pontos internos da função e obter um erro de truncamento da ordem de $h^{2}$, utiliza-se as fórmulas de diferenças finitas central com dois pontos para a derivada primeira (Eq. (3.1)), com três pontos para a derivada segunda (Eq. (3.2)) e com cinco 
pontos para a derivada quarta (Eq. (3.3)), todas avaliadas no ponto $n$ em relação à coordenada $z$.

$$
\begin{gathered}
\frac{\mathrm{d} Y_{n}}{\mathrm{~d} z}=\frac{-Y_{n-1}+Y_{n+1}}{2 l} \\
\frac{\mathrm{d}^{2} Y_{n}}{\mathrm{~d} z^{2}}=\frac{Y_{n-1}-2 Y_{n}+Y_{n+1}}{l^{2}} \\
\frac{\mathrm{d}^{4} Y_{n}}{\mathrm{~d} z^{4}}=\frac{Y_{n-2}-4 Y_{n-1}+6 Y_{n}-4 Y_{n+1}+Y_{n+2}}{l^{4}}
\end{gathered}
$$

Substituindo essas derivadas na equação governante completa do sistema com o arrasto linear (Eq. (2.6)) e considerando $z=(n-1) l$ em $Y_{n}$, obtém-se o seguinte sistema discretizado:

$$
\begin{aligned}
\frac{\mathrm{d}^{2} Y_{n}}{\mathrm{~d} t^{2}}= & -\frac{E J}{m} \frac{\left(Y_{n-2}-4 Y_{n-1}+6 Y_{n}-4 Y_{n+1}+Y_{n+2}\right)}{l^{4}}+\left((n-1) g^{\prime} l+v^{2}\right) \frac{\left(Y_{n-1}-2 Y_{n}+Y_{n+1}\right)}{l^{2}} \\
& +g^{\prime} \frac{\left(-Y_{n-1}+Y_{n+1}\right)}{2 l}-2 \alpha \frac{\mathrm{d} Y_{n}}{\mathrm{~d} t}
\end{aligned}
$$

onde $n \in(3, \ldots, N-2)$ é a posição do elemento avaliado.

Destaca-se que a Eq. (3.4) é válida para todos os pontos internos da função $\Upsilon(z, t)$ que não são afetados pelas condições de contorno.

\subsubsection{Condições de Contorno}

Os pontos afetados pelas condições de contorno são os dois primeiros e os dois últimos da discretização. Considerando $U(t)$ como sendo a posição da plataforma, determinada pelo sistema DP, as condições de contorno são:

- No equipamento submarino, a equação do movimento é definida pela Eq. (2.13);

- Na extremidade superior do riser, a posição é determinada pela posição da plataforma $\Upsilon(L, t)=U(t)$ e $\frac{\partial \Upsilon}{\partial z}(L, t)=0$, pois considera-se que o riser é conectado à plataforma por um suporte engastado.

Conforme visto, para estimar as derivadas do primeiro elemento da função, deve-se utilizar a fórmula de diferenças finitas progressiva. Além disso, como o primeiro elemento da discretização é justamente o equipamento submarino, sua equação do movimento é definida pela Eq. (2.13), de acordo com a primeira condição de contorno.

Agora, entretanto, como está sendo considerada a equação governante completa do sistema, o

termo de viga $E J \frac{\partial^{4} \Upsilon}{\partial z^{4}}$, associado à resistência do riser a flexão, deve ser considerado na expressão da força exercida pelo riser sobre o equipamento submarino (Eq. (2.14)). Assim, para se obter um erro de truncamento da ordem de $h^{2}$, utiliza-se as fórmulas progressivas de três e seis pontos 
para as derivadas primeira e quarta, respectivamente:

$$
\begin{gathered}
\frac{\mathrm{d} Y_{n}}{\mathrm{~d} z}=\frac{-3 Y_{n}+4 Y_{n+1}-Y_{n+2}}{2 l} \\
\frac{\mathrm{d}^{4} Y_{n}}{\mathrm{~d} z^{4}}=\frac{3 Y_{n}-14 Y_{n+1}+26 Y_{n+2}-24 Y_{n+3}+11 Y_{n+4}-2 Y_{n+5}}{l^{4}}
\end{gathered}
$$

Combinando a Eq. (2.13) com as Eqs. (3.5) e (3.6), obtém-se a equação discretizada do movimento para o primeiro elemento:

$$
\begin{aligned}
\frac{\mathrm{d}^{2} Y_{1}}{\mathrm{~d} t^{2}}= & -\frac{E J}{m_{t e}} \frac{\left(3 Y_{1}-14 Y_{2}+26 Y_{3}-24 Y_{4}+11 Y_{5}-2 Y_{6}\right)}{l^{4}}+\frac{T_{e}}{m_{t e}} \frac{\left(-3 Y_{1}+4 Y_{2}-Y_{3}\right)}{2 l} \\
& -2 \alpha_{e} \frac{\mathrm{d} Y_{1}}{\mathrm{~d} t}
\end{aligned}
$$

Nota-se, pela Eq. (3.3), que para estimar a derivada quarta pela fórmula central, é necessário conhecer os dois pontos anteriores ao ponto em análise. Assim, não é possível utilizá-la para estimar essa derivada do segundo elemento da discretização. Portanto, utiliza-se a fórmula progressiva com seis pontos (Eq. (3.6)) para estimar a derivada quarta do segundo elemento. Para as demais derivadas, é cabível a utilização da fórmula central. Obtém-se, assim, a equação discretizada do movimento para o segundo elemento:

$$
\begin{aligned}
\frac{\mathrm{d}^{2} Y_{2}}{\mathrm{~d} t^{2}}= & -\frac{E J}{m} \frac{\left(3 Y_{2}-14 Y_{3}+26 Y_{4}-24 Y_{5}+11 Y_{6}-2 Y_{7}\right)}{l^{4}} \\
& +\left(g^{\prime} l+v^{2}\right) \frac{\left(Y_{1}-2 Y_{2}+Y_{3}\right)}{l^{2}}+g^{\prime} \frac{\left(-Y_{1}+Y_{3}\right)}{2 l}-2 \alpha \frac{\mathrm{d} Y_{2}}{\mathrm{~d} t}
\end{aligned}
$$

Como o último elemento da discretização corresponde ao ponto a $l$ de distância da extremidade superior do riser, pode-se utilizar a fórmula central para estimar todas as suas derivadas, inclusive a de maior ordem. Isso é possível, pois assume-se que $Y_{N+1}=Y_{N+2}=U(t)$, uma vez que esses dois pontos têm suas posições determinadas pelo sistema DP da plataforma, conforme a segunda condição de contorno. Assim, na forma discretizada, a equação do movimento para o último elemento é:

$$
\begin{aligned}
\frac{\mathrm{d}^{2} Y_{N}}{\mathrm{~d} t^{2}}= & -\frac{E J}{m} \frac{\left(Y_{N-2}-4 Y_{N-1}+6 Y_{N}-3 U(t)\right)}{l^{4}} \\
& +\left((N-1) g^{\prime} l+v^{2}\right) \frac{\left(Y_{N-1}-2 Y_{N}+U(t)\right)}{l^{2}}+g^{\prime} \frac{\left(-Y_{N-1}+U(t)\right)}{2 l} \\
& -2 \alpha \frac{\mathrm{d} Y_{N}}{\mathrm{~d} t}
\end{aligned}
$$

O penúltimo elemento também sofre influência da condição de contorno na extremidade superior do riser. De forma análoga à apresentada para o último elemento da discretização, pode-se utilizar a fórmula central para avaliar todas as suas derivadas. Neste caso, substitui-se $Y_{N+1}$ 
por $U(t)$ na estimativa da derivada quarta. Assim, a equação discretizada do movimento para o penúltimo elemento é:

$$
\begin{aligned}
\frac{\mathrm{d}^{2} Y_{N-1}}{\mathrm{~d} t^{2}}= & -\frac{E J}{m} \frac{\left(Y_{N-3}-4 Y_{N-2}+6 Y_{N-1}-4 Y_{N}+U(t)\right)}{l^{4}} \\
& +\left((N-2) g^{\prime} l+v^{2}\right) \frac{\left(Y_{N-2}-2 Y_{N-1}+Y_{N}\right)}{l^{2}}+g^{\prime} \frac{\left(-Y_{N-2}+Y_{N}\right)}{2 l} \\
& -2 \alpha \frac{\mathrm{d} Y_{N-1}}{\mathrm{~d} t}
\end{aligned}
$$

\subsubsection{Modelo Discreto com o Arrasto Linear}

Especificadas as equações discretizadas do movimento de cada um dos elementos, representa-se o sistema, considerando o arrasto linear, pelo seguinte espaço de estados:

$$
\left\{\begin{array}{l}
\dot{\mathbf{x}}=\mathbf{A x}+\mathbf{B} u \\
y=\mathbf{C x}
\end{array}\right.
$$

onde $\mathbf{A}$ é a matriz de estados $(2 N \times 2 N)$, B é a matriz de entrada $(2 N \times 1)$, $\mathbf{C}$ é a matriz de saída $(1 \times 2 N)$, $u$ é a entrada do sistema, $y$ é a saída do sistema, $\mathbf{x}$ é o vetor de estados $(2 N \times 1)$ e $\dot{\mathbf{x}}$ é a sua derivada temporal.

A entrada do sistema $u$ é adotada como sendo a trajetória de controle $\Upsilon_{o}(L, t)$, obtida pelo método analítico. A saída do sistema $y$ é escolhida como sendo a trajetória do equipamento submarino $\Upsilon(0, t)$. Assim, pode-se compará-la à trajetória de referência $\Upsilon_{R}(0, t)$ e verificar a validade das simplificações assumidas no desenvolvimento analítico.

$\mathrm{O}$ vetor de estados $\mathbf{x}$ contém o deslocamento e a velocidade de cada elemento da estrutura e, consequentemente, $\dot{x}$ contém as velocidades e as acelerações correspondentes. O vetor de estados é representado por:

$$
\mathbf{x}=\left[\begin{array}{c}
Y_{1} \\
Y_{2} \\
\vdots \\
Y_{N} \\
\frac{\mathrm{d} Y_{1}}{\mathrm{~d} t} \\
\frac{\mathrm{d} Y_{2}}{\mathrm{~d} t} \\
\vdots \\
\frac{\mathrm{d} Y_{N}}{\mathrm{~d} t}
\end{array}\right]_{2 N \times 1}
$$

A matriz de estados A descreve o comportamento do sistema e é representada por:

$$
\mathbf{A}=\left[\begin{array}{cc}
\mathbf{0} & \mathbf{I} \\
\mathbf{A}^{\prime} & -\mathbf{K}
\end{array}\right]_{2 N \times 2 N}
$$


onde $\mathbf{0}$ é uma matriz nula $(N \times N)$, $\mathbf{I}$ é a matriz identidade $(N \times N)$, $\mathbf{K}$ é uma matriz diagonal $(N \times N)$ que contém as acelerações associadas ao arrasto dissipativo linear e $\mathbf{A}^{\prime}$ é a matriz de rigidez $(N \times N)$.

A matriz $\mathbf{K}$ é representada por:

$$
\mathbf{K}=\left[\begin{array}{ccccc}
2 \alpha_{e} & 0 & 0 & \cdots & 0 \\
0 & 2 \alpha & 0 & \cdots & 0 \\
\vdots & \vdots & \ddots & \vdots & \vdots \\
0 & \cdots & 0 & 2 \alpha & 0 \\
0 & \cdots & 0 & 0 & 2 \alpha
\end{array}\right]_{N \times N}
$$

A matriz de rigidez $\mathbf{A}^{\prime}$ contém as acelerações internas da estrutura e seus termos são definidos pelas equações discretizadas do movimento de cada elemento (Eqs. (3.4) e (3.7)-(3.10)). Destacase que a matriz de rigidez é quase toda simétrica, com exceção de suas duas primeiras e duas últimas linhas, que representam, respectivamente, os dois primeiros e os dois últimos elementos da discretização. Assim, pode-se representar a matriz de rigidez por:

$$
\mathbf{A}^{\prime}=\left[\begin{array}{l}
\mathbf{A}_{1}^{\prime} \\
\mathbf{A}_{2}^{\prime}
\end{array}\right]_{N \times N}
$$

A matriz $\mathbf{A}_{\mathbf{1}}^{\prime}$ contém os termos associados às duas primeiras linhas da matriz $\mathbf{A}^{\prime}$ :

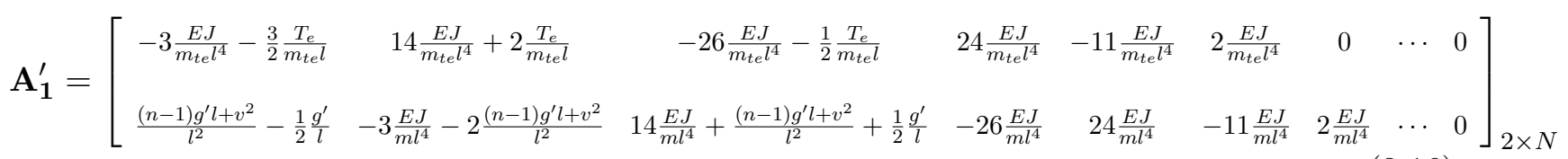

onde $n$ representa o elemento correspondente.

A matriz $\mathbf{A}_{2}^{\prime}$ representa as demais linhas da matriz $\mathbf{A}^{\prime}$ :

$$
\mathbf{A}_{2}^{\prime}=\left[\begin{array}{cccccccccc}
a_{1}^{\prime} & a_{2}^{\prime} & a_{3}^{\prime} & a_{4}^{\prime} & a_{1}^{\prime} & 0 & 0 & 0 & \cdots & 0 \\
0 & a_{1}^{\prime} & a_{2}^{\prime} & a_{3}^{\prime} & a_{4}^{\prime} & a_{1}^{\prime} & 0 & 0 & \cdots & 0 \\
0 & 0 & a_{1}^{\prime} & a_{2}^{\prime} & a_{3}^{\prime} & a_{4}^{\prime} & a_{1}^{\prime} & 0 & \cdots & 0 \\
\vdots & \vdots & \vdots & \ddots & \ddots & \ddots & \ddots & \ddots & \vdots & \vdots \\
0 & \cdots & 0 & 0 & a_{1}^{\prime} & a_{2}^{\prime} & a_{3}^{\prime} & a_{4}^{\prime} & a_{1}^{\prime} & 0 \\
0 & \cdots & 0 & 0 & 0 & a_{1}^{\prime} & a_{2}^{\prime} & a_{3}^{\prime} & a_{4}^{\prime} & a_{1}^{\prime} \\
0 & \cdots & 0 & 0 & 0 & 0 & a_{1}^{\prime} & a_{2}^{\prime} & a_{3}^{\prime} & a_{4}^{\prime} \\
0 & \cdots & 0 & 0 & 0 & 0 & 0 & a_{1}^{\prime} & a_{2}^{\prime} & a_{3}^{\prime}
\end{array}\right]_{(N-2) \times N}
$$


cujos os termos são:

$$
\begin{aligned}
& a_{1}^{\prime}=-\frac{E J}{m l^{4}} \\
& a_{2}^{\prime}=4 \frac{E J}{m l^{4}}+\frac{(n-1) g^{\prime} l+v^{2}}{l^{2}}-\frac{1}{2} \frac{g^{\prime}}{l} \\
& a_{3}^{\prime}=-6 \frac{E J}{m l^{4}}-2 \frac{(n-1) g^{\prime} l+v^{2}}{l^{2}} \\
& a_{4}^{\prime}=4 \frac{E J}{m l^{4}}+\frac{(n-1) g^{\prime} l+v^{2}}{l^{2}}+\frac{1}{2} \frac{g^{\prime}}{l}
\end{aligned}
$$

A matriz de entrada $\mathbf{B}$ é uma matriz-coluna que contém a aceleração da estrutura associada ao deslocamento da extremidade superior do riser, e pode ser representada por:

$$
\mathbf{B}=\left[\begin{array}{c}
0 \\
\vdots \\
0 \\
-\frac{E J}{m l^{4}} \\
3 \frac{E J}{m l^{4}}+\frac{(N-1) g^{\prime} l+v^{2}}{l^{2}}+\frac{g^{\prime}}{2 l}
\end{array}\right]_{2 N \times 1}
$$

A matriz de saída $\mathbf{C}$ é uma matriz-linha com apenas o primeiro termo diferente de zero, justamente para se obter a trajetória do equipamento submarino:

$$
\mathbf{C}=\left[\begin{array}{llll}
1 & 0 & \cdots & 0
\end{array}\right]_{1 \times 2 N}
$$

\subsubsection{Modelo Discreto com o Arrasto Não-linear}

O método numérico também permite que se simule o sistema considerando o termo de arrasto dissipativo não-linear na equação governante completa (Eq. (2.5)). Para isto, basta substituir o termo de arrasto linear $2 \alpha$, presente nas equações discretizadas do movimento de cada elemento (Eqs. (3.4) e (3.7)-(3.10)), pelo respectivo termo de arrasto não-linear $\frac{\mu}{m}\left|\frac{\partial \Upsilon}{\partial t}\right|$.

Assim, a equação discretizada do movimento, considerando o arrasto não-linear, para o primeiro elemento é:

$$
\begin{aligned}
\frac{\mathrm{d}^{2} Y_{1}}{\mathrm{~d} t^{2}}= & -\frac{E J}{m_{t e}} \frac{\left(3 Y_{1}-14 Y_{2}+26 Y_{3}-24 Y_{4}+11 Y_{5}-2 Y_{6}\right)}{l^{4}}+\frac{T_{e}}{m_{t e}} \frac{\left(-3 Y_{1}+4 Y_{2}-Y_{3}\right)}{2 l} \\
& -\frac{\mu_{e}}{m_{t e}} \frac{\mathrm{d} Y_{1}}{\mathrm{~d} t}\left|\frac{\mathrm{d} Y_{1}}{\mathrm{~d} t}\right|
\end{aligned}
$$

Para o segundo elemento é: 


$$
\begin{aligned}
\frac{\mathrm{d}^{2} Y_{2}}{\mathrm{~d} t^{2}}= & -\frac{E J}{m} \frac{\left(3 Y_{2}-14 Y_{3}+26 Y_{4}-24 Y_{5}+11 Y_{6}-2 Y_{7}\right)}{l^{4}} \\
& +\left(g^{\prime} l+v^{2}\right) \frac{\left(Y_{1}-2 Y_{2}+Y_{3}\right)}{l^{2}}+g^{\prime} \frac{\left(-Y_{1}+Y_{3}\right)}{2 l}-\frac{\mu}{m} \frac{\mathrm{d} Y_{2}}{\mathrm{~d} t}\left|\frac{\mathrm{d} Y_{2}}{\mathrm{~d} t}\right|
\end{aligned}
$$

Para os elementos $n \in(3, \ldots, N-2)$ é:

$$
\begin{aligned}
\frac{\mathrm{d}^{2} Y_{n}}{\mathrm{~d} t^{2}}= & -\frac{E J}{m} \frac{\left(Y_{n-2}-4 Y_{n-1}+6 Y_{n}-4 Y_{n+1}+Y_{n+2}\right)}{l^{4}}+\left((n-1) g^{\prime} l+v^{2}\right) \frac{\left(Y_{n-1}-2 Y_{n}+Y_{n+1}\right)}{l^{2}} \\
& +g^{\prime} \frac{\left(-Y_{n-1}+Y_{n+1}\right)}{2 l}-\frac{\mu}{m} \frac{\mathrm{d} Y_{n}}{\mathrm{~d} t}\left|\frac{\mathrm{d} Y_{n}}{\mathrm{~d} t}\right|
\end{aligned}
$$

Para o penúltimo elemento é:

$$
\begin{aligned}
\frac{\mathrm{d}^{2} Y_{N-1}}{\mathrm{~d} t^{2}}= & -\frac{E J}{m} \frac{\left(Y_{N-3}-4 Y_{N-2}+6 Y_{N-1}-4 Y_{N}+U(t)\right)}{l^{4}} \\
& +\left((N-2) g^{\prime} l+v^{2}\right) \frac{\left(Y_{N-2}-2 Y_{N-1}+Y_{N}\right)}{l^{2}}+g^{\prime} \frac{\left(-Y_{N-2}+Y_{N}\right)}{2 l} \\
& -\frac{\mu}{m} \frac{\mathrm{d} Y_{N-1}}{\mathrm{~d} t}\left|\frac{\mathrm{d} Y_{N-1}}{\mathrm{~d} t}\right|
\end{aligned}
$$

Por fim, para o último elemento é:

$$
\begin{aligned}
\frac{\mathrm{d}^{2} Y_{N}}{\mathrm{~d} t^{2}}= & -\frac{E J}{m} \frac{\left(Y_{N-2}-4 Y_{N-1}+6 Y_{N}-3 U(t)\right)}{l^{4}} \\
& +\left((N-1) g^{\prime} l+v^{2}\right) \frac{\left(Y_{N-1}-2 Y_{N}+U(t)\right)}{l^{2}}+g^{\prime} \frac{\left(-Y_{N-1}+U(t)\right)}{2 l} \\
& -\frac{\mu}{m} \frac{\mathrm{d} Y_{N}}{\mathrm{~d} t}\left|\frac{\mathrm{d} Y_{N}}{\mathrm{~d} t}\right|
\end{aligned}
$$

Assim, especificadas as equações discretizadas de cada elemento, representa-se o sistema com o arrasto não-linear, pelo seguinte espaço de estados:

$$
\left\{\begin{array}{l}
\dot{\mathbf{x}}=\mathbf{A}_{1} \mathbf{x}+\mathbf{A}_{2} \mathbf{x}|\mathbf{x}|+\mathbf{B} u \\
y=\mathbf{C x}
\end{array}\right.
$$

onde $\mathbf{A}_{\mathbf{1}}$ é a matriz de estados $(2 N \times 2 N)$, $\mathbf{A}_{\mathbf{2}}$ é a matriz $(2 N \times 2 N)$ que contém somente os termos associados ao arrasto não-linear. Os demais parâmetros do sistema são os mesmos apresentados para o sistema discreto com o arrasto linear.

A matriz de estados $\mathbf{A}_{\mathbf{1}}$ possui a mesma estrutura da matriz de estados $\mathbf{A}$ do sistema discreto linear, com exceção da parte que contém as acelerações relativas ao arrasto:

$$
\mathbf{A}_{\mathbf{1}}=\left[\begin{array}{cc}
\mathbf{0} & \mathbf{I} \\
\mathbf{A}^{\prime} & \mathbf{0}
\end{array}\right]_{2 N \times 2 N}
$$


A matriz $\mathbf{A}_{2}$ contém, justamente, os termos associados ao arrasto não-linear:

$$
\mathbf{A}_{\mathbf{2}}=\left[\begin{array}{cc}
\mathbf{0} & \mathbf{0} \\
\mathbf{0} & -\mathbf{K}^{\prime}
\end{array}\right]_{2 N \times 2 N}
$$

onde $\mathbf{K}^{\prime}$ é definida por:

$$
\mathbf{K}^{\prime}=\left[\begin{array}{ccccc}
\frac{\mu_{e}}{m_{t e}} & 0 & 0 & \cdots & 0 \\
0 & \frac{\mu}{m} & 0 & \cdots & 0 \\
\vdots & \vdots & \ddots & \vdots & \vdots \\
0 & \cdots & 0 & \frac{\mu}{m} & 0 \\
0 & \cdots & 0 & 0 & \frac{\mu}{m}
\end{array}\right]_{N \times N}
$$

\subsection{Resultados}

Os parâmetros do sistema, adotados em todas as simulações numéricas, são os mesmos considerados no desenvolvimento analítico e podem ser verificados na Tab. 2.1.

Para verificar a precisão da solução analítica proposta na Seção 2.3, com todas as suas suposições e simplificações, a trajetória de controle $\Upsilon_{o}(L, t)$ do sistema DP, encontrada integrando numericamente a Eq. (2.58), é utilizada como entrada do sistema discreto para as simulações numéricas.

Em todas as simulações numéricas considerou-se um sistema de ordem 200, uma vez que discretizou-se o sistema em $N=100$ elementos. Como esta etapa tem o objetivo de validar a solução analítica, também não se considerou a presença de perturbações externas.

As simulações numéricas foram dividas em três etapas. Na primeira, simulou-se o modelo discreto com o arrasto dissipativo linear, conforme apresentado na Seção 3.2.3. Esta etapa teve como objetivo evidenciar a influência do termo de viga $E J \frac{\partial^{4} \Upsilon}{\partial z^{4}}$, associado à resistência do riser a flexão, na resposta do sistema e verificar se a hipótese de desprezá-lo é razoável ou não.

Na segunda etapa, simulou-se o modelo discreto com o arrasto dissipativo não-linear, conforme apresentado na Seção 3.2.4. Esta etapa teve como objetivo evidenciar a influência da nãolinearização do termo de arrasto na resposta do sistema e verificar se a hipótese de linearizá-lo é razoável ou não.

$\mathrm{Na}$ terceira etapa, buscou-se verificar o impacto na trajetória do equipamento submarino ao se considerar a entrada do sistema como sendo uma trajetória em rampa, ao invés da trajetória de controle $\Upsilon_{o}(L, t)$ do sistema DP. Assim, pode-se evidenciar a importância da fase de planejamento de trajetória.

Assim, a primeira simulação numérica foi a do modelo discreto com arrasto linear (Eq. (3.11)). A Fig. 3.1 mostra em azul a reposta da simulação numérica, que representa a trajetória do equipamento submarino obtida pelo método numérico $\Upsilon_{N}(0, t)$. Também são apresentadas: em vermelho a trajetória de referência do equipamento submarino $\Upsilon_{R}(0, t)$, utilizada como condição de contorno para a solução analítica, e em preto a trajetória de controle $\Upsilon_{o}(L, t)$ obtida pelo método analítico. 


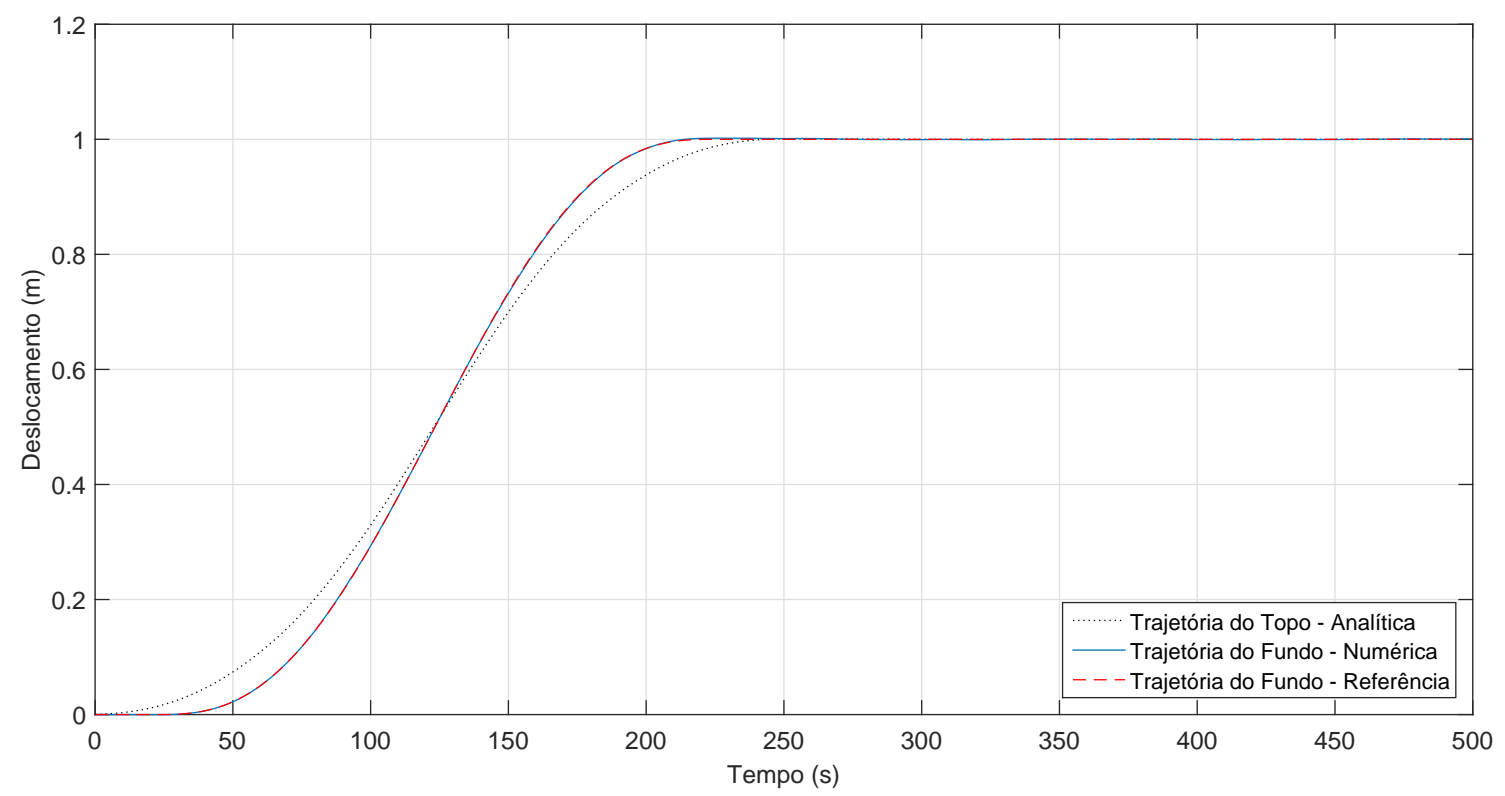

Figura 3.1: Simulação numérica do modelo discreto do sistema com o arrasto linear

Conforme apresentado na Subseção 2.3.1, destaca-se que $\Upsilon_{R}(0, t)$ é uma trajetória polinomial que desloca suavemente o equipamento submarino para uma posição final a 1 metro de distância de sua posição inicial.

Observa-se pela Fig. 3.1 que a resposta da simulação numérica $\Upsilon_{N}(0, t)$ está bem próxima da trajetória de referência do equipamento submarino. Como esperado, a suposição de modelar o riser desprezando-se sua resistência a flexão é válida e não impactou significativamente a resposta do sistema.

A segunda simulação numérica foi a do modelo discreto com arrasto não-linear (Eq. (3.25)). Novamente, utilizou-se como entrada a trajetória de controle $\Upsilon_{o}(L, t)$ do sistema DP. A Fig. 3.2 mostra em azul a reposta da simulação numérica, que representa a trajetória do equipamento submarino obtida pelo método numérico $\Upsilon_{N}(0, t)$, em vermelho a trajetória de referência do equipamento submarino $\Upsilon_{R}(0, t)$, e em preto a trajetória de controle $\Upsilon_{o}(L, t)$. Para fins de visualização, apresenta-se na Fig. 3.3 a imagem ampliada do comportamento do sistema na região próxima ao local de instalação. 


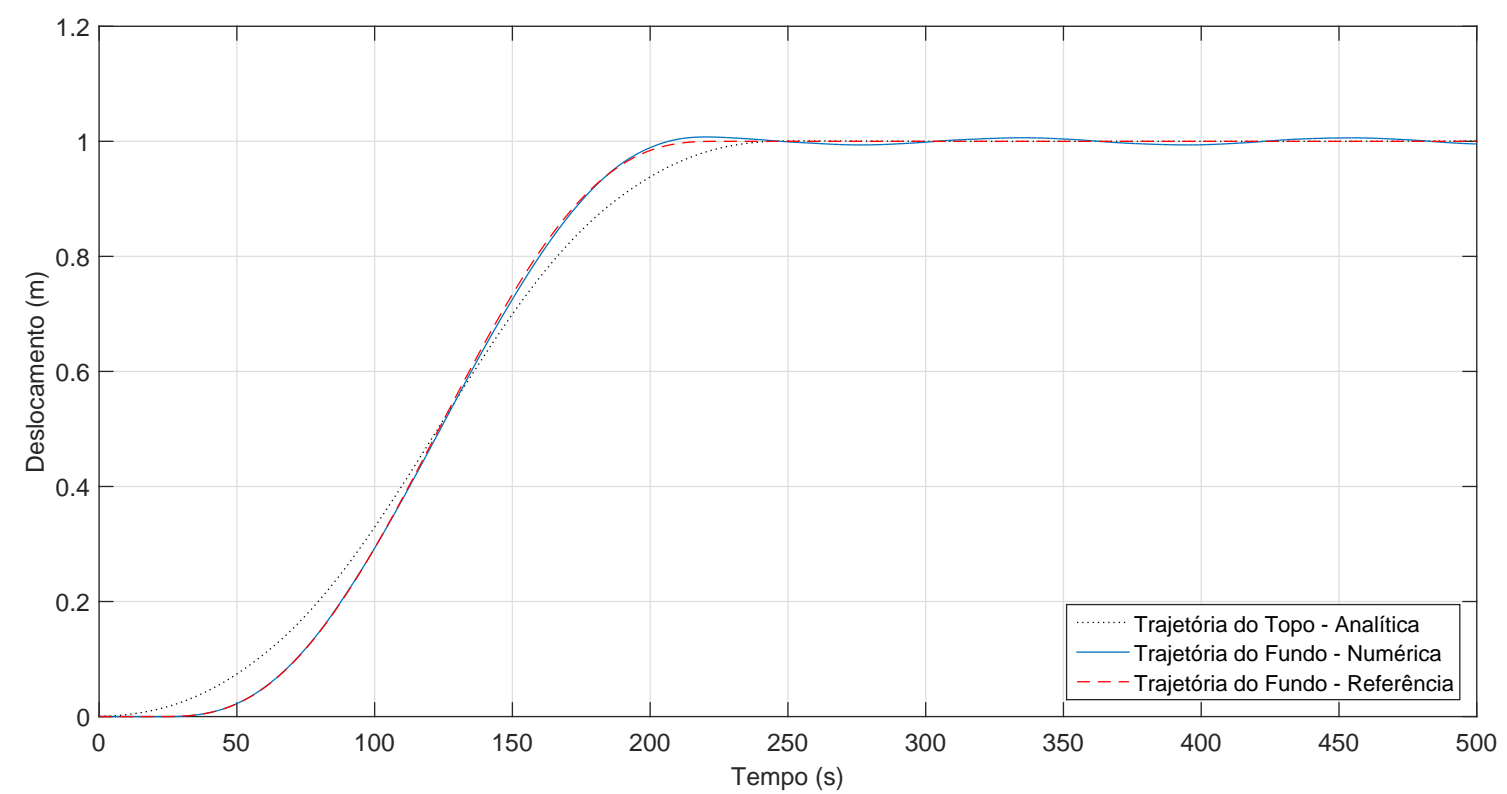

Figura 3.2: Simulação numérica do modelo discreto do sistema com o arrasto não-linear

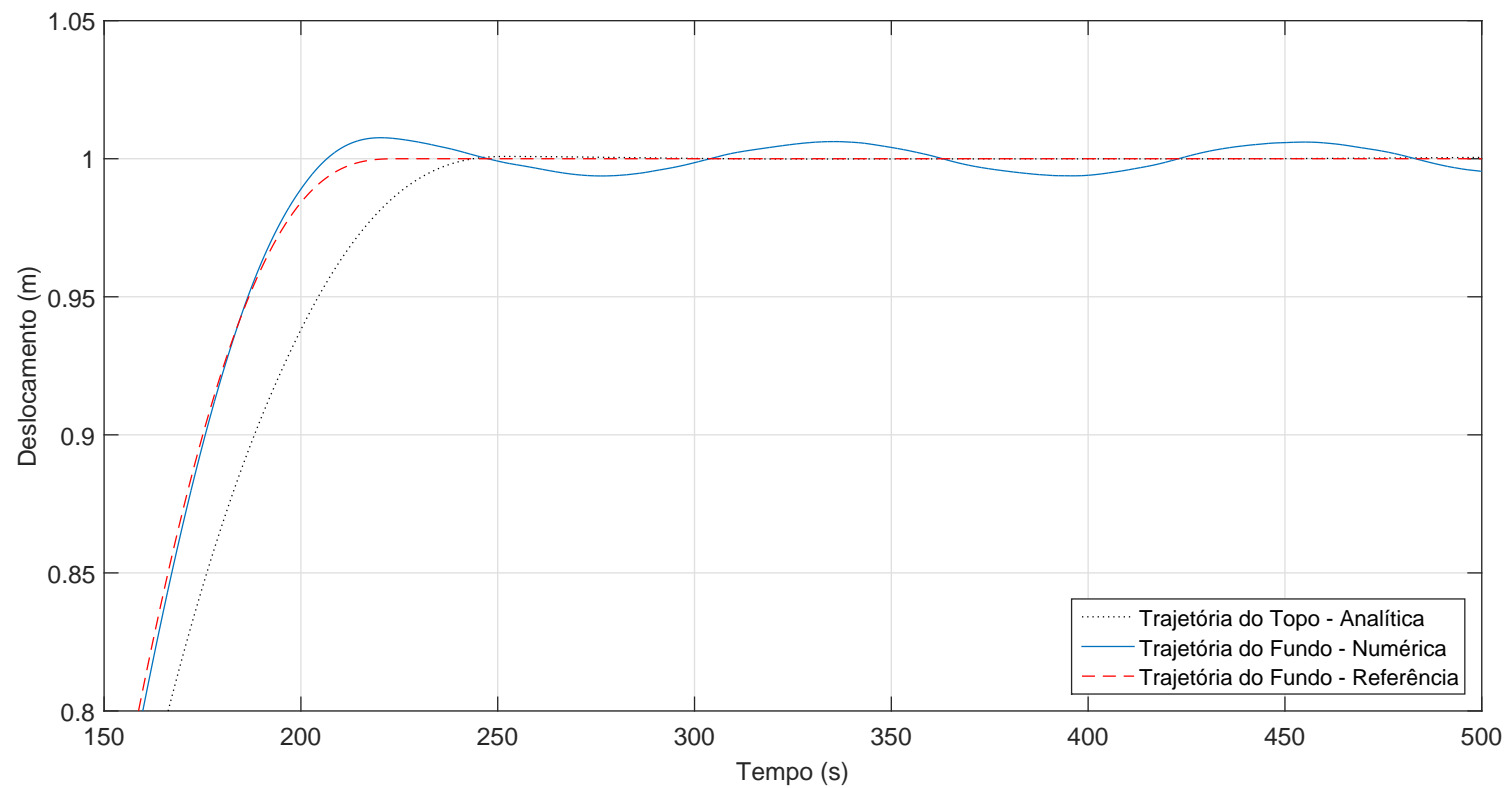

Figura 3.3: Imagem ampliada da simulação numérica do modelo discreto do sistema com o arrasto não-linear

Nota-se pela Fig. 3.2 que a trajetória do equipamento submarino, obtida pela simulação numérica, é bem próxima da trajetória adotada como referência, apresentando, apenas, uma pequena oscilação ao redor da posição final, melhor evidenciada na Fig. 3.3. Pela Fig. 3.3, verifica-se que essa oscilação tem amplitude da ordem de $6 \times 10^{-3} \mathrm{~m}$ e, portanto, não pode ser considerada como significativa na resposta do sistema. Assim, considera-se como válida a simplificação de linearizar 
o termo de arrasto dissipativo da equação governante do sistema.

Para a última simulação numérica, considerou-se como entrada, para ambos os modelos discretos, uma trajetória em forma de rampa para o sistema DP. Destaca-se que essa trajetória foi escolhida de modo que a sua velocidade média fosse igual à da trajetória de controle, para que isto não influenciasse na resposta do sistema. A Fig. 3.4 apresenta em azul a reposta da simulação numérica para o modelo linear, em verde a resposta para o modelo não-linear, em vermelho a trajetória de referência do equipamento submarino $\Upsilon_{R}(0, t)$, e em preto a trajetória em forma de rampa para o sistema DP.

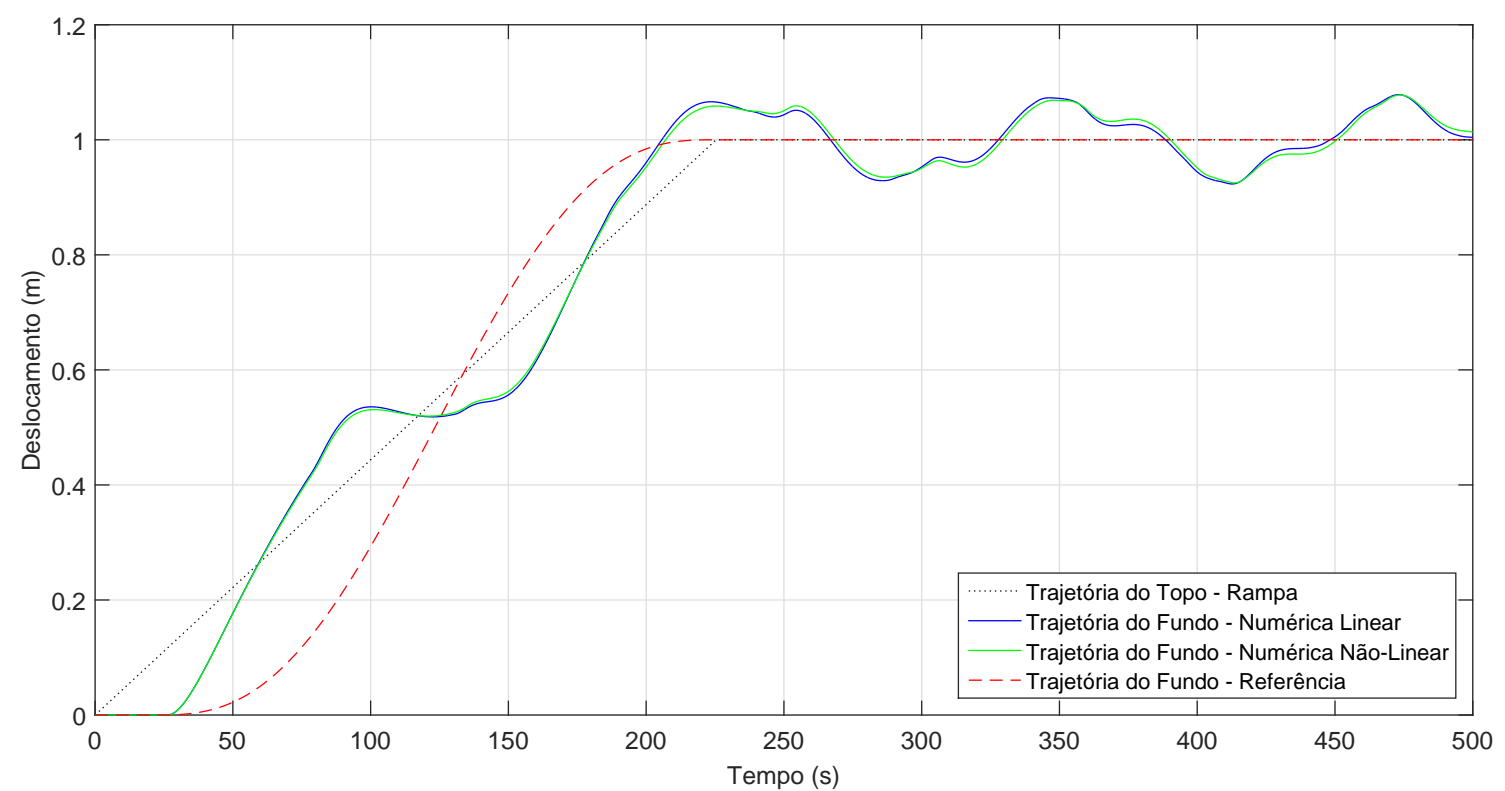

Figura 3.4: Respostas dos modelos discretos para uma entrada em forma de rampa

Nota-se pela Fig. 3.4 dois resultados interessantes. O primeiro é que as trajetórias obtidas para o equipamento submarino por ambos os modelos discretos são bem próximas. Isto já era esperado, pois verificou-se pelas simulações anteriores que a linearização do arrasto não alterava significativamente o comportamento do sistema.

O segundo resultado é que, ao se considerar uma trajetória em rampa para o sistema DP da plataforma, obtém-se uma trajetória bem menos comportada para o equipamento submarino, conforme pode ser visto pela comparação com a trajetória de referência. Assim, evidencia-se a importância da etapa de planejamento de trajetória realizada no Capítulo 2.

\subsection{Conclusões}

Neste capítulo apresentou-se um método numérico para avaliar e validar a solução analítica obtida no Capítulo 2. Utilizando diferenças finitas, discretizou-se a equação governante completa do sistema, obtendo-se dois modelos discretos, um para o caso do arrasto linear e o outro para o 
caso do arrasto não-linear.

Simulações numéricas foram realizadas para avaliar as hipóteses e simplificações consideradas no desenvolvimento analítico. Verificou-se que, para o caso em estudo, tanto a desconsideração do termo associado à resistência do riser a flexão quanto a linearização do termo de arrasto dissipativo são válidas e não impactam significativamente o comportamento do sistema. Evidenciou-se, também, a importância da etapa de planejamento de trajetória no preciso posicionamento do equipamento submarino.

No Capítulo 4 será apresentado um método de redução de ordem do sistema, baseando-se na teoria de análise modal. Essa redução de ordem será necessária para o posterior desenvolvimento do sistema de controle de trajetória, apresentado no Capítulo 5. 


\section{Capítulo 4}

\section{Modelo Reduzido}

\subsection{Introdução}

Em um caso real de instalação de equipamento submarino há a presença de perturbações externas desconhecidas, como correntezas oceânicas, ventos e ondas. Assim, o planejamento de trajetória, desenvolvido no Capítulo 2, não assegura que, de fato, o equipamento submarino irá seguir a trajetória de referência. Assim, faz-se necessário o desenvolvimento de um sistema de controle para garantir a tarefa de acompanhamento de trajetória. Entretanto, a elevada ordem do sistema torna inviável o projeto do controlador.

Assim, este capítulo apresenta uma fase preliminar e fundamental para o desenvolvimento do sistema de controle, que é a obtenção de um modelo reduzido que será utilizado como base para o projeto do controlador. O modelo reduzido será obtido a partir do modelo discreto com o arrasto linear (Eq. (3.11)), utilizando-se uma estratégia de redução de ordem, baseada na teoria de análise modal. Entretanto, a redução modal faz aparecer no modelo um comportamento que não é observado no caso real. Para atenuar esse comportamento, é utilizada a estratégia proposta por Fortaleza [18] de introdução de um atraso no sistema.

\subsection{Redução Modal}

Conforme apresentado no Capítulo 3, ao se discretizar a equação governante do sistema em $N$ elementos, fez-se necessário escolher um $N$ grande o suficiente para se obtivesse uma aproximação confiável do comportamento real do sistema. Por consequência, obteve-se um modelo discreto de ordem $2 N$.

Entretanto, o projeto de um controlador em cima desse modelo de ordem elevada torna-se impraticável. Faz-se necessário, então, utilizar uma estratégia de redução de ordem, obtendose, assim, um modelo discreto reduzido. A ordem do modelo reduzido deve ser pequena, para que o desenvolvimento do sistema de controle seja viável, mas suficiente, para bem representar o comportamento do modelo original. 
Um método bastante empregado para reduzir a ordem de um sistema e, ao mesmo tempo, manter o comportamento do sistema original é o método da Redução Modal. Esse método baseiase na aplicação de uma transformação de coordenadas no sistema original, colocando-o na base modal. Posteriormente, analisa-se quais os modos do sistema que mais influenciam a sua resposta. Os modos que não possuírem contribuições importantes são eliminados, reduzindo-se, assim, a ordem do sistema.

Essa redução de ordem é possível, pois, de um modo geral, apenas alguns modos têm efeito significativo nas características dinâmicas do sistema, de acordo com o intervalo de frequências de interesse [25].

\subsubsection{Base Modal}

A transformação de coordenadas que coloca o sistema na base modal é chamada de decomposição modal. Essa transformação utiliza os autovetores da matriz de estados $\mathbf{A}$ do sistema discreto original (Eq. (3.11)).

Assim, o primeiro passo é calcular a matriz de autovetores $\mathbf{V}$ da matriz de estados $\mathbf{A}$, que também é uma matriz $(2 N \times 2 N)$. A matriz $\mathbf{V}$ possui pares de colunas contendo autovetores complexos conjugados $\left(\mathrm{v}_{j, k}=\gamma_{j, k} \pm i \varphi_{j, k}\right)$ :

$$
\mathbf{V}=\left[\begin{array}{ccccc}
\gamma_{1,1}+i \varphi_{1,1} & \gamma_{1,1}-i \varphi_{1,1} & \cdots & \gamma_{1, N}+i \varphi_{1, N} & \gamma_{1, N}-i \varphi_{1, N} \\
\vdots & \vdots & \cdots & \vdots & \vdots \\
\gamma_{2 N, 1}+i \varphi_{2 N, 1} & \gamma_{2 N, 1}-i \varphi_{2 N, 1} & \cdots & \gamma_{2 N, N}+i \varphi_{2 N, N} & \gamma_{2 N, N}-i \varphi_{2 N, N}
\end{array}\right]_{2 N \times 2 N}
$$

Seguindo a ideia apresentada em [18], para que não seja necessário trabalhar com números complexos, pode-se definir uma nova matriz de autovetores $\tilde{\mathbf{V}}$, onde substitui-se os pares de colunas contendo os autovetores complexos conjugados da matriz $\mathbf{V}$ por duas novas colunas, a primeira contendo a parte real do autovetor e a segunda a sua parte imaginária.

Assim, a matriz $\widetilde{\mathbf{V}}$, que será utilizada para a decomposição modal, possui a seguinte estrutura:

$$
\widetilde{\mathbf{V}}=\left[\begin{array}{ccccc}
\gamma_{1,1} & -\varphi_{1,1} & \cdots & \gamma_{1, N} & -\varphi_{1, N} \\
\vdots & \vdots & \cdots & \vdots & \vdots \\
\gamma_{2 N, 1} & -\varphi_{2 N, 1} & \cdots & \gamma_{2 N, N} & -\varphi_{2 N, N}
\end{array}\right]_{2 N \times 2 N}
$$

Pode-se, então, aplicar a seguinte transformação de coordenadas para colocar o sistema na base modal:

$$
\widetilde{\mathbf{x}}=\widetilde{\mathbf{V}}^{-1} \mathbf{x}
$$

onde $\widetilde{\mathbf{x}}$ é o vetor de estados $(2 N \times 1)$ na base modal.

Utilizando essa transformação, pode-se reescrever as equações do modelo discreto com o arrasto 
linear (Eq. (3.11)) na base modal:

$$
\left\{\begin{array}{l}
\dot{\tilde{\mathbf{x}}}=\widetilde{\mathbf{A}} \widetilde{\mathbf{x}}+\widetilde{\mathbf{B}} u \\
y=\widetilde{\mathbf{C}} \widetilde{\mathbf{x}}
\end{array}\right.
$$

onde $\widetilde{\mathbf{A}}, \widetilde{\mathbf{B}}$ e $\widetilde{\mathbf{C}}$ são, respectivamente, as matrizes de estados $(2 N \times 2 N)$, de entrada $(2 N \times 1)$ e de saída $(1 \times 2 N)$, todas na base modal.

A matriz de estados $\widetilde{\mathbf{A}}$ é obtida pela seguinte transformação:

$$
\widetilde{\mathbf{A}}=\widetilde{\mathbf{V}}^{-1} \mathbf{A} \widetilde{\mathbf{V}}
$$

Ela é uma matriz bloco diagonal, composta pelas partes reais e imaginárias dos autovalores complexos conjugados $\left(\lambda_{j}=\sigma_{j} \pm i \omega_{j}\right)$ da matriz de estados $\mathbf{A}$ do modelo original:

$$
\widetilde{\mathbf{A}}=\left[\begin{array}{ccccccc}
\sigma_{1} & \omega_{1} & 0 & 0 & 0 & \cdots & 0 \\
-\omega_{1} & \sigma_{1} & 0 & 0 & 0 & \cdots & 0 \\
0 & 0 & \sigma_{2} & \omega_{2} & 0 & \cdots & 0 \\
0 & 0 & -\omega_{2} & \sigma_{2} & 0 & \cdots & 0 \\
\vdots & \vdots & \vdots & \vdots & \ddots & \vdots & \vdots \\
0 & \cdots & 0 & 0 & 0 & \sigma_{N} & \omega_{N} \\
0 & \cdots & 0 & 0 & 0 & -\omega_{N} & \sigma_{N}
\end{array}\right]_{2 N \times 2 N}
$$

A matriz de entrada $\widetilde{\mathbf{B}}$ é calculada pela seguinte transformação:

$$
\widetilde{\mathbf{B}}=\widetilde{\mathbf{V}}^{-1} \mathbf{B}
$$

Por fim, a matriz de saída $\widetilde{\mathbf{C}}$ é obtida pela seguinte transformação:

$$
\widetilde{\mathbf{C}}=\mathbf{C} \tilde{\mathbf{V}}
$$

\subsubsection{Redução do Modelo}

A redução modal é uma das técnicas de redução de modelo mais utilizadas para sistemas dinâmicos estruturais lineares [25]. De um modo geral, dependendo da frequência de interesse, apenas alguns modos têm efeito significativo sobre as características dinâmicas do sistema.

Assim, a redução modal permite que se elimine os modos que não têm contribuições significativas para as respostas do sistema, fazendo com que o número de coordenadas modais acumulados seja muito menor do que o número de coordenadas físicas, reduzindo-se a ordem do sistema.

No caso em estudo, os modos de baixa frequência têm maior influência na resposta do sistema. Já os modos de alta frequência não tem grande impacto no comportamento do sistema e podem ser eliminados, uma vez que eles são atenuados pelas forças hidrodinâmicas e pela suavidade da 
entrada do sistema.

Uma maneira de se determinar quais subsistemas devem ser selecionados para melhor representar o sistema original é por meio da análise do ganho estático associado a cada autovalor. O ganho estático é definido pela razão entre a variação da saída e a variação da entrada do sistema. Considerando o sistema na base modal, pode-se obter uma matriz $\mathbf{G}_{\mathbf{e}}(2 N \times 1)$ que contém o ganho estático associado a cada autovalor:

$$
\mathbf{G}_{\mathbf{e}}=-\operatorname{diag}(\widetilde{\mathbf{C}}) \widetilde{\mathbf{A}}^{-1} \widetilde{\mathbf{B}}
$$

onde $\operatorname{diag}(\widetilde{\mathbf{C}})$ representa uma matriz diagonal $(2 N \times 2 N)$ com os elementos da matriz $\widetilde{\mathbf{C}}$ na diagonal principal.

Os autovalores com os maiores ganhos estáticos têm maior influência na resposta do sistema e podem ser selecionados para fazer parte do modelo reduzido. Deve-se ponderar duas questões para se determinar a quantidade de modos a ser mantida no sistema reduzido: quanto maior a quantidade de modos mantidos, melhor será a precisão do modelo reduzido, entretanto, também demandará um maior custo computacional.

Definida a quantidade de modos a ser mantida e determinados os subsistemas que farão parte do modelo reduzido, elimina-se os modos restantes. Para compensar o ganho estático perdido ao se eliminar os demais autovalores, adiciona-se às equações do modelo reduzido uma transferência direta $\widetilde{D}_{R}$.

A transferência direta é um escalar e é calculada, justamente, pela diferença entre o ganho estático do sistema original e o ganho do sistema reduzido:

$$
\widetilde{D}_{R}=\widetilde{\mathbf{C}}_{\mathbf{R}} \widetilde{\mathbf{A}}_{\mathbf{R}}^{-1} \widetilde{\mathbf{B}}_{\mathbf{R}}-\mathbf{C A}^{-1} \mathbf{B}
$$

Obtém-se, então, o seguinte espaço de estados para o modelo reduzido:

$$
\left\{\begin{array}{l}
\dot{\tilde{\mathbf{x}}}_{\mathbf{R}}=\widetilde{\mathbf{A}}_{\mathbf{R}} \widetilde{\mathbf{x}}_{\mathbf{R}}+\widetilde{\mathbf{B}}_{\mathbf{R}} u \\
y=\widetilde{\mathbf{C}}_{\mathbf{R}} \widetilde{\mathbf{x}}_{\mathbf{R}}+\widetilde{D}_{R} u
\end{array}\right.
$$

onde $\widetilde{\mathbf{A}}_{\mathbf{R}}, \widetilde{\mathbf{B}}_{\mathbf{R}}$ e $\widetilde{\mathbf{C}}_{\mathbf{R}}$ são as matrizes reduzidas que contêm apenas os termos das matrizes $\widetilde{\mathbf{A}}, \widetilde{\mathbf{B}}$ e $\widetilde{\mathbf{C}}$, respectivamente, referentes aos modos selecionados, e $\widetilde{\mathbf{x}}_{\mathbf{R}}$ é o vetor de estados do correspondente.

\subsubsection{Introdução do Atraso}

Segundo Fortaleza [18], o aparecimento dessa transferência direta $\widetilde{D}_{R}$ dá ao modelo um comportamento que não é comum para esse tipo de estrutura, pois esse elevado valor implica em um comportamento de alta frequência para o modelo, o que não é observado no caso real.

Em [18] foi proposta uma solução para melhorar a precisão do modelo reduzido. A solução foi introduzir um atraso $\epsilon$ no modelo, de forma que o valor da transferência direta seja pequeno, próximo de zero. Assim, melhor representa-se o comportamento dinâmico real do modelo. 
Esse atraso deve ser escolhido de modo que o sistema permaneça em seu estado inicial durante o intervalo de tempo $0<t<\epsilon$ e, para $t>\epsilon$, ambos os sistemas apresentem a mesma saída. Então, representa-se o sistema reduzido com atraso pelo seguinte espaço de estados:

$$
\left\{\begin{array}{l}
\dot{\tilde{\mathbf{x}}}_{\mathbf{R}}=\widetilde{\mathbf{A}}_{\mathbf{R}} \widetilde{\mathbf{x}}_{\mathbf{R}}+\widetilde{\mathbf{B}}_{\mathbf{D}} u(t-\epsilon) \\
y=\widetilde{\mathbf{C}}_{\mathbf{R}} \widetilde{\mathbf{x}}_{\mathbf{R}}+\widetilde{D}_{D} u(t-\epsilon)
\end{array}\right.
$$

onde $\widetilde{\mathbf{B}}_{\mathbf{D}}$ é a nova matriz de entrada e $\widetilde{D}_{D}$ é um escalar e representa a nova transferência direta.

Destaca-se que $\widetilde{\mathbf{B}}_{\mathbf{D}}$ e $\widetilde{D}_{D}$ devem satisfazer (ver [18]):

$$
\begin{aligned}
& \widetilde{\mathbf{B}}_{\mathbf{D}}=\widetilde{\mathbf{A}}_{\mathbf{R}}\left(e^{\epsilon \widetilde{\mathbf{A}}_{\mathbf{R}}}-\mathbf{I}\right) \widetilde{\mathbf{A}}_{\mathbf{R}}^{-1} \widetilde{\mathbf{B}}_{\mathbf{R}}+\widetilde{\mathbf{B}}_{\mathbf{R}} \\
& \widetilde{D}_{D}=\widetilde{\mathbf{C}}_{\mathbf{R}}\left(e^{\epsilon \widetilde{\mathbf{A}}_{\mathbf{R}}}-\mathbf{I}\right) \widetilde{\mathbf{A}}_{\mathbf{R}}^{-1} \widetilde{\mathbf{B}}_{\mathbf{R}}+\widetilde{D}_{R}
\end{aligned}
$$

sendo I a matriz identidade.

\subsection{Resultados}

Para determinar a quantidade de modos a ser preservada no modelo reduzido, analisou-se a resposta de modelos reduzidos de diferentes ordens a uma entrada em degrau unitário, conforme é apresentado na Fig. 4.1.

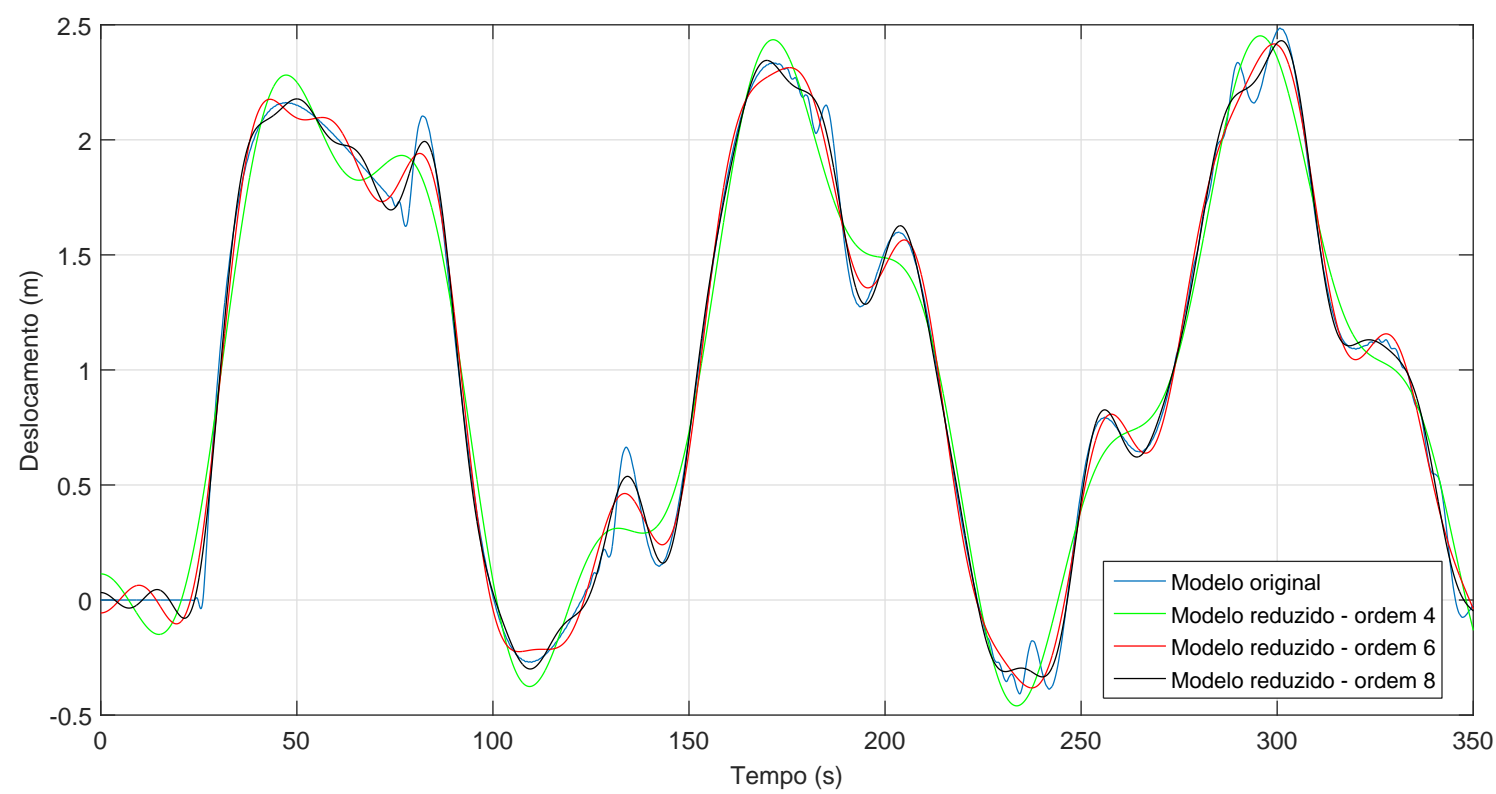

Figura 4.1: Respostas dos modelos a uma entrada em degrau unitário

A Fig. 4.1 mostra em azul a resposta do modelo discreto original (Eq. (3.11)), que possui 
ordem 200, em verde a resposta do modelo reduzido de ordem 4, em vermelho a resposta do modelo reduzido de ordem 6 , e em preto a resposta do modelo reduzido de ordem 8 . Para fins de melhor comparação, apresenta-se na Fig. 4.2 o comportamento dos sistemas para o intervalo de tempo de 0 a 90 segundos.

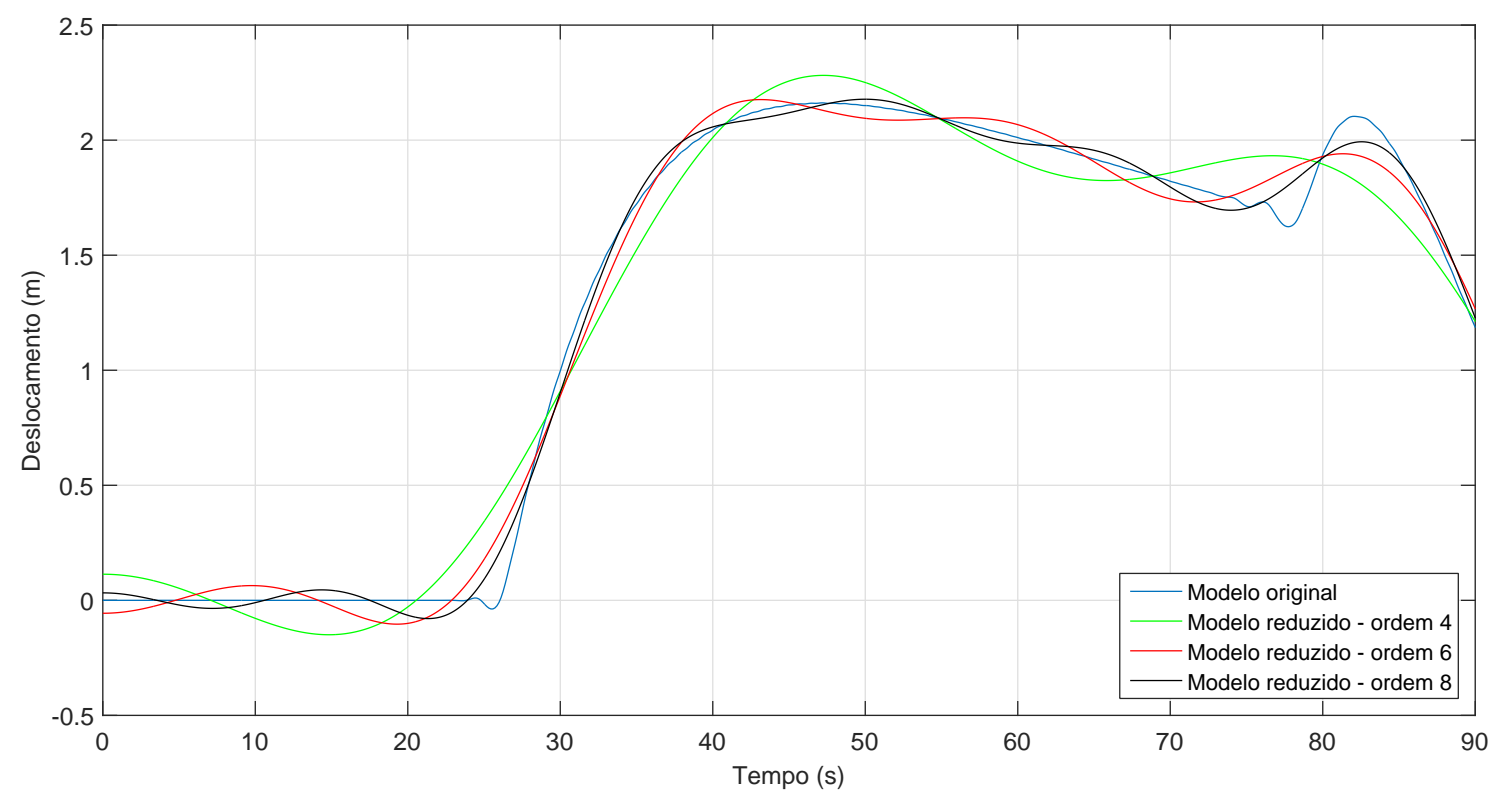

Figura 4.2: Imagem ampliada das respostas dos modelos a uma entrada em degrau unitário

Nota-se pela Fig. 4.2 que quanto maior a ordem do sistema reduzido, mais próximo é o seu comportamento em relação ao sistema original. Entretanto, quanto maior a ordem escolhida, maior é o custo computacional de se trabalhar com mais equações do sistema. Assim, deve-se ponderar esses dois fatores em cada caso em estudo.

Neste trabalho, optou-se pelo modelo reduzido de ordem 4, uma vez que ele representa o modelo original com uma precisão aceitável e, como ele será utilizado para o projeto do controlador, quanto maior a ordem do sistema reduzido, mais suscetível ao ruído de medida será o controlador.

Observa-se pela Fig. 4.2 a clara influência da transferência direta no comportamento inicial dos modelos reduzidos, dando um comportamento que não é observado no modelo original. Percebe-se que quanto menor a ordem do modelo reduzido, maior é o valor absoluto da transferência direta correspondente. Para o modelo reduzido de ordem 4 o valor da transferência direta $\widetilde{D}_{R}$ é de 0,1135 .

Assim, seguindo a ideia proposta por Fortaleza [18], deve-se introduzir um atraso $\epsilon$ no modelo reduzido para garantir que ele permaneça em seu estado inicial durante o intervalo de tempo $0<t<\epsilon$ e, para $t>\epsilon$, ambos apresentem saídas parecidas.

Nota-se pela Fig. 4.2 que a partir do instante de tempo $t=20,57 \mathrm{~s}$, as respostas do modelo original e do modelo reduzido de ordem 4 se assemelham. Assim, assume-se o atraso $\epsilon$ como sendo esse valor. 
A Fig. 4.3 apresenta a comparação do comportamento do modelo original e do modelo reduzido de ordem 4 com a introdução do atraso.

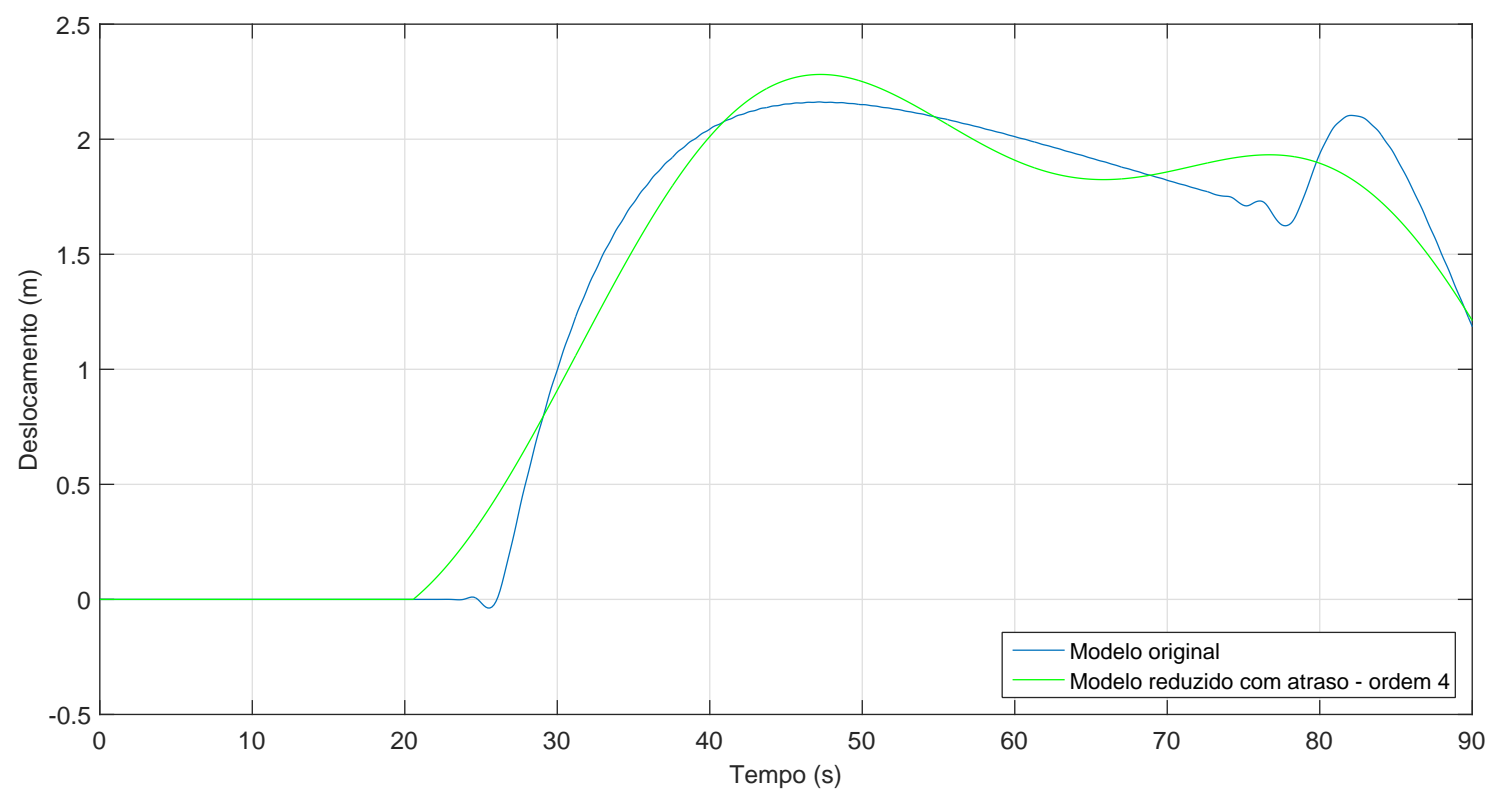

Figura 4.3: Comparação da respostas do modelo original e do modelo reduzido de ordem 4 com atraso a uma entrada em degrau unitário

Nota-se pela Fig. 4.3 que a introdução do atraso reduz consideravelmente o valor da transferência direta $\left(\widetilde{D}_{D}=9,6 \times 10^{-4}\right)$, melhorando bastante o comportamento dinâmico do modelo reduzido.

\subsection{Conclusões}

Neste capítulo apresentou-se uma estratégia de redução de ordem do modelo discreto com o arrasto linear a fim de possibilitar o desenvolvimento do sistema de controle que será apresentado no Capítulo 5.

A estratégia baseou-se na teoria de análise modal, na qual analisou-se quais modos tinham contribuição significativa na resposta do sistema, de acordo com a faixa de frequência de interesse. Então, preservou-se no modelo reduzido os modos com os maiores ganhos estáticos e eliminou-se o restante. Assim, reduziu-se a ordem do modelo de 200 para 4.

A redução modal introduziu no modelo um comportamento que não é verificado no caso real, assim, seguindo a ideia proposta por Fortaleza [18], introduziu-se um atraso no sistema a fim de melhor aproximá-lo ao modelo original.

No Capítulo 5 será apresentado o desenvolvimento do sistema de controle de trajetória via saídas planas, devido à característica de planicidade diferencial do sistema. 


\section{Capítulo 5}

\section{Controle de Trajetória via Planicidade Diferencial}

\subsection{Introdução}

Neste capítulo será apresentado o desenvolvimento de um sistema de controle de trajetória via planicidade diferencial para o problema de posicionamento do equipamento submarino. O projeto de um controlador é necessário, pois em operações reais há a presença de perturbações ambientes desconhecidas, como correntezas oceânicas, ondas e ventos, que não foram modeladas na equação governante do sistema e tendem a retirar o equipamento submarino de sua trajetória de referência, impossibilitando o seu preciso posicionamento. O controlador será feito com base no modelo reduzido de ordem 4, apresentado na Seção 4.2.3, e será aplicado ao sistema discreto original com o arrasto não-linear. Sua performance será avaliada a partir de simulações numéricas.

Antes do projeto propriamente dito, será apresentado: na Seção 5.2 o conceito de sistemas diferencialmente planos no contexto de sistemas lineares invariantes no tempo; na Seção 5.3 o procedimento de obtenção da saída plana para sistemas com apenas uma entrada e uma saída (SISO - Single Input Single Output, do inglês); na Seção 5.4 o observador de estados que será utilizado para estimar o vetor de estados no domínio das saídas planas; na Seção 5.5 a definição do termo de correção para o controlador, de forma a permitir o acompanhamento de trajetória; e na Seção 5.6 a estrutura do preditor de Smith que será utilizado para facilitar o projeto do controlador.

\subsection{Sistema Diferencialmente Plano}

O conceito de sistema diferencialmente plano (ou differentially flat, do inglês) foi introduzido por Fliess et al. [26]. Um sistema é considerado diferencialmente plano se todas as variáveis de estado e de entrada podem ser diretamente expressas, sem a necessidade de integrar qualquer equação diferencial, em função de outras variáveis, denominadas saídas planas, e de um número 
finito de suas derivadas temporais [26].

Dado um sistema linear invariante no tempo com um vetor de estados $\mathbf{x} \in \mathbb{R}^{n}$ e um vetor de entrada $\mathbf{u} \in \mathbb{R}^{m}$, então o sistema é considerado diferencialmente plano se existem as relações [27]:

$$
\begin{aligned}
& \phi=\mathbb{R}^{n} \times\left(\mathbb{R}^{m}\right)^{r+1} \rightarrow \mathbb{R}^{m} \\
& \psi=\left(\mathbb{R}^{m}\right)^{r} \rightarrow \mathbb{R}^{n} \\
& \eta=\left(\mathbb{R}^{m}\right)^{r+1} \rightarrow \mathbb{R}^{m}
\end{aligned}
$$

de tal modo que:

$$
\begin{aligned}
& \mathbf{F}=\phi\left(\mathbf{x}, \mathbf{u}, \dot{\mathbf{u}}, \cdots, \mathbf{u}^{(r)}\right) \\
& \mathbf{x}=\psi\left(\mathbf{F}, \dot{\mathbf{F}}, \cdots, \mathbf{F}^{(r-1)}\right) \\
& \mathbf{u}=\eta\left(\mathbf{F}, \dot{\mathbf{F}}, \cdots, \mathbf{F}^{(r-1)}, \mathbf{F}^{(r)}\right)
\end{aligned}
$$

onde $r$ é um número inteiro finito e $\mathbf{F} \in \mathbb{R}^{m}$ é o vetor de saídas planas do sistema.

Nota-se pela Eq. (5.2) que todas as variáveis do sistema são expressas em função das saídas planas e das suas sucessivas derivadas temporais. Assim, verifica-se que um sistema diferencialmente plano permite a parametrização de suas variáveis em função de um conjunto finito de variáveis "endógenas", denominadas saídas planas, e de um número finito de suas derivadas temporais. Uma variável é dita "endógena" se ela pode ser expressa como uma combinação linear das variáveis do sistema e de um número finito de suas derivadas temporais [28].

\subsection{Saída Plana}

Considerando um sistema linear SISO invariante no tempo, representado na forma de espaço de estados:

$$
\left\{\begin{array}{l}
\dot{\mathbf{x}}=\mathbf{A} \mathbf{x}+\mathbf{B} u \\
y=\mathbf{C x}+D u
\end{array}\right.
$$

onde $\mathbf{x} \in \mathbb{R}^{n}$ é o vetor de estados, $u \in \mathbb{R}$ é a entrada, $y \in \mathbb{R}$ é a saída, $\mathbf{A}$ é a matriz de estados $(n \times n)$, B é a matriz de entrada $(n \times 1)$, $\mathbf{C}$ é a matriz de saída $(1 \times n)$ e $D$ é a transferência direta.

Segundo Sira-Ramírez e Agrawal [28], esse sistema é diferencialmente plano se, e somente se, o sistema é controlável. Uma condição necessária e suficiente para o sistema ser dito controlável é a matriz de controlabilidade de Kalman $\mathbf{C}_{\mathbf{K}}$ ter posto igual à ordem do sistema [29].

No caso do sistema SISO, sua matriz de controlabilidade de Kalman tem ordem $(n \times n)$ e é definida por:

$$
\mathbf{C}_{\mathbf{K}}=\left[\begin{array}{llll}
\mathbf{B} & \mathbf{A B} & \cdots & \mathbf{A}^{n-1} \mathbf{B}
\end{array}\right]_{n \times n}
$$

Destaca-se que o posto é determinado pela quantidade de colunas independentes da matriz. Assim, constatando-se que posto $\left(\mathbf{C}_{\mathbf{K}}\right)=n$, o sistema é dito controlável. Sendo controlável, sua 
saída plana $F \in \mathbb{R}$ pode ser determinada pela combinação linear dos estados obtidos da última linha da inversa da matriz de controlabilidade de Kalman:

$$
F=\left[\begin{array}{llll}
0 & \cdots & 0 & 1
\end{array}\right]_{1 \times n} \mathbf{C}_{\mathbf{K}}^{-1} \mathbf{x}
$$

\subsubsection{Forma Canônica de Controle}

A descrição do espaço de estado de um determinado sistema não é único, uma vez que existem diversos modelos de espaços de estados que dão a mesma dinâmica entre a sua entrada e a sua saída [30].

Algumas formas particulares de representação por espaço de estados apresentam características úteis, entre elas, destacam-se as chamadas formas canônicas. Uma forma canônica em especial que será útil para a obtenção da saída plana do sistema e o posterior desenvolvimento do controlador é a forma canônica de controle.

As formas canônicas possuem a característica de serem obtidas diretamente da expressão da função de transferência $G(s)$ de um dado sistema. A função de transferência de um sistema representado na forma de espaço de estados pode ser obtida por:

$$
G(s)=\frac{y(s)}{u(s)}=\mathbf{C}(\mathbf{I} s-\mathbf{A})^{-1} \mathbf{B}+D
$$

sendo I a matriz identidade $(n \times n)$.

Cuja forma geral pode ser representada por:

$$
G(s)=\frac{b_{0} s^{n}+b_{1} s^{n-1}+\ldots+b_{n-1} s+b_{n}}{s^{n}+a_{1} s^{n-1}+\ldots+a_{n-1} s+a_{n}}
$$

Entretanto, caso o sistema esteja representado na forma de espaço de estados, pode-se simplesmente aplicar uma transformação de coordenadas e colocá-lo na forma canônica desejada, dispensando a etapa de obtenção da função de transferência do sistema.

Assim, considerando o sistema linear SISO invariante no tempo dado pela Eq. (5.3), pode-se aplicar a seguinte transformação de coordenadas para colocar o sistema na forma canônica de controle:

$$
\overline{\mathbf{x}}=\mathbf{T}^{-1} \mathbf{x}
$$

onde $\overline{\mathbf{x}} \in \mathbb{R}^{n}$ é o vetor de estados na forma canônica de controle e $\mathbf{T}$ é a matriz de transformação $(n \times 1)$. 
A inversa da matriz da transformação é dada por (ver [31]):

$$
\mathbf{T}^{-1}=\left[\begin{array}{c}
\Theta \\
\Theta \mathbf{A} \\
\Theta \mathbf{A}^{2} \\
\vdots \\
\Theta \mathbf{A}^{n-1}
\end{array}\right]_{n \times 1}
$$

onde $\Theta$ é obtida por:

$$
\Theta=\left[\begin{array}{llll}
0 & \cdots & 0 & 1
\end{array}\right]_{1 \times n} \mathbf{C}_{\mathbf{K}}^{-1}
$$

Aplicando essa transformação no sistema original, pode-se reescrever as equações do sistema na forma canônica de controle:

$$
\left\{\begin{array}{l}
\dot{\overline{\mathbf{x}}}=\overline{\mathbf{A}} \overline{\mathbf{x}}+\overline{\mathbf{B}} u \\
y=\overline{\mathbf{C}} \overline{\mathbf{x}}+\bar{D} u
\end{array}\right.
$$

onde $\overline{\mathbf{A}}, \overline{\mathbf{B}}$ e $\overline{\mathbf{C}}$ são, respectivamente, as matrizes de estados, de entrada e de saída, e $\bar{D}$ é a transferência direta, todas na forma canônica de controle.

A matriz de estados $\overline{\mathbf{A}}$ é obtida aplicando-se a seguinte transformação:

$$
\overline{\mathbf{A}}=\mathbf{T}^{-1} \mathbf{A T}
$$

A matriz $\overline{\mathbf{A}}$ possui a seguinte estrutura padrão:

$$
\overline{\mathbf{A}}=\left[\begin{array}{cccccc}
0 & 1 & 0 & 0 & \cdots & 0 \\
0 & 0 & 1 & 0 & \cdots & 0 \\
\vdots & \vdots & \vdots & \ddots & \vdots & \vdots \\
0 & \cdots & 0 & 0 & 1 & 0 \\
0 & \cdots & 0 & 0 & 0 & 1 \\
-a_{n} & \cdots & -a_{4} & -a_{3} & -a_{2} & -a_{1}
\end{array}\right]_{n \times n}
$$

onde os termos $a_{i}$ representam os coeficientes do polinômio característico do denominador da função de transferência do sistema original (Eq. (5.7)).

A matriz de entrada $\overline{\mathbf{B}}$ é obtida aplicando-se a seguinte transformação:

$$
\overline{\mathbf{B}}=\mathbf{T}^{-1} \mathbf{B}
$$


A matriz $\overline{\mathbf{B}}$ possui a seguinte estrutura padrão:

$$
\overline{\mathbf{B}}=\left[\begin{array}{c}
0 \\
0 \\
\vdots \\
0 \\
1
\end{array}\right]_{n \times 1}
$$

A matriz de saída $\overline{\mathbf{C}}$ é obtida aplicando-se a seguinte transformação:

$$
\overline{\mathbf{C}}=\mathbf{C T}
$$

A matriz $\overline{\mathbf{C}}$ possui a seguinte estrutura padrão:

$$
\overline{\mathbf{C}}=\left[\begin{array}{llll}
b_{n}-a_{n} b_{0} & b_{n-1}-a_{n-1} b_{0} & \cdots & b_{1}-a_{1} b_{0}
\end{array}\right]_{1 \times n}
$$

onde os termos $b_{i}$ representam os coeficientes do polinômio característico do numerador da função de transferência do sistema original (Eq. (5.7)).

A transferência direta $\bar{D}$ não é alterada pela transformação de coordenadas, assim:

$$
\bar{D}=D=b_{0}
$$

Destaca-se que a aplicação dessa transformação de coordenadas para colocar o sistema na forma canônica de controle é sempre possível quando se trata de sistemas lineares controláveis, entretanto o mesmo nem sempre ocorre para sistemas não lineares [29].

\subsubsection{Saída Plana para o Sistema na Forma Canônica de Controle}

A vantagem de se representar o sistema na forma canônica de controle é facilitar o projeto do controlador via planicidade diferencial, uma vez que a expressão da saída plana obtida é a mais simples possível.

Considerando o sistema linear SISO invariante no tempo representado na forma canônica de controle (Eq. (5.11)), sua matriz de controlabilidade assume a forma:

$$
\mathbf{C}_{\mathbf{K}}=\left[\begin{array}{cccccc}
0 & \cdots & 0 & 0 & 0 & 1 \\
0 & \cdots & 0 & 0 & 1 & \xi_{1} \\
0 & \cdots & 0 & 1 & \xi_{1} & \xi_{2} \\
\vdots & \vdots & . & . \cdot & . \cdot & \vdots \\
0 & 1 & \xi_{1} & \xi_{2} & \cdots & \xi_{n-2} \\
1 & \xi_{1} & \xi_{2} & \cdots & \xi_{n-2} & \xi_{n-1}
\end{array}\right]_{n \times n}
$$


onde facilmente verifica-se que posto $\left(\mathbf{C}_{\mathbf{K}}\right)=n$, independentemente dos parâmetros $\xi_{i}$ do sistema.

Assim, utilizando a Eq. (5.5) e assumindo que o vetor de estados tem a forma $\overline{\mathbf{x}}=\left[\begin{array}{llll}\bar{x}_{1} & \bar{x}_{2} & \ldots & \bar{x}_{n}\end{array}\right]^{T}$, obtém-se a seguinte saída plana:

$$
F=\bar{x}_{1}
$$

De acordo com a Eq. (5.2), nota-se que é necessário calcular as sucessivas derivadas temporais da saída plana até a ordem $r$ a fim de parametrizar o sistema, assim:

$$
\left\{\begin{array}{l}
\dot{F}=\dot{\bar{x}}_{1}=\bar{x}_{2} \\
\ddot{F}=\dot{\bar{x}}_{2}=\bar{x}_{3} \\
\vdots \\
F^{(r-1)}=\dot{\bar{x}}_{n-1}=\bar{x}_{n} \\
F^{(r)}=\dot{\bar{x}}_{n}=-a_{n} \bar{x}_{1}-a_{n-1} \bar{x}_{2}-\ldots-a_{1} \bar{x}_{n}+u
\end{array}\right.
$$

Com as Eqs. (5.20) e (5.21), pode-se montar a seguinte equação matricial:

$$
\left[\begin{array}{c}
\bar{x}_{1} \\
\bar{x}_{2} \\
\vdots \\
\bar{x}_{n} \\
u
\end{array}\right]=\mathbf{M}^{-1}\left[\begin{array}{c}
F \\
\dot{F} \\
\vdots \\
F^{(r-1)} \\
F^{(r)}
\end{array}\right]
$$

onde a matriz $\mathbf{M}$ é dada por:

$$
\mathbf{M}=\left[\begin{array}{ccccc}
1 & 0 & 0 & \cdots & 0 \\
0 & 1 & 0 & \cdots & 0 \\
\vdots & \vdots & \ddots & \vdots & \vdots \\
0 & \cdots & 0 & 1 & 0 \\
-a_{n} & \cdots & -a_{2} & -a_{1} & 1
\end{array}\right]_{(n+1) \times(n+1)}
$$

Resolvendo a Eq. (5.22), obtém-se a completa parametrização do sistema em função da saída plana e de suas derivadas temporais:

$$
\left\{\begin{array}{l}
\bar{x}_{1}=F \\
\bar{x}_{2}=\dot{F} \\
\vdots \\
\bar{x}_{n}=F^{(r-1)} \\
u=a_{n} F+a_{n-1} \dot{F}+\ldots+a_{1} F^{(r-1)}+F^{(r)}
\end{array}\right.
$$

A redefinição estado-dependente da entrada do sistema por $\nu=F^{(r)}=-a_{n} F-a_{n-1} \dot{F}-\ldots-$ 
$a_{1} F^{(r-1)}+u$ transforma o sistema para a forma canônica de Brunovsky [28]:

$$
\left[\begin{array}{c}
\dot{F} \\
\vdots \\
F^{(r-1)} \\
F^{(r)}
\end{array}\right]=\left[\begin{array}{cccc}
0 & 1 & \cdots & 0 \\
\vdots & \vdots & \ddots & \vdots \\
0 & \cdots & 0 & 1 \\
0 & \cdots & 0 & 0
\end{array}\right]\left[\begin{array}{c}
F \\
\dot{F} \\
\vdots \\
F^{(r-1)}
\end{array}\right]+\left[\begin{array}{c}
0 \\
\vdots \\
0 \\
1
\end{array}\right] \nu
$$

Desta maneira, toda a dinâmica da saída plana é determinada por $\nu$, sendo possível determinar uma realimentação endógena para alocação de polos do sistema representado na forma canônica de Brunovsky. O cálculo desse controlador será apresentado na Seção 5.5.

\subsection{Observador de Estado}

Para o controlador em malha fechada faz-se necessário conhecer os estados do sistema a todo instante para realimentá-lo com os devidos termos de correção. Devido à propriedade plana do sistema, ele pode ser reescrito na forma canônica de Brunovsky, onde os novos estados do sistema representam a própria saída plana e as suas derivadas temporais.

Entretanto, como a saída plana foi obtida em cima do sistema reduzido na base modal, suas variáveis de estado não podem ser medidas diretamente por sensores. Assim, para estimá-las em tempo real, faz-se necessário utilizar um observador de estados.

Um observador de estado é uma estrutura que estima as variáveis de estado com base nas medições das variáveis de saída e de controle do sistema [30]. Um tipo de observador de estado bastante utilizado é o filtro de Kalman [32].

O filtro de Kalman é um importante algoritmo matemático utilizado para estimar as variáveis de estado de um sistema que assume-se ser influenciado por perturbações brancas. O filtro de Kalman produz uma estimativa ótima no sentido de minimizar a variância do erro de estimativa do vetor de estado $e_{x}$, definido por:

$$
e_{x}=\widehat{\mathbf{x}}-\mathbf{x}
$$

onde $\widehat{\mathbf{x}}$ é a estimativa ótima do vetor de estados $\mathbf{x}$.

Uma condição necessária para a implementação do filtro de Kalman é o sistema ser observável. Um sistema é dito observável se, e somente se, a matriz de observabilidade $\mathbf{O}$ tem posto completo, ou seja, se é igual à ordem do sistema [30]. Considerando um sistema linear SISO invariante no tempo (Eq. (5.3)), sua matriz de observabilidade é definida por:

$$
\mathbf{O}=\left[\begin{array}{c}
\mathbf{C} \\
\mathbf{C A} \\
\vdots \\
\mathbf{C A}^{n-1}
\end{array}\right]_{n \times n}
$$


Sendo $\operatorname{posto}(\mathbf{O})=n$, o sistema é observável e pode-se utilizar o filtro de Kalman.

O filtro de Kalman assume que o sistema a ter seus estados estimados é excitado por um ruído branco do sistema $w$ e que as medições de sua saída contêm um ruído branco de medição $v$ [27]:

$$
\left\{\begin{array}{l}
\dot{\mathbf{x}}=\mathbf{A} \mathbf{x}+\mathbf{B} u+w \\
y=\mathbf{C x}+D u+v
\end{array}\right.
$$

Ambos os ruídos são assumidos como sendo ruídos brancos, gaussianos e de média nula, ou seja, ruídos aleatórios normalmente distribuídos, com valores médios nulos e não correlacionados no tempo. A variância do ruído do sistema $w$ é representada pela matriz $\mathbf{Q}$, enquanto que a variância do ruído de medição $v$ é dada pela matriz $\mathbf{R}$.

Assim, o filtro de Kalman é um observador de estados linear dado por:

$$
\dot{\hat{\mathbf{x}}}=\mathbf{A} \widehat{\mathbf{x}}+\mathbf{B} u+\mathbf{K}_{\mathbf{f}}(y-\mathbf{C} \widehat{\mathbf{x}}-D u)
$$

onde $\mathbf{K}_{\mathbf{f}}$ é a matriz de ganho do filtro de Kalman.

Nota-se que o filtro de Kalman consiste na equação do sistema adicionada de um termo de correção $\mathbf{K}_{\mathbf{f}}(y-\mathbf{C} \widehat{\mathbf{x}}-D u)$, onde o ganho do filtro de Kalman é calculado por:

$$
\mathbf{K}_{\mathbf{f}}=\mathbf{P C}^{T} \mathbf{R}^{-1}
$$

onde $\mathbf{P}$ é a matriz de covariância do erro de estimativa do vetor de estados.

A matriz de covariância do erro de estimativa é encontrada pela solução da seguinte equação de Riccati:

$$
\dot{\mathbf{P}}=\mathbf{A P}+\mathbf{P A}^{T}+\mathbf{Q}-\mathbf{P C}^{T} \mathbf{R}^{-1} \mathbf{C P}
$$

Assim, a escolha do ganho $\mathbf{K}_{\mathbf{f}}$ é, na verdade, a solução de um problema de otimização [27]. O ganho deve ser escolhido de tal modo a minimizar a covariância do erro de estimativa.

\subsection{Acompanhamento de Trajetória}

Na presença de perturbações externas, o controle nominal, obtido no planejamento de trajetória, não mais garante que o sistema irá seguir a trajetória de referência. Sendo assim, faz-se necessário o desenvolvimento de uma lei de controle para garantir esse acompanhamento de trajetória.

Essa lei de controle deve levar em consideração medições, ou observações, das variáveis de estado a todo instante. Partindo do pressuposto que essas medições estão disponíveis, é possível verificar o desvio entre as trajetórias real e de referência. Assim, pode-se deduzir um termo de correção no controle para eliminar esse desvio. Essa tarefa é chamada de acompanhamento de trajetória e esse tipo de controle é chamado de controle por realimentação ou controle em malha fechada. 
Conforme expõe Levine [29], no caso de sistemas diferencialmente planos, a tarefa de acompanhamento de trajetória pode ser facilmente realizada utilizando a estratégia de equivalência do sistema pela forma canônica de Brunovsky. Sendo $F^{*}$ a trajetória de referência da saída plana $F$, pode-se denotar o erro de acompanhamento de trajetória para a saída plana do sistema por:

$$
e=F-F^{*}
$$

Derivando o erro $r$ vezes, tem-se:

$$
e^{(r)}=F^{(r)}-F^{*(r)}=\nu-\nu^{*}
$$

É suficiente, então, definir a seguinte lei de controle a partir da dinâmica do erro:

$$
\nu=\nu^{*}-\sum_{i=0}^{r-1} k_{i} e^{(i)}=\nu^{*}-\sum_{i=0}^{r-1} k_{i}\left(F^{(i)}-F^{*(i)}\right)
$$

onde os ganhos $k_{i}$ são escolhidos de forma que o polinômio $p(s)=s^{r}+\sum_{i=0}^{r-1} k_{i} s^{(i)}$ tenha suas raízes com parte real estritamente negativa.

Assim, o erro $e$ converge exponencialmente para 0 e a saída plana $F$ e todas as suas derivadas temporais até a ordem $r$ convergem para suas respectivas trajetórias de referência $F^{*}, \ldots, F^{*(r)}$. Então, conclui-se que o vetor de estados $\mathbf{x}$ e a entrada $u$ do sistema original convergem exponencialmente para suas referências $\mathbf{x}^{*}$ e $u^{*}$, respectivamente [29].

\subsection{Preditor de Smith}

O controle de um sistema com atraso, utilizando um controlador por realimentação comum, não é uma tarefa simples. Conforme destacam Normey-Rico e Camacho [33], alguns fatores que dificultam o controle são: os efeitos de uma perturbação externa demoram a ser detectados pelo controlador; as ações de controle demoram a surtir efeito na variável controlada; e a ação de controle baseada no erro atual tenta, na verdade, corrigir uma situação passada.

Uma ferramenta bastante utilizada para facilitar o projeto do controlador quando se tem um sistema com atraso é o preditor de Smith. O preditor de Smith, desenvolvido por Smith [34], representa um compensador de atraso, permitindo que se projete o controlador com base nas equações do modelo sem considerar o atraso.

A Fig. 5.1 apresenta a estrutura de um preditor de Smith, sendo que: $\mathbf{P}$ representa a planta do sistema, $\mathbf{C}$ um controlador por realimentação, RM o modelo reduzido da planta sem o atraso, e $e^{-\epsilon s}$ o atraso puro. 


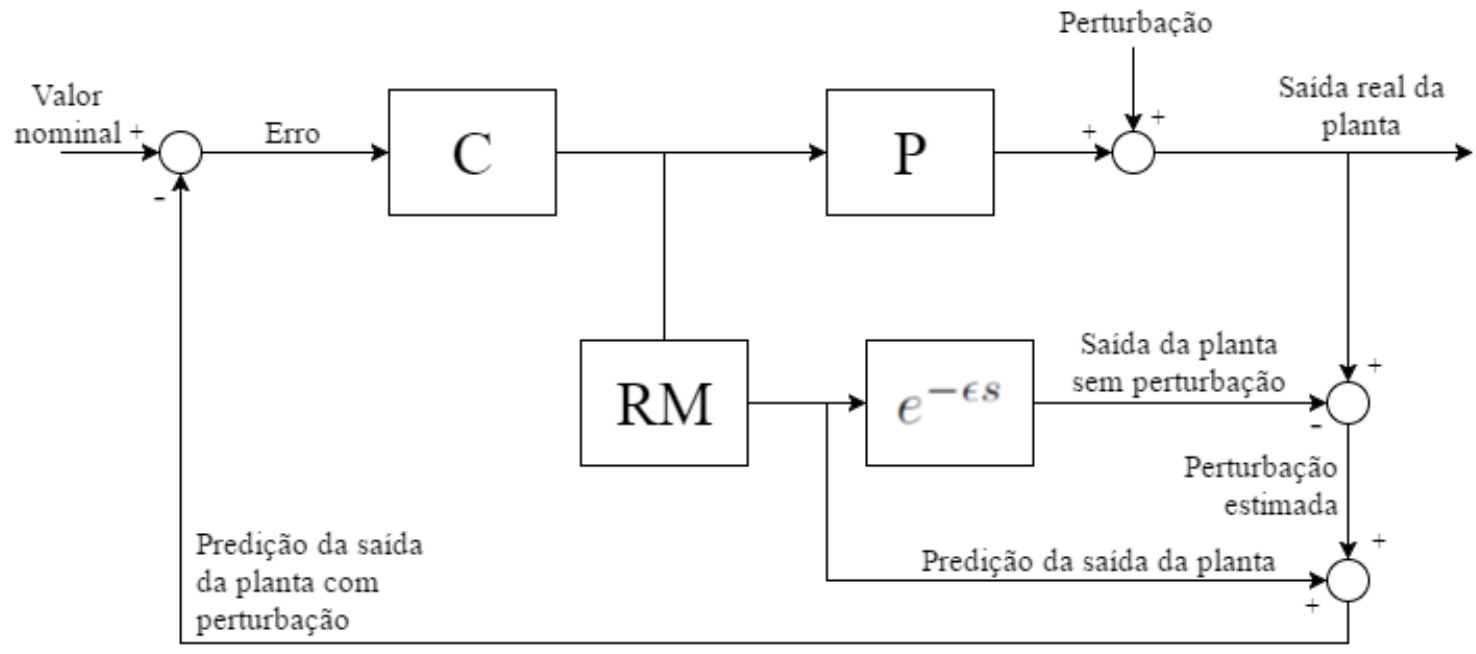

Figura 5.1: Estrutura de um preditor de Smith, adaptado de [2]

Nota-se pela Fig. 5.1 que a saída do modelo reduzido com o atraso representa uma estimativa da saída da planta na ausência de perturbação. Caso o modelo com o atraso represente bem o comportamento da planta, sua saída será uma versão sem perturbação da saída real da planta. Já a saída do modelo reduzido sem o atraso representa uma predição da saída da planta na ausência de perturbação após ter transcorrido o atraso.

Destaca-se que ao subtrair a saída do modelo reduzido com o atraso da saída real da planta, obtém-se uma estimativa da perturbação. Ao somar essa estimativa à saída do modelo sem o atraso, obtém-se uma predição da saída da planta na presença da perturbação. Assim, a realimentação considera a perturbação sem, no entanto, ser influenciada pelo atraso.

Pode-se, então, desenvolver o controlador com base no modelo reduzido sem considerar o atraso. Essa é a grande vantagem de se utilizar a estrutura do preditor de Smith no projeto do controlador de sistemas com atraso conhecido. Desta maneira, as técnicas apresentadas na Seção 5.5 podem ser aplicadas ao sistema em estudo utilizando a estrutura do preditor de Smith.

\subsection{Projeto do Controlador}

Conforme apresentado no Capítulo 4, escolheu-se um modelo reduzido de ordem 4 para representar o modelo discreto de ordem 200 com o arrasto linear e, assim, viabilizar o projeto de um controlador. Entretanto, para melhor aproximá-lo ao comportamento do modelo original, introduziu-se um atraso $\epsilon$ no modelo.

Sendo esse atraso conhecido, pode-se, então, utilizar a estratégia do preditor de Smith para o projeto do controlador. Assim, considera-se apenas as equações do modelo reduzido, sem levar em conta o atraso entre sua entrada e saída.

Como o modelo reduzido é um sistema SISO invariante no tempo e controlável, pode-se seguir o procedimento apresentado na Seção 5.3.1 e representá-lo na forma canônica de controle. Sendo 
seu novo vetor de estados representado por $\overline{\mathbf{x}}=\left[\begin{array}{llll}\bar{x}_{1} & \bar{x}_{2} & \bar{x}_{3} & \bar{x}_{4}\end{array}\right]^{T}$, obtém-se a seguinte saída plana para o sistema:

$$
F=\bar{x}_{1}
$$

Calcula-se, então, suas sucessivas derivadas temporais até a ordem 4:

$$
\left\{\begin{array}{l}
\dot{F}=\dot{\bar{x}}_{1}=\bar{x}_{2} \\
\ddot{F}=\dot{\bar{x}}_{2}=\bar{x}_{3} \\
F^{(3)}=\dot{\bar{x}}_{3}=\bar{x}_{4} \\
F^{(4)}=\dot{\bar{x}}_{4}=-a_{4} \bar{x}_{1}-a_{3} \bar{x}_{2}-a_{2} \bar{x}_{3}-a_{1} \bar{x}_{4}+u
\end{array}\right.
$$

sendo que os termos $a_{i}$ correspondem aos termos da última linha da matriz de estados do sistema reduzido, representado na forma canônica de controle.

Assim, pode-se parametrizar o sistema em função da saída plana e de suas derivadas temporais:

$$
\left\{\begin{array}{l}
\bar{x}_{1}=F \\
\bar{x}_{2}=\dot{F} \\
\bar{x}_{3}=\ddot{F} \\
\bar{x}_{4}=F^{(3)} \\
u=a_{4} F+a_{3} \dot{F}+a_{2} \ddot{F}+a_{1} F^{(3)}+F^{(4)}
\end{array}\right.
$$

Redefinindo a entrada do sistema por $\nu=F^{(4)}=-a_{4} F-a_{3} \dot{F}-a_{2} \ddot{F}-a_{1} F^{(3)}+u$, o sistema é, então, representado na forma canônica de Brunovsky:

$$
\left[\begin{array}{c}
\dot{F} \\
\ddot{F} \\
F^{(3)} \\
F^{(4)}
\end{array}\right]=\left[\begin{array}{llll}
0 & 1 & 0 & 0 \\
0 & 0 & 1 & 0 \\
0 & 0 & 0 & 1 \\
0 & 0 & 0 & 0
\end{array}\right]\left[\begin{array}{c}
F \\
\dot{F} \\
\ddot{F} \\
F^{(3)}
\end{array}\right]+\left[\begin{array}{l}
0 \\
0 \\
0 \\
1
\end{array}\right] \nu
$$

Pela Eq. (5.34), pode-se definir o controlador em malha fechada:

$$
\nu=F^{*(4)}-k_{3}\left(F^{(3)}-F^{*(3)}\right)-k_{2}\left(\ddot{F}-\ddot{F}^{*}\right)-k_{1}\left(\dot{F}-\dot{F}^{*}\right)-k_{0}\left(F-F^{*}\right)
$$

com os ganhos $\left(k_{3}, k_{2}, k_{1}\right.$ e $\left.k_{0}\right)$ escolhidos de tal forma que o polinômio $p(s)=s^{4}+k_{3} s^{3}+k_{2} s^{2}+$ $k_{1} s+k_{0}$ tenha suas raízes com parte real estritamente negativa.

A Fig. 5.2 apresenta o diagrama de blocos da estrutura do sistema de controle, sendo que: a planta $\mathbf{P}$ é assumida como sendo o modelo discreto de ordem 200 com o arrasto não-linear (Eq. (3.25)); C é o controlador via planicidade diferencial desenvolvido nesta seção; KF é o filtro

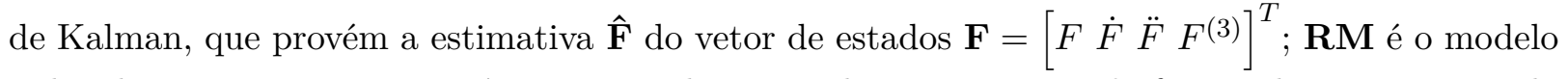
reduzido sem o atraso, que é representado separadamente por $e^{-\epsilon s}$, formando a estrutura do preditor de Smith; e $y_{p}$ representa a predição da saída da planta. 


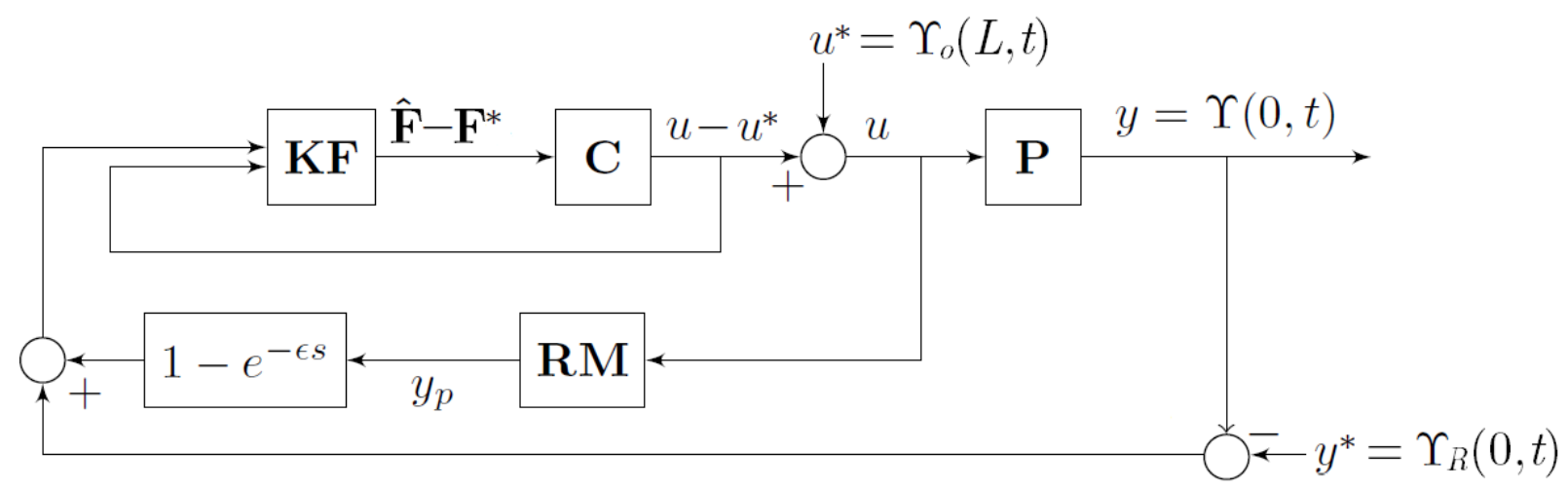

Figura 5.2: Diagrama de blocos da estrutura do sistema de controle, adaptado de [3]

Pela característica de linearidade do sistema, o princípio da superposição das respostas é válido. Logo, pode-se tratar separadamente o problema de planejamento de trajetória (através da solução analítica) e o problema do acompanhamento de trajetória (através da estimação dos estados do erro e da realimentação dinâmica associada). Desta maneira, pode-se trabalhar com um controlador atuando apenas na dinâmica do erro de acompanhamento de trajetória $\left(y-y^{*}\right)$.

Pela Fig. 5.2, verifica-se que para o controlador atuar apenas na dinâmica do erro de acompanhamento de trajetória, subtrai-se da saída real da planta $y$ seu valor nominal $y^{*}$, que é justamente a trajetória de referência do equipamento submarino $\Upsilon_{R}(0, t)$, utilizada no planejamento de trajetória. Assim, faz-se necessário somar à saída do controlador o controle nominal $u^{*}=\Upsilon_{o}(L, t)$ obtido pela solução analítica, apresentada no Capítulo 2.

Como o controlador só atua na dinâmica do erro de trajetória, as trajetórias de referência da saída plana $F^{*}$ e das suas sucessivas derivadas temporais $\dot{F}^{*}, \ldots, F^{*(4)}$ devem ser nulas, uma vez que deseja-se que o erro de acompanhamento de trajetória seja nulo. Assim, o termo de correção do controlador (Eq. (5.39)) pode ser reescrito por:

$$
\nu=-k_{3} F^{(3)}-k_{2} \ddot{F}-k_{1} \dot{F}-k_{0} F
$$

Substituindo $F^{(4)}=\nu$ na expressão da entrada parametrizada do sistema, apresentada na Eq. (5.37), obtém-se a expressão do sinal do controlador em malha fechada:

$$
u=\left(a_{4}-k_{0}\right) F+\left(a_{3}-k_{1}\right) \dot{F}+\left(a_{2}-k_{2}\right) \ddot{F}+\left(a_{1}-k_{3}\right) F^{(3)}
$$

Desta forma, garante-se que a trajetória de referência seja seguida mesmo na presença de perturbações externas. 


\subsection{Resultados}

Para verificar a performance do sistema de controle de trajetória via planicidade diferencial três diferentes casos foram simulados. As simulações foram realizadas no ambiente Simulink do software MATLAB ${ }^{\circledR}$.

Os parâmetros do sistema, adotados em todas as simulações numéricas, são os mesmos considerados no desenvolvimento analítico e podem ser verificados na Tab. 2.1.

Conforme apresentado na Subseção 2.3.1, destaca-se que a trajetória de referência do equipamento submarino $\Upsilon_{R}(0, t)$ é uma trajetória polinomial que desloca suavemente o equipamento submarino para uma posição final a 1 metro de distância de sua posição inicial.

Considerou-se, também, um tempo de simulação de $t_{s}=1500 \mathrm{~s}$ e um passo de tempo de $\Delta t=0,1 s$, valores comuns a todas as simulações.

Os ganhos $\left(k_{0}, k_{1}, k_{2}\right.$ e $\left.k_{3}\right)$ do controlador, descrito pela Eq. (5.41), foram definidos de forma que o polinômio característico tivesse a forma:

$$
p(s)=(s+3)^{4}
$$

Assim, os ganhos encontrados foram:

$$
k_{0}=4,096 \times 10^{-5} \quad k_{1}=0,002048 \quad k_{2}=0,0384 \quad k_{3}=0,32
$$

Para o filtro de Kalman, as matrizes de variância do ruído do sistema $\mathbf{Q}$ e do ruído de medição $\mathbf{R}$ são assumidas como sendo diagonais, com elementos iguais a 0,0001 e 1, respectivamente. Destaca-se que, ao considerar $\mathbf{Q} \ll \mathbf{R}$, o filtro de Kalman valoriza o modelo, pois considera que as medições são menos confiáveis.

Na primeira simulação, procurou-se simular a presença de uma correnteza constante no procedimento de posicionamento do equipamento submarino. Este caso pode ser aproximado por um posicionamento considerando um desvio inicial em relação às trajetórias de referência, tanto do equipamento como do controle nominal. Assim, adotou-se como condição inicial do sistema um desvio de $0,2 m$ em relação à trajetória de referência.

A Fig. 5.3 apresenta a performance do controlador para este caso. Destaca-se que em azul é representada a trajetória do equipamento submarino em malha fechada, em preto a trajetória do equipamento submarino em malha aberta e em vermelho a trajetória de referência do equipamento submarino $\Upsilon_{R}(0, t)$. 


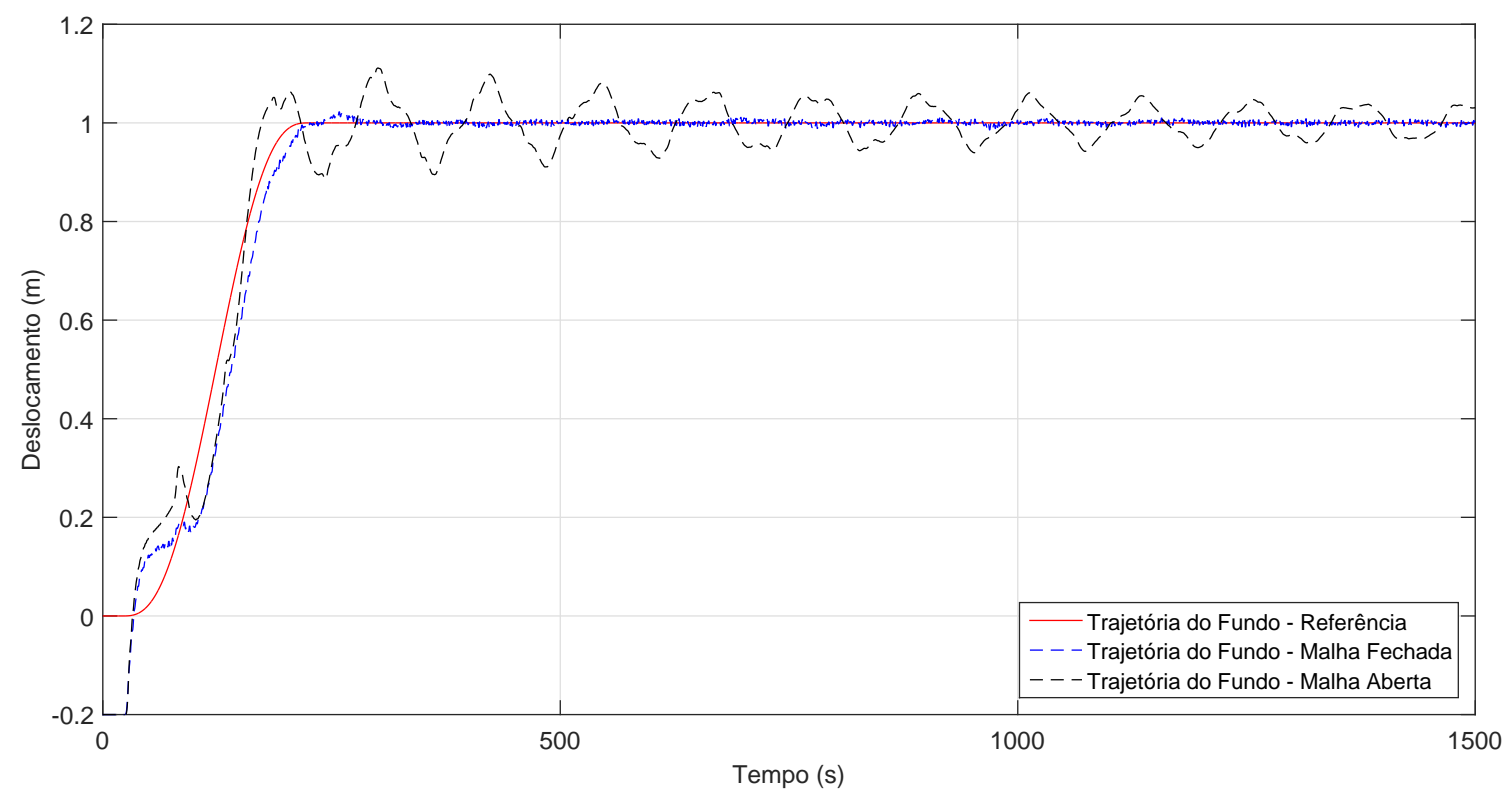

Figura 5.3: Comparação das respostas em malha aberta e em malha fechada para o caso do sistema deslocado de $0,2 m$ da referência

Adotando como critério de comparação o tempo necessário para o equipamento submarino ser posicionado em uma faixa de estabilização de $5 \%$ para mais e para menos do deslocamento total $([0,95 m-1,05 m])$, pode-se comparar a performance do controlador.

Nota-se pela Fig. 5.3 que o sistema em malha aberta se mantém nesta faixa apenas a partir do instante $t=1196 \mathrm{~s}$, já o sistema em malha fechada se mantém nesta faixa a partir do instante $t=205 \mathrm{~s}$. Desta maneira, verifica-se que, ao utilizar o controlador, obtém-se uma redução de 82, $9 \%$ do tempo necessário para o sistema atingir a faixa de estabilização.

Na segunda simulação, procurou-se simular o caso do posicionamento do equipamento submarino na presença de uma perturbação transiente aplicada à plataforma, como por exemplo a causada pela quebra de uma onda durante o procedimento. Assim, para simular este caso, considerou-se uma perturbação transiente de $0,5 \mathrm{~m}$ aplicada ao controle nominal durante o intervalo $100 s \leq t \leq 120 s$.

A Fig. 5.4 apresenta a performance do controlador para este caso. Novamente, representa-se em azul a trajetória do equipamento submarino em malha fechada, em preto a trajetória em malha aberta e em vermelho a trajetória de referência $\Upsilon_{R}(0, t)$. 


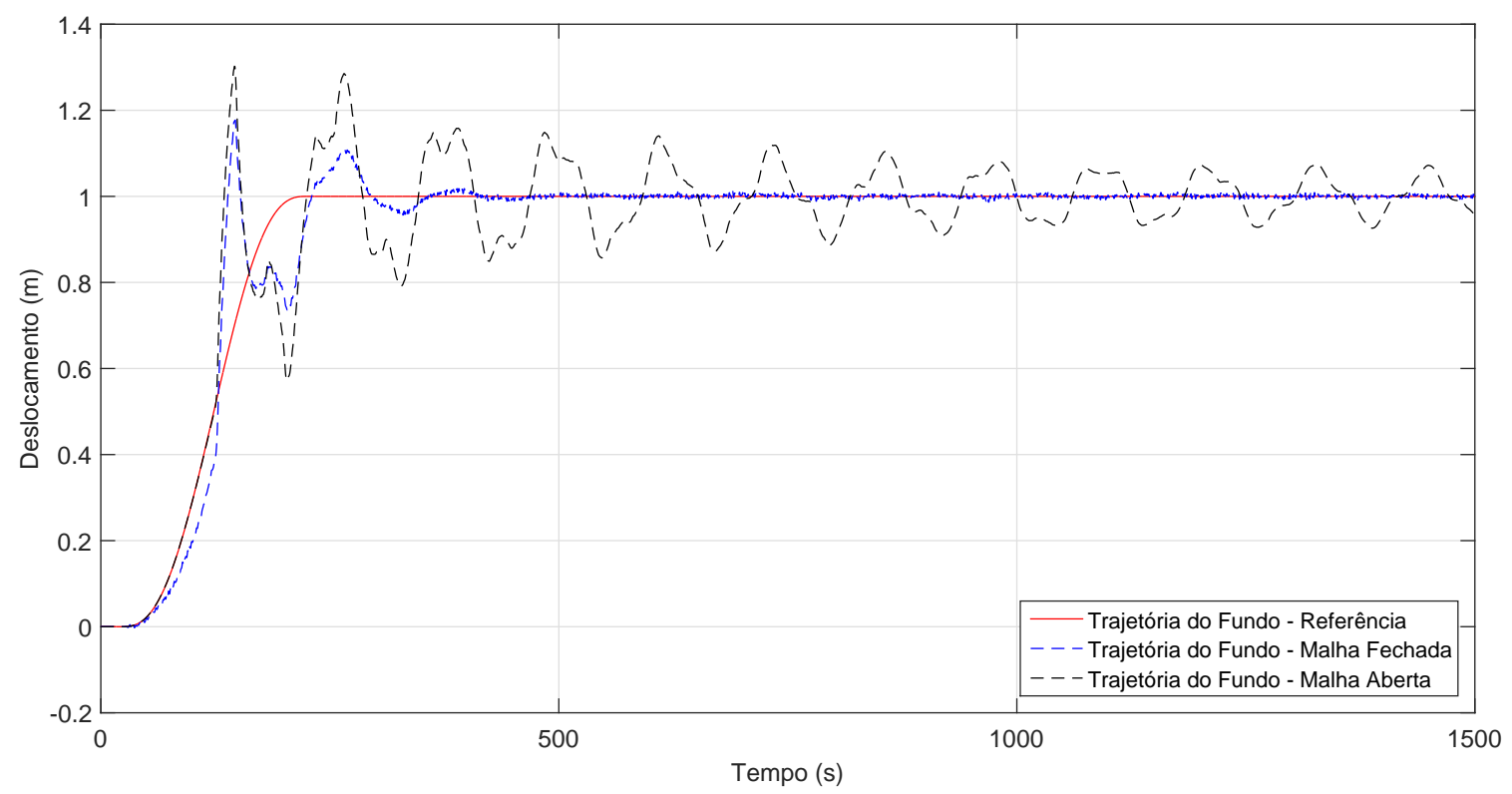

Figura 5.4: Comparação das respostas em malha aberta e em malha fechada para o caso da perturbação transiente de $0,5 \mathrm{~m}$

Neste caso, adotou-se como critério de comparação o tempo necessário para o equipamento submarino ser posicionado em uma faixa de estabilização de $10 \%$ para mais e para menos do deslocamento total $([0,9 m-1,1 m])$.

Nota-se pela Fig. 5.4 que o sistema em malha aberta se mantém na faixa de estabilização apenas a partir de $t=860 \mathrm{~s}$, já o sistema em malha fechada se mantém na faixa a partir de $t=274 \mathrm{~s}$. Desta maneira, ao utilizar o controlador, obtém-se uma redução de $68,1 \%$ do tempo necessário para estabilizar o sistema nesta faixa.

Na terceira simulação, procurou-se simular o caso do posicionamento do equipamento submarino na presença de ondas oceânicas. Segundo Fortaleza [18], as ondas têm suas energias concentradas nos primeiros metros a partir da superfície. Assim, este caso pode ser aproximado por um posicionamento considerando uma perturbação externa $p_{\text {ext }}(t)$ aplicada somente ao controle nominal do sistema DP durante todo o tempo da simulação.

Conforme descrito em [3], assume-se que $p_{\text {ext }}(t)$ é composta por elementos senoidais e cossenoidais de diferentes frequências e amplitudes:

$$
p_{\text {ext }}(t)=0,15 \operatorname{sen}(0,2 \pi t)+0,1 \cos (\pi t)
$$

Nota-se que $p_{\text {ext }}(t)$ apresenta a combinação de dois tipos de ondas: uma de maior amplitude e menor frequência e outra de menor amplitude e maior frequência.

A Fig. 5.5 apresenta a performance do controlador para este caso. Novamente, representa-se em azul a trajetória do equipamento submarino em malha fechada, em preto a trajetória em malha 
aberta e em vermelho a trajetória de referência $\Upsilon_{R}(0, t)$.

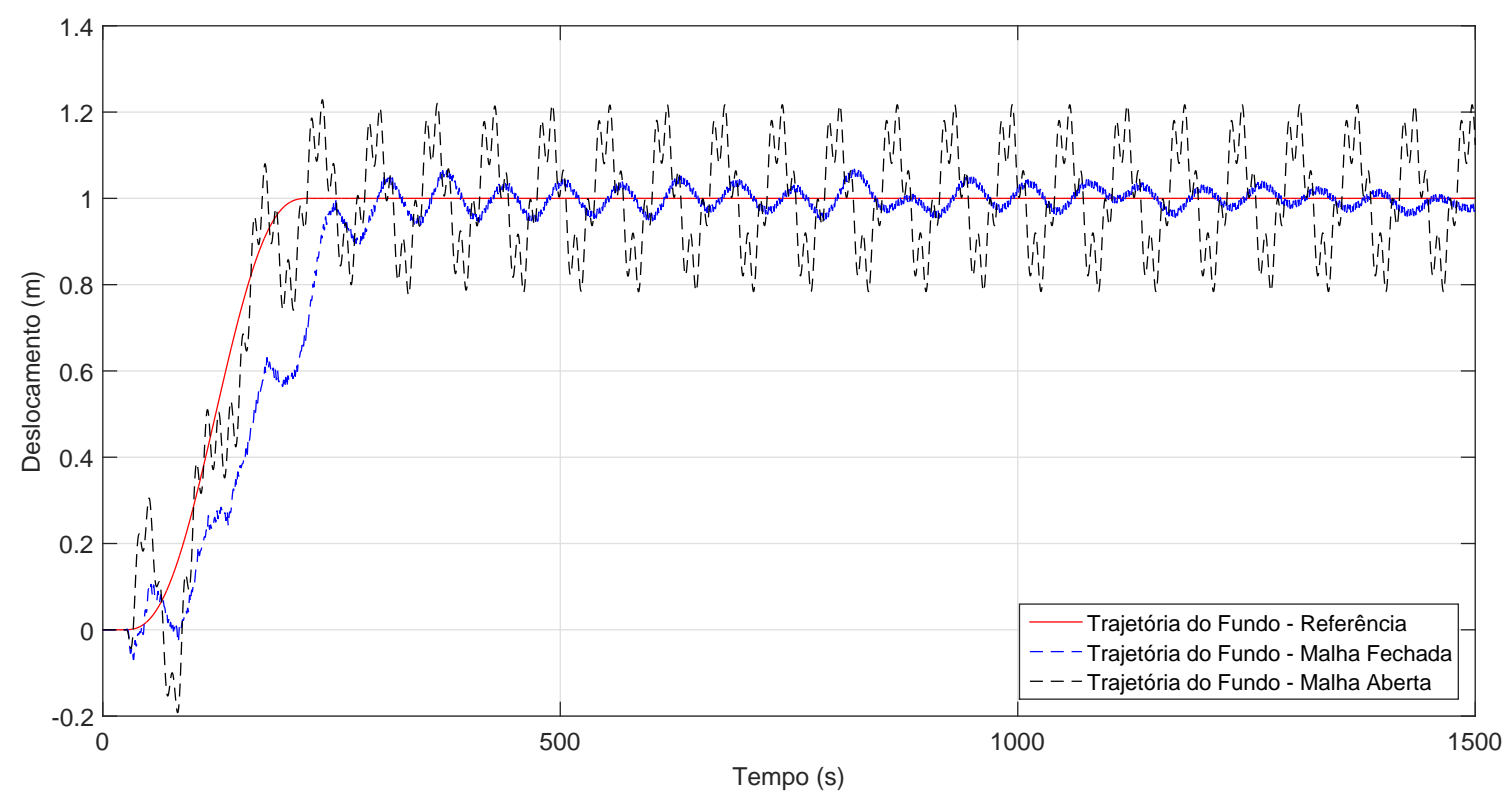

Figura 5.5: Comparação das respostas em malha aberta e em malha fechada para o caso da perturbação $p_{\text {ext }}(t)$

Neste caso, como a perturbação é permanente, o sistema em malha aberta não apresenta uma tendência de estabilização e, por isso, não é interessante utilizar o critério de faixa de estabilização para fins de comparação dos sistemas. Assim, para verificar a performance do controlador, adota-se como critério a atenuação da oscilação obtida pelo sistema em malha fechada.

Nota-se pela Fig. 5.5 que a distância entre os valores máximo (pico) e mínimo (vale) de cada oscilação do sistema em malha aberta é praticamente constante e igual a $0,43 m$ durante todo o tempo de simulação. Já no caso do sistema em malha fechada essa oscilação não é uniforme. Assim, analisou-se individualmente cada oscilação e obteve-se um valor médio da distância pico/vale de 0,08m. Desta maneira, verifica-se que o controlador, apesar de não conseguir eliminar a oscilação do equipamento submarino em torno da posição final, consegue atenuá-la em 81,4\%.

\subsection{Conclusões}

Neste capítulo apresentou-se o desenvolvimento de um sistema de controle de trajetória, baseado na teoria de planicidade diferencial, para o modelo reduzido de ordem 4 apresentado no Capítulo 4.

Três simulações numéricas foram realizadas para verificar a performance do controlador. A primeira considerou o sistema inicialmente deslocado da trajetória de referência. A segunda considerou uma perturbação transiente aplicada ao controle nominal durante um certo intervalo da simulação. A terceira considerou uma perturbação composta de termos senoidais e cossenoidais 
aplicada durante todo o tempo da simulação.

Nas duas primeiras simulações comparou-se o tempo necessário para estabilizar o sistema em malha fechada e em malha aberta, considerando como critério uma faixa de estabilização definida. Verificou-se que a presença do controlador fez reduzir o tempo de estabilização em $82,9 \%$ na primeira simulação e em $68,1 \%$ na segunda.

$\mathrm{Na}$ última simulação verificou-se que a presença da perturbação oscilatória fez o equipamento submarino oscilar ao redor de sua posição final, tanto em malha aberta como em malha fechada. Apesar disso, verificou-se que a utilização do controlador permitiu uma atenuação de $81,4 \%$ da amplitude da oscilação. 


\section{Capítulo 6}

\section{Conclusões}

Neste manuscrito foi apresentado o desenvolvimento de um sistema de controle para o sistema DP de uma plataforma com a finalidade de permitir o preciso posicionamento de um equipamento submarino em uma típica operação de instalação submarina em águas ultraprofundas. Pela utilização de um sistema de controle essa operação pode ser realizada sem a direta interferência do operador humano. Desta maneira, aumenta-se a confiabilidade e eficiência da operação e reduz-se o risco de dano ao equipamento.

O desenvolvimento do sistema de controle englobou duas etapas: o planejamento de trajetória e o acompanhamento de trajetória. A etapa de planejamento de trajetória consistiu na obtenção de uma expressão que relaciona a trajetória do equipamento submarino com a trajetória do sistema DP da plataforma. Esta etapa foi desenvolvida a partir da modelagem matemática do sistema apresentada no Capítulo 2. Obteve-se, então, a equação governante e apresentou-se uma abordagem analítica para solucioná-la. A validade da solução analítica foi verificada no Capítulo 3 a partir da simulação da estrutura discretizada pelo método de diferenças finitas.

A etapa de acompanhamento de trajetória foi desenvolvida para permitir o preciso posicionamento do equipamento na presença de perturbações externas não modeladas. Para realizar essa etapa, fez-se necessário o desenvolvimento de um controlador. Como etapa preliminar ao projeto do controlador, apresentou-se uma estratégia de redução do modelo no Capítulo 4, utilizando a teoria de análise modal. A obtenção de um modelo reduzido permitiu o desenvolvimento do controlador via saídas planas. O projeto do controlador baseou-se na teoria de planicidade diferencial, conforme apresentado no Capítulo 5. A performance do controlador pôde ser verificada a partir de simulações numéricas considerando o posicionamento do equipamento submarino na presença de perturbações externas.

\subsection{Trabalhos Futuros}

Algumas possíveis sugestões para trabalhos futuros são resumidas a seguir:

1. Aperfeiçoar o sistema de controle apresentado, de forma a melhorar sua performance na 
presença da perturbação de média não-nula;

2. Otimizar o filtro de Kalman apresentado;

3. Submeter o sistema a outros tipos de perturbação externa, de forma a melhor representar as perturbações ambientes que são verificadas no caso real;

4. Realizar experimentos para validar as etapas de planejamento de trajetória e acompanhamento de trajetória propostas.

\subsection{Publicação}

O trabalho desenvolvido neste manuscrito permitiu o desenvolvimento do seguinte artigo:

1. SIMÕES, R. D. P.; FORTALEZA, E. L. F. Active Control System for Subsea Installations. In: 23rd ABCM International Congress of Mechanical Engineering (COBEM 2015). Rio de Janeiro, Rio de Janeiro. Brasil. 2015 


\section{REFERÊNCIAS BIBLIOGRÁFICAS}

[1] FORTAlEZA, E.; ALBUQUERQUE, D.; YAMAMOTO, M. An investigation about the trajectory control during the subsea equipment installation using cable. In: Proceedings of the ASME 2012 31st International Conference Ocean, Offshore and Artic Engineering - OMAE2012. Rio de Janeiro, Brazil: [s.n.], 2012.

[2] VANDOREN, V. Overcoming process deadtime with a smith predictor. Acessado: 25-03-2016. Disponível em: <http://www.controleng.com/single-article/overcoming-processdeadtime-with-a-smith-predictor/8c727a1371eb45011801350175606812.html> .

[3] MOnteiro, F. R.; FILHO, J. O. d. A. L.; FORTALEZA, E. L. F. Modal reduction based tracking control for installation of subsea equipments. IFAC-PapersOnLine, Elsevier, v. 48, n. 6, p. 15-20, 2015.

[4] BAI, Y.; BAI, Q. Subsea engineering handbook. [S.l.]: Gulf Professional Publishing, 2012.

[5] CHAKRABARTI, S. Handbook of Offshore Engineering (2-volume set). [S.1.]: Elsevier, 2005.

[6] HOW, B. V. E.; GE, S. S.; CHOO, Y. S. Load positioning for subsea installation via approximation based adaptive control. In: IEEE. Control Applications, 2007. CCA 200\%. IEEE International Conference on. [S.1.], 2007. p. 723-728.

[7] HOW, B. V. E.; GE, S. S.; CHOO, Y. S. Dynamic load positioning for subsea installation via adaptive neural control. Oceanic Engineering, IEEE Journal of, IEEE, v. 35, n. 2, p. 366-375, 2010.

[8] HOW, B. V. E.; GE, S. S.; CHOO, Y. S. Control of coupled vessel, crane, cable, and payload dynamics for subsea installation operations. Control Systems Technology, IEEE Transactions on, IEEE, v. 19, n. 1, p. 208-220, 2011.

[9] MORAIS, J. M. d. Petróleo em águas profundas: uma história tecnológica da petrobras na exploração e produção offshore. Instituto de Pesquisa Econômica Aplicada (Ipea), 2013.

[10] BURKE, B. An analysis of marine risers for deep water. Journal of Petroleum Technology, Society of Petroleum Engineers, v. 26, n. 4, p. 455-465, 1974.

[11] BROUWERS, J. Analytical methods for predicting the response of marine risers. MECHANICS, v. 85, n. 4, 1982. 
[12] CHAKRABARTI, S. K.; FRAMPTON, R. E. Review of riser analysis techniques. Applied Ocean Research, Elsevier, v. 4, n. 2, p. 73-90, 1982.

[13] PATEL, M.; JESUDASEN, A. Theory and model tests for the dynamic response of free hanging risers. Journal of sound and vibration, Elsevier, v. 112, n. 1, p. 149-166, 1987.

[14] HOVER, F. S. Experiments in dynamic positioning of a towed pipe. In: IEEE. OCEANS'93. Engineering in Harmony with Ocean. Proceedings. [S.1.], 1993. p. III484-III490.

[15] PETIT, N.; ROUCHON, P. Flatness of heavy chain systems. In: Proceedings of the 10th Offshore Symposium on Dynamic Problems of Mechanics. Houston, TX: [s.n.], 2001.

[16] FORTALEZA, E.; CREFF, Y.; LÉVINE, J. Active control of a dynamically positioned vessel for the installation of subsea structures. In: Mathematical and Computer Modelling of Dynamical Systems, Vol. 17, No. 1, pp. 71-84. [S.1.: s.n.], 2011.

[17] ALBUQUERQUE, D. G. Modelagem e controle de risers em operações offshore. 2012.

[18] FORTALEZA, E. Active control applied to offshore structures: positioning and attenuation of vortex induced vibrations. Tese (Doutorado) - École Nationale Supérieure des Mines de Paris, France, 2009.

[19] YAMAMOTO, M.; MOROOKA, C. K. Dynamic positioning of floating platform coupled with a drilling riser. 2007.

[20] FARD, M. P. Modelling and control of mechanical flexible systems. Tese (Doutorado) Norwegian University of Science and Technology, Norway, 2001.

[21] BRUnetTI, F. Mecânica dos fluidos. 2. ed. [S.1.]: São Paulo: Pearson Prentice Hall, 2008.

[22] ABRAMOWITZ, M.; STEGUN, I. A. Handbook of Mathematical Functions with Formulas, Graphs, and Mathematical Tables. Tenth printing. [S.1.]: National Bureau of Standards Applied Mathematics Series 55, 1972.

[23] MIKUSINSKI, J. Operational calculus. Vol. 1: Elsevier, 2014.

[24] GILAT, A.; SUBRAMANIAM, V. Métodos numéricos para engenheiros e cientistas: uma introdução com aplicações usando o MATLAB. [S.l.]: Bookman, 2008.

[25] QU, Z.-Q. Model order reduction techniques with applications in finite element analysis. [S.1.]: Springer Science \& Business Media, 2013.

[26] FLIESS, M. et al. Sur les systemes non linéaires différentiellement plats. Comptes rendus de l'Académie des sciences. Série 1, Mathématique, Elsevier, v. 315, n. 5, p. 619-624, 1992.

[27] RIGATOS, G. G. Nonlinear control and filtering using differential flatness approaches: applications to electromechanical systems. [S.1.]: Springer, 2015.

[28] SIRA-RAMÍREZ, H.; AGRAWAL, S. K. Differentially Flat Systems. New York, USA: Marcel Dekker, 2004. (Control Engineering Series). 
[29] LEVINE, J. Analysis and Control of Nonlinear Systems: A Flatness-Based Approach. New York, USA: Springer, 2010. (Mathematical Engineering).

[30] OGATA, K. Modern control engineering. 5. ed. [S.l.]: Prentice Hall PTR, 2010.

[31] FRAnKLIN, G. F.; POWELL, J. D.; EMAMI-NAEINI, A. Feedback Control of Dynamic Systems (6th Edition). 6. ed. [S.l.]: Prentice Hall, 2009.

[32] KALMAN, R. E. A new approach to linear filtering and prediction problems. Journal of basic Engineering, American Society of Mechanical Engineers, v. 82, n. 1, p. 35-45, 1960.

[33] NORMEY-RICO, J. E.; CAMACHO, E. F. Control of Dead-time Processes. [S.l.]: Springer, 2007. (Advanced textbooks in control and signal processing).

[34] SMITH, O. J. M. Closer control of loops with dead time. CHEMICAL ENGINEERING PROGRESS, v. 53, p. 217-219, 1957. 